T.C.

MARMARA UNIVERSITY

INSTITUTE FOR GRADUATE STUDIES IN

PURE AND APPLIED SCIENCES

\title{
FATIGUE LIFE PREDICTION OF A DRAG LINK BY USING FINITE ELEMENT METHOD
}

\author{
Barış KOCA \\ (Mechanical Engineer)
}

\begin{abstract}
THESIS
FOR THE DEGREE OF MASTER OF SCIENCE

IN

MECHANICAL ENGINEERING PROGRAMME
\end{abstract}

SUPERVISOR

Assistant Professor Dr. Bülent EKİCi 
T.C.

MARMARA UNIVERSITY

THE INSTITUTE FOR

GRADUATE STUDIES IN PURE AND APPLIED SCIENCES

\section{ACCEPTANCE AND APPROVAL DOCUMENT}

\section{FATIGUE LIFE PREDICTION OF A DRAG LINK BY USING FINITE ELEMENT METHOD}

Established committee listed below, on 17/01/08 and B.30.2.MAR.0.C1.00.00.4663 by the INSTITUTE FOR GRADUATE STUDIES IN PURE AND APPLIED SCIENCES' Executive Committee, have accepted Mr. Barıș KOCA 's Master of Science thesis, titled as "FATIGUE LIFE PREDICTION OF A DRAG LINK BY USING FINITE ELEMENT METHOD” in Mechanical Engineering .

\section{COMMITTEE}

Advisor $\quad$ : Assist. Prof. Dr. Bülent EKİCI

Member $\quad$ : Prof. Dr. A. Kerim KAR

Member : : Assoc. Prof. Dr. Nihat AKKUȘ

Date of thesis' / dissertation's defense before the committee :

\section{APPROVAL}

Mr. Barış KOCA has satisfactorily completed the requirements for the degree of Master of Science in Mechanical Engineering at Marmara University. Mr. Barış KOCA is eligible to have the degree awarded at our convocation on Diploma and transcripts so noted will be available after that date. 


\section{ACKNOWLEDGMENT}

First and foremost, I would like to thank to my supervisor, Dr. Bülent EKİCİ, for his valuable helps and for his support and his encouragement throughout the preparation of this thesis.

I am deeply grateful to Figes Company for their valuable helps for using the Ansys Fatigue Module . And also I am so greteful to Aydin Kutay from the BIAS Company who has contributed with his time, knowledge about Msc. Nastran and GlyphWorks .

Also I would like to thank to my colleagues, espically to my chief Dr. Yaşar Doğruer who has given so much encouragement and his valuable academic advices and Veysel Çataltepe who has helped me for filtering the data in GlyphWorks.

Finally, I would like to express my deapest gratitude for their constant support and understandings to my family especially to Nurdan Sel. I would like to dedicate this thesis to Miss Sel for her great understanding and confidence for me throughout the preparing of this thesis. 


\section{CONTENTS}

PAGE

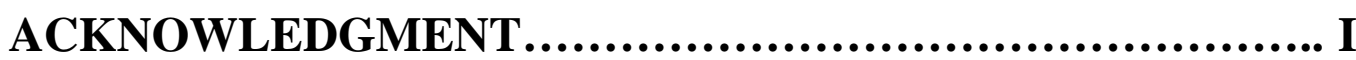

CONTENTS.................................................... II

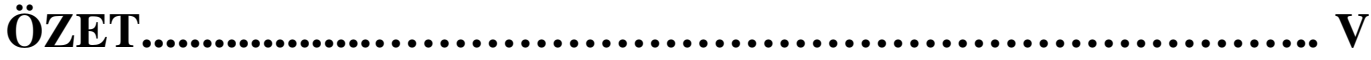

ABSTRACT............................................................ V

LIST OF SYMBOLS............................................... VI

LIST OF FIGURES........................................... VIII

LIST OF TABLES............................................ XI

CHAPTER I. INTRODUCTION.................................1

CHAPTER II. GENERAL BACKROUND......................... 4

II.1 HISTORY OF FATIGUE ....................................... 4

II.1.1 1837-1858 : The Time Before Wöhler.......................... 4

II.1.2 1858-1870 : Wöhler........................................ 5

II.1.3 1870-1905................................................... 7

II.1.4 1905-1925.................................................. 7

II.1.5 1920-1945 : With Special Emphasis

On The German Contribution..................................... 8

II.1.6 The Period of 1945-1960....................................... 9

II.1.7 1960 - 1994.................................................. 10

II.2 FACTORS AFFECTING FATIGUE PERFORMANCE..........12

II.3 FATIGUE DAMAGE THEORIES.............................13

II.3.1 Cumulative Damage Models - The Damage

Curve Approach............................................... 14

II.3.2 Linear Damage Models..................................... 18

II.3.3 Double Linear Damage Rule by Manson and Halford...... 20

II.4. STRESS BASED FATIGUE ANALYSIS AND DESIGN...........23 
II.4.1 S-N Curves.................................................. 25

II.4.2 Material Properties.......................................... 28

II.4.3 Modifying Factors.......................................... 30

II.4.4 Notch Effect..................................................... 34

II.4.5 Stress Concentrations...................................... 34

II.4.6 Mean Stresses..............................................37

II.5 STRAIN BASED FATIGUE ANALYSIS AND DESIGN............39

II.5.1 Cyclic Material Properties................................. 42

II.5.1.1 Transient Cyclic Response..........................42

II.5.1.2 Steady-State Cyclic Stress-Strain Behavior..............43

II.5.2 Stress Concentrations....................................... 45

II.5.3 Mean Stresses.............................................48

II.5.3.1 Morrow's Mean Stress Correction Method............... 48

II.5.3.2 Smith-Watson-Topper (SWT) Model...................49

II.5.4 Notch Analysis.............................................. 51

II.6 FATIGUE ANALYSIS IN THE FREQUENCY DOMAIN........ 53

II.6.1 A Random Sample Time History ..........................5 53

II.6.2 A Random Process..........................................56

II.6.3 Fourier Analysis............................................ 59

II.6.4 Spectral Density..........................................61

II.6.5 Level Crossing Rate of Narrow-Band Random Processes...65

II.6.6 Models Of Fatigue Damage Under

Narrowband Random Processes............................69

II.6.7 Models Of Fatigue Damage Under

Wide-Band Random Processes.............................73

\section{CHAPTER III. FATIGUE LIFE PREDICTION OF}

A DRAG LINK …............................................75

III.1 FATIGUE LIFE PREDICTION ANALYSIS

BY USING THE EXPERIMENTAL LOADS..................77

III.2 FATIGUE LIFE PREDICTION BY USING THE ROAD

LOADS IN THE TIME DOMAIN ............................................... 88

III.2.1 Collecting Strain From The Critical Points................ 88

III.2.2 Fatigue Life Prediction Analysis

By Using The Road Loads................................. 91

III.3 FATIGUE LIFE PREDICTION BY USING

THE ROAD LOADS IN THE FREQUENCY DOMAIN ......... 96

CHAPTER IV. RESULTS.....................................101

CHAPTER V. CONCLUSIONS AND RECOMMENDATIONS.105

REFERENCES.......................................................................................107

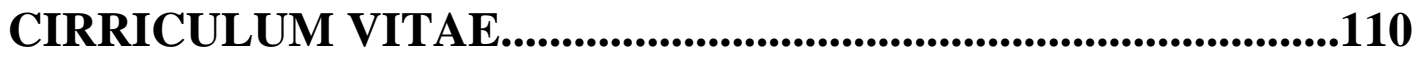




\section{ÖZET}

\section{SONLU ELEMANLAR METODU İLE BİR DİREKSIYYON ROT KOLUNUN YORULMA ÖMRÜNÜN SAPTANMASI}

$\mathrm{Bu}$ tezin odak noktası bir midibüse ait direksiyon rot kolunun, farklı yol ve yüklenme şartlarında yorulma ömrünün saptanmasıdır. Yorulma ömrünün saptanmasında sonlu elemanlar metodu kullanılacak ve parçanın o şartlar altındaki yorulma ömrü saptanacaktır.

Birinci ve ikinci bölümde, öncelikle yorulma kavramının ve hesap metotlarındaki gelişmelerin tarhsel gelişimi anlatılmıştır. Yorulmaya etki eden faktörler ve yorulma hasar teorileri detaylıca anlatılmıştır. Gerilme ve genleme tabanlı yorulma analizleri ve ömür hesap teknikleri anlatılmıştır. Son olarak ise ; diğerlerine göre daha yeni bir metot olan frekans alanında yorulma analiz metotları anlatılmıştır.

Tezin uygulama bölümü olan üçüncü bölümde iki ayrı direksiyon rot kolu incelenmiş ve farklı yol ve yüklenme şartlarında yorulma ömürleri saptanmaya çalışılmışıtır. Öncelikle her iki rot kolu için de aynı standartlarda belirtilen şartlarda yorulma analizleri yapılmış ve sonuçlar rot kolu imalatçısına yaptırılan yorulma testleri sonuçlarıyla karşılaştııılmıştır. Daha sonra ömrü diğerine oranla daha yüksek olan rot kolu seçilmiş, bu rot kolu kullanılarak yol datası toplanmış olan başka bir çalışmadan, yol dataları alınmış ve o yol, yüklenme şartları için zamana bağlı yorulma analizleri yapılmıştır. Son olarak; aynı datalar frekans alanına çevrilmiş ve frekans alanında yorulma analizleri yapılmıştır. Zamana bağlı yorulma analizleri ve frekans alanında yapılan yorulma analizleri sonuçları karşılaştırılmış ve metotların birbirlerine göre üstünlükleri ortaya konulmuştur.

Kasım , 2007

Barış KOCA 


\section{ABSTRACT}

\section{FATIGUE LIFE PREDICTION OF A DRAG LINK BY USING FINITE ELEMENT METHOD}

The focus of this thesis is to find fatigue behaviour and fatigue life of a drag link in the different road and loading conditions. Finite element method was used for fatigue analysis and fatigue life of the drag link was predicted.

Firstly, the historical changes in the concept of the fatigue and fatigue life calculation methods were explained in the chapter one and two. Factor affecting the fatigue performance was explained. Stress and strain based fatigue analysis methods were described clearly. Finally, fatigue life analysis in the frequency domain which is a new method relative to the others was explained .

In the chapter three, two different steering drag links of a midibus were examined and fatigue life calculations of these two drag links were made. The fatigue life analysis in the time domain of the drag links were made in the static steering conditions and the results were compared with the test results made by the vendor of the drag links. In the next section , the drag link which has a greater fatigue life than the other was selected, the road loads were taken from another test report which was made by using the same drag link and the fatigue life of the drag link was computed by using the finite element method in the time domain. Finally, the same road loads were converted in the frequency domain and the fatigue life analysis of the same drag link were made in the frequency domain. The results from the time domain and the frequency domain were compared and the advantages of the fatigue life analysis in the frequency domain were expressed. 


\section{LIST OF SYMBOLS}

\begin{tabular}{|c|c|}
\hline$a_{0}$ & : The size of a crack at the end of the initiation stage \\
\hline A & : The amplitude ratio \\
\hline $\mathrm{b}$ & : Fatigue strength exponent \\
\hline c & : Fatigue ductility exponent \\
\hline$C_{k}$ & : The complex coefficients \\
\hline $\mathrm{D}$ & : Cumulative damage \\
\hline E & : Elastic modulus \\
\hline $\mathrm{E}$ & : The nominal strain \\
\hline$K_{t}$ & : The elastic stress concentration factor \\
\hline$K_{S F}$ & : Surface finish factor \\
\hline$K_{f}$ & : The fatigue notch factor \\
\hline$\Delta K_{t h}$ & : The range of the threshold intensity factor \\
\hline $\mathrm{K}^{\prime}$ & : Cyclic strength coefficient \\
\hline$K_{\sigma}$ & : The true stress concentration \\
\hline$K_{\varepsilon}$ & : The true strain concentration \\
\hline $\mathrm{N}_{\mathrm{p}}$ & : Fatigue-crack-propagation life \\
\hline $\mathrm{N}_{\mathrm{i}}$ & : Fatigue-crack initiation life \\
\hline$N_{f}$ & : The fatigue life \\
\hline$n^{\prime}$ & : Cyclic strain hardening exponent \\
\hline $\mathrm{R}$ & : The stress ratio \\
\hline$R(\tau)$ & : The autocorrelation function \\
\hline$S_{u}$ & : The ultimate tensile strength of a material \\
\hline$\Delta S_{e}$ & : The stress range at the fatigue limit \\
\hline$S_{r}$ & : Constant stress range \\
\hline$S_{a}$ & : Constant stress amplitude \\
\hline$S_{\max }$ & : The maximum stress \\
\hline$S_{\min }$ & : The minimum stress \\
\hline$S_{m}$ & : The mean stress \\
\hline$S_{a, i}$ & : Constant stress amplitude \\
\hline$S_{r, i}$ & : Constant stress range \\
\hline$S_{f}^{\prime}$ & : The fatigue strength coefficient \\
\hline
\end{tabular}




$\begin{array}{ll}\sigma^{e} & : \text { The maximum elastic notch stress } \\ \mathrm{q} & : \text { Notch radius } \\ \Delta \varepsilon & : \text { Total strain range } \\ \Delta \sigma & : \text { Total stress range } \\ \varepsilon^{\prime} f & : \text { Fatigue ductility coefficient } \\ \sigma_{f}^{\prime} & : \text { Fatigue strength coefficient } \\ \rho & : \text { The correlation coefficient } \\ \xi_{W} & : \text { The rainflow correction factor } \\ \lambda & : \text { The spectral width parameter }\end{array}$




\section{LIST OF FIGURES}

\section{PAGE NO}

Figure I.1 The Fatigue Process: A Thin Plate Under Cyclic Tensile Loading... 1

Figure I.2 The Stages Of Total Fatigue Life................................

Figure I.3 Typical Fatigue-Failure Surfaces................................ 3

Figure II.1 Fatigue In A Railcar Axle ........................................ 7

Figure II.2 Fracture Surface Markings and Striations............................ 14

Figure II.3 A Block Of Two-Step High-Low Sequence Loading................16

Figure II.4 Nonlinear Damage Accumulation.................................. 17

Figure II.5 Linear Damage Accumulation.......................................19

Figure II.6 Double Linear Damage Accumulation........................... 20

Figure II.7 Phase I and Phase II Linear Damage Rules....................... 21

Figure II.8 Double Linear Damage and Damage Curve

Accumulations For Two-Step Load............................. 22

Figure II.9 Two Knee Point Coordinates For The

Double Linear Damage Rules....................................22

Figure II.10 Symbols Used With Cyclic Stresses And Cycles....................... 25

Figure II.11 A Typical S-N Material Data................................ 26

Figure II.12 Shematic Of An S-N Curve For Steels.......................... 26

Figure II.13 Represent The S-N Curve With Fatigue Limit Data................ 28

Figure II.14 Ultimate Strength Is Also Called The Tensile Strength............ 28

Figure II.15 Tensile Strength vs. Fatigue Strength............................. 29

Figure II.16 Related Between Material Parameters............................. 30

Figure II.17 Modified S-N Curves For Smooth Components Made Of Steels 31

Figure II.18 Effect Of Surface Factor.................................... 32

Figure II.19 Effect Of Surface Factor On FatigueLimit......................... 32

Figure II.20 Effect Of Stress Concentration Factor..............................35

Figure II.21 Radius Versus Notch Sensitivity Factor..........................36

Figure II.22 Notching Effect In Fatigue Life................................. 37

Figure II.23 Haig's Plot For Goodman's And Gerber's Diagrams................ 38

Figure II.24 Concept Of The Local Strain Life Approach..................... 41

Figure II.25 Test Specimen.............................................. 41

Figure II.26 Transient Behavior - Cyclic Hardening........................... 42

Figure II.27 Hysterisis Diagram........................................... 43

Figure II.28 Strain Versus Fatigue Life................................. 44

Figure II.29 Fatigue Ductility Coefficient, Fatigue Ductility Exponent, Fatigue

Strength Coefficient And Fatigue Strength Exponent................44

Figure II.30 Stress Amplitude Versus Strain Amplitude........................45

Figure II.31 Stress Concentration Factor In Fatigue Life......................... 46 
Figure II.32 Radius Versus Notch Sensitivity Factor............................46

Figure II.33 Real Stress Positions According To Neuber's Rule................ 47

Figure II.34 Morrow’s Mean Stress Correction Model.........................49

Figure II.35 Smith-Watson-Topper Model....................................49

Figure II.36 The Maximum Stress In The Hysteresis Loop...................... 50

Figure II.37 The SWT Mean Stress Correction Model. Reprinted By

Permission Of Pearson Education, Inc.,Upper Saddle

River, NJ, From ' Mechanical Behavior

Of Materials,”' 2nd Edition By Dowling (1998)..................... 51

Figure II.38 Stresses And Strains At A Notch.......................... 52

Figure II.39 Schematic Of Concentration Factors........................... 52

Figure II.40 Probability Density Function (PDF) For A Random Process X(T).. 54

Figure II.41 PDF For A Digitized Random Process $X(T) \ldots \ldots \ldots \ldots \ldots \ldots \ldots \ldots 5$

Figure II.42 PDF For A Gaussian Process.................................... 56

Figure II.43 Random Process_-Ensemble Of Random Sample Time Histories... 57

Figure II.44 Illustration Of Ensemble Statistical Data.......................... 58

Figure II.45 Autocorrelation Function $R_{X}(\tau)$ Of A

Stationary Random Process...................................... 59

Figure II.46 Relationship Between The Spectral Density And Root

Mean Square Of Normalized Stationary Random Process.

Figure II.47 (A) Narrow-Band, Wide-Band, And White Noise Random

Processes,(B) Power Spectral Densities (Psds) Of Narrow-Band,

Wide-Band, And White Noise RandomProcesses.....................64

Figure II.48 The Region Where Event A Occurs............................6 66

Figure II.49 Calculation Of The Irregularity Factor $\gamma \ldots \ldots \ldots \ldots \ldots \ldots \ldots \ldots \ldots . \ldots \ldots$

Figure II.50 Moments From A One-Side PSD................................ 68

Figure II.51 Continuous PDF Of Stress Amplitude.......................... 72

Figure III.1 Steering Mechanism And Drag Link............................. 76

Figure III.2 A Viewing Of The Drag Link Which Will Be Used For Analysises.76

Figure III.3 Crosss section areas of the drag links..................................... 77

Figure III.4 Used Fatigue Test System.................................. 78

Figure III.5 The Load Curve.............................................. 79

Figure III.6 The S-N Curve Of A1-1648 (St 52).......................... 79

Figure III.7 Boundary Conditions........................................ 80

Figure III.8 Meshed Drag Link (Extended Critical Area)....................... 80

Figure III.9 The Fatigue Life Of A1-1648 In Cycles........................ 81

Figure III.10 The Fatigue Life Contours. (Extended Critical Area)........... 82

Figure III.11 The Safety Factor Contours For A1-1648.......................... 82

Figure III.12 The Damage Contours For A1-1648.........................83

Figure III.13 The S-N Curve Of A1-2377 (Sae 1045 Normalized)............... 84

Figure III.14 The Fatigue Life Of A1-2377 In Cycles........................... 84

Figure III.15 The Safety Factor Of A1-2377 ............................ 85

Figure III.16 The Damage Factor Of A1-2377............................ 85

Figure III.17 The Cracking Zone From The Fatigue Tests.................... 86

Figure III.18 A Photograph Of The A1-1648 After The Fatigue Test

(Crack Sprey Squirted On The Drag Link After The Fatigue Test

To See The Cracks)...........................................87

Figure III.19 Cracks Occurs At The Inferior Zone Of The Bending Area........87

Figure III.20 Strain Gauges On The Drag Link.......................... 89 
Figure III.21 ESAM Traveller Plus 32 Channel Signal

Conditioning Amplifier In The Bus............................99

Figure III.22 PSD Graph Of The Loads Before The Filtering..................... 91

Figure III.23 PSD Graph Of The Loads After The Filtering.......................92

Figure III.24 A View Of Glyphworks And The Filtering Operation............. 92

Figure III.25 Rainflow Histogram Of The Loads................................93

Figure III.26 Load Vs Time Graph..................................... 93

Figure III.27 Fatigue Life Distribution.................................. 94

Figure III.28 Damage Distribution..................................... 95

Figure III.29 Vibration Fatigue Procedure................................... 96

Figure III.30 Effect Of Frequency Resolution................................ 98

Figure III.31 Maximum Pricipal Stress Contours At $0 \mathrm{~Hz} . \ldots \ldots \ldots \ldots \ldots \ldots \ldots . . . . . . . .98$

Figure III.32 Maximum Pricipal Stress Vs. Frequency....................... 99

Figure III.33 Vibration Fatigue Life Contours............................... 100 


\section{LIST OF TABLES}

PAGE NO

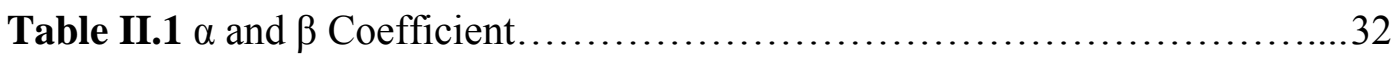

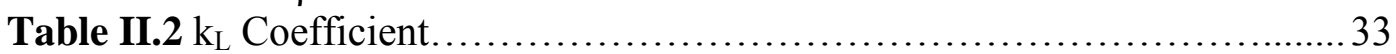

Table III.1 Properties Of The Drag Links................................... 77

Table III.2 The Loading Properties......................................... 78

Table III.3 Correlation Between The Test Results And FEA Results..............86

Table III.4 Predicted Life Values From The Time Domain And Frequency Domain.................................................. 100

Table IV.1 Mean Stress Theories For A1-2377 (Exp. Loads) ............................. 103 


\section{CHAPTER I}

\section{INTRODUCTION}

Fatigue is a process in which damage accumulates due to the repetitive application of loads that may be well below the yield point [1]. It is the result of the cumulative process consisting of crack initation, propagation and final fracture of a component. During cyclic loading, localized plastic deformation may occur at the highest stress site. This plastic deformation induces permanent damage to the component and a crack develops. As the component experiences an increasing number of loading cycles, the length of the crack increases. After a certain number of loading cycles, the crack will cause the component to fail [2]. In one popular view of fatigue in metals, the fatigue process is thought to begin at an internal or surface flaw where the stresses are concentrated and consist initially of shear flow along slip planes. Over a number of cycles, the slip generates intrusions and extrusions that begin to resemble a crack. A true crack running inward from an intrusion region may propagate initially along one of the original slip planes, but eventually turns to propagate transversely to the principal normal stress as seen in Fig. I.1.[1]

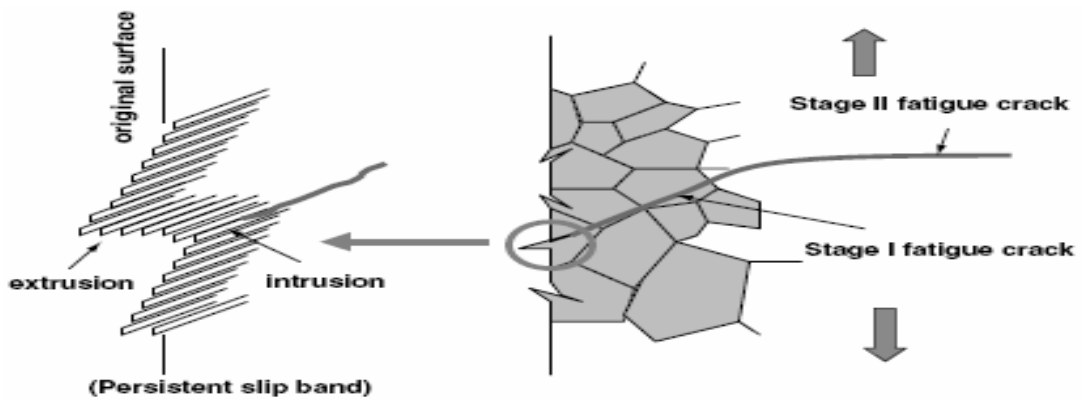

Figure I.1 The Fatigue Process: A Thin Plate Under Cyclic Tensile Loading. 
A graphical representation of the fatigue damage process shows where crack nucleation starts at the highest stress concentration sites in the persistent slip bands. The next step in the fatigue process is the crack growth stage. This stage is divided between the growth of Stage I and Stage II cracks. Stage I crack nucleation and growth are usually considered to be the initial short crack propagation across a finite length of the order of a couple of grains on the local maximum shear stress plane. In this stage, the crack tip plasticity is greatly affected by the slip characteristic, grain size, orientation, and stress level, because the crack size comparable to the material microstructure. Stage II crack growth refers to long crack propagation normal to the principal tensile stress plane globally and in the maximum shear stress directin locally. In this stage, the chararacteristics of the long crack are less affected by the properties of the microstructure than the Stage I crack. This is because the crack tip plastic zone for Stage II crack is much larger than the material microstructure [2].

The number of cycles required to initiate a fatigue crack is the fatigue-crack initiation life, $N_{i}$. The number of cycles required to propagate a fatigue crack to a critical size is called the fatigue-crack-propagation life, $N_{p}$. The total fatigue life $N_{t}$ is the sum of the initiation and propagation lives, that is

$$
N_{t}=N_{i}+N_{p}
$$

The total fatigue life can be shown schematically as seen in Figure I.2. [3]

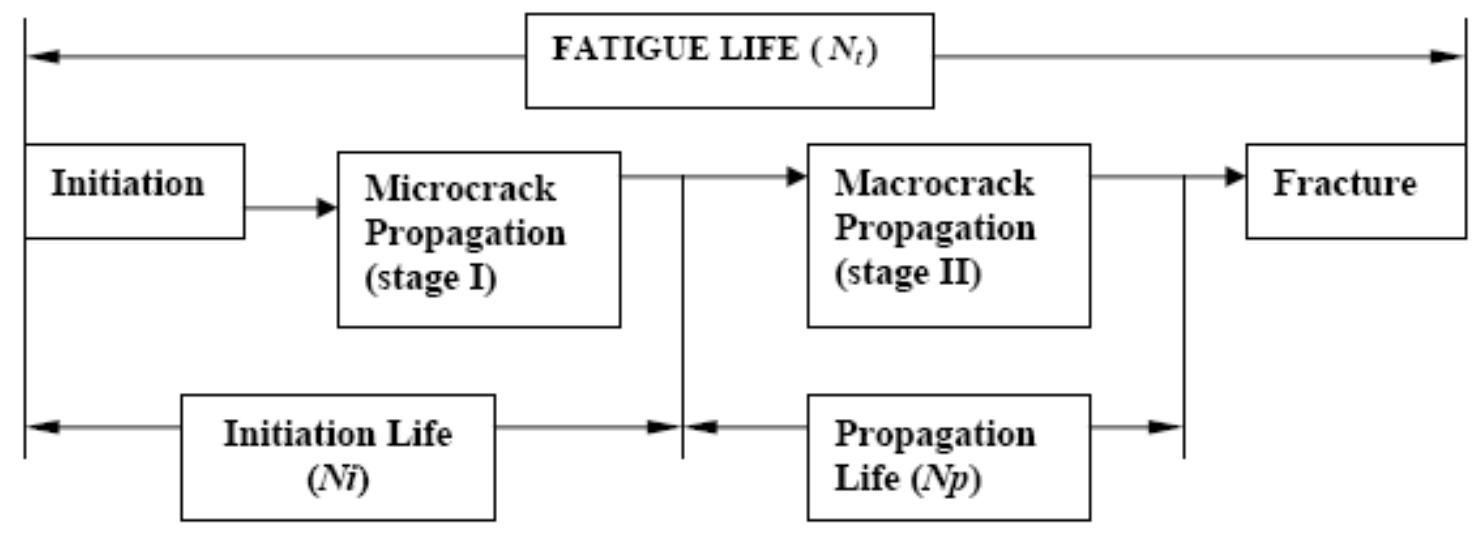

Figure I.2 The Stages Of Total Fatigue Life. [3] 
When the failure surface of fatigued specimen is examined, a region crack growth is usually evident in the form of a "clamshell" concentric around the location of the initial flaw. (See Fig.I.3.) The clamshell region often contains concentric "beach marks" at which the crack was arrested for some number of cycles before resuming its growth. Eventually, the crack may become large enough to satisfy the energy or stress intensity criteria for propagation, following the previous expressions for fracture mechanics. This final phase produces the rough surface typical of fast fracture. In postmortem examination of failed parts, it is often possible to correlate the beach marks with specific instances of overstress, and to estimate the applied stress at failure from the size of the crack just before rapid propagation and the fracture toughness of the material [1] .

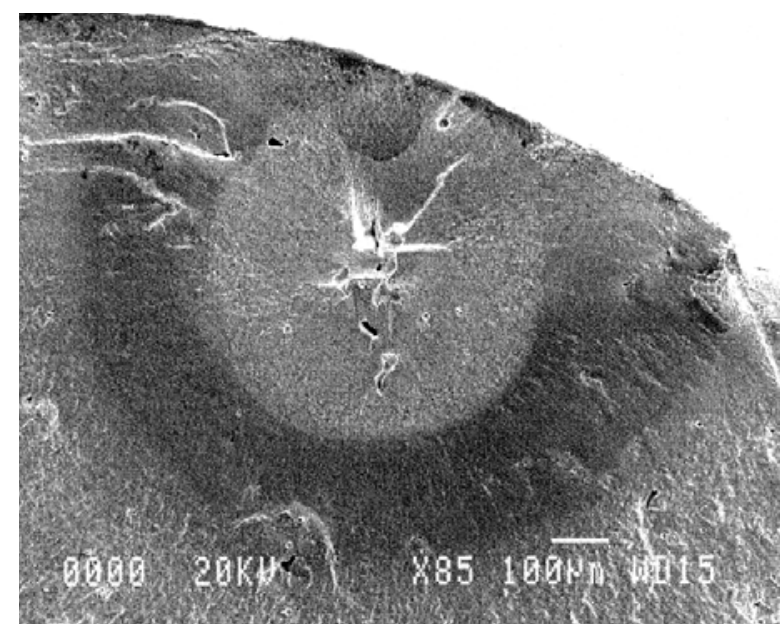

Figure I.3 Typical Fatigue Failure Surfaces

In real conditions, many parts and products fracture due to the fatigue cracks. Due to the fatigue cracks in the automobiles or other machines some serious accidents can occur which causes serious injuries. Because of these reasons, the focus of this thesis was selected as finding fatigue behaviour and fatigue life of a drag link in the different road and loading conditions. The other objective of the thesis is to find good converging fatigue results from FEA and to expose the importance of the vibration fatigue analysis. 


\section{CHAPTER II}

\section{GENERAL BACKROUND}

\section{II.1 HISTORY OF FATIGUE}

\section{II.1.1 1837-1858 : The Time Before Wöhler}

The history of fatigue begins with Albert, who was a Royal Hannoverian "Oberbergrat" (civil servant for mines). In 1837 he published in Clausthal the first fatigue-test results known. For this purpose he constructed a test machine for the conveyor chains which had failed in service in the Clausthal mines. As early as that, he therefore tested actual component, not just the material! Since chains at the time could only be replaced by hemp rope which had to be imported at great cost, Albert invented the wire rope- surely more important than those first fatigue tests.

In 1842, Rankine, better known from thermodynamics by the "Rankine process", discussed the fatigue strength of railway axles. He suggested that these axles be forged with a hub of englarged diameter and large radii, so that the grain flow would not be cut more than necessary by machining. York conducted experiments with railway axles.

In 1853 the Frenchman Morin in his book discussed reports of two engineers responsible for horse-drawn mail coaches. The replacement of the axles of the coaches was prescribed after $60000 \mathrm{~km}$, an early example of the "safe life" design approach. The axles of other mail coaches were to be inspected thoroughly after $70000 \mathrm{~km}$, cracks to be rapaired by "fire-welding". It was noted that those cracks mainly occured at section changes. 
The term "fatigue" was mentioned for the first time by the Englishman Braithwaite in 1854 contrary to a widespread belief which ascribes it to Morin. Braithwaite, howewever, says that a Mr. Field coined the term. In his paper Braithwaite describes many service fatigue failures of brewery equipment, water pumps, propeller shafts, crankshafts, railway axles, levers, craners, etc.

In this period many disastrous railroad accidents due to the fatigue occured. For example, on 5th October 1842, a locomotive axle broke at Versailles, claiming the lives of 60 people, about the same number as were lost in the two "Comet" crashes of 1954. [4]

\section{II.1.2 1858-1870 : Wöhler}

Wöhler, Royal "Obermaschinenmeister" of the "Niederschlesisch- Mahrische" Railways in Frankurt an der Oder, measured the service loads of railways axles with self-developed deflection gages as early as 1858 and 1860. Specifically, this was accomplished for a number of four-wheeled and six-wheeled freight and passenger cars on trips between Breslau and Berlin as well as Frankurt an der Oder and Berlin. The measurements were carried out for $22,000 \mathrm{~km}$. The deflection of the axle was scratched on a zinc plate by a scriber by means of a compound lever system. Only the largest deflection per trip was measured. Wöhler then draws the following conclusions from his measurements. And then, Wöhler implicitly suggested design for finite fatigue life, taking into consideration even the scatter of fatigue life or in other words, the probability of failure. Since no fatigue-test data were available to him at that early date, he estimates them and arrives at an allowable axle for 200, 000 cycles of 136 "Zentner".

Beginning in 1860 , Wöhler published the result of fatigue tests with railway axles. Since the rotating-bending test machine he designed and built ran at a very low frequency, he designed new machines for carrying out axial-bending and torsion tests on different notched and unnotched specimens. In 1870 he presented a final report containing the following conclusions, often called "Wöhler's laws": "Material can be induced to fail by many repetitions of stress, all of which are lower than the static strength. The stress amplitudes are decisive for the destructions of the cohesion of the material. The maximum stress is of influence only in so far as the higher it is, the lower are the stress amplitudes which lead to failure". Wöhler therefore stated the 
stress amplitudes to be the most important parameter for fatigue life, but a tensile mean stress also to have a detrimental influence.

Wöhler then suggest a safety factor of two for static strength and an additional one of two for fatigue strength. In his opinion, this is adequate for all circumtances. These factor, however, are only valid for unnotched sections, because "the strength of joints in the form of riveted joints, keyed joints and such kind, and different shapes require special tests. The result of the tests with sharply notched specimens have proved the necessity of such special tests". Thus Wöhler correctly does not present the additional safety factors for these joints, but requires special tests.

Wöhler then describes the forces acting on the axle in service, for example the static load, lateral loads due to cornering, wind pressure, etc. He calculates the service stresses via the measured loads and the axle diameter. By comparing these stresses with the result of his fatigue tests he concludes that axle are completely safe. Furthermore, he describes the allowable axle loads according to the "Technical Regulations of the German Railways", which depend on the material, diameter, etc., and which also contain rules about the size of the radii between the axle and journal diameter. The "metallurgical size effect" was already taken into account at that time, i.e. the allowable stresses for thinner axles were higher than those for thicker axles, "because it was assumed that smaller dimensions allow the material to be worked better and therefore would result in higher fatigue strength".

In summary one can only admire the work of Wöhler in its entirety, encompassing the measurements of service loads, the calculation of the corresponding service stresses, the design for finite life including scatter up to the observation of crack propagation and the quantitative suggestions for the decrease of the notch effect.

Wöhler incidentally represented his test result in the form of tables. Only his successor Spangenberg as director of the "Mechanisch-Technische-Versuchsanstalt" in Berlin plotted them as curves, although in the unusual form of linear abscissa and ordinate. The S-N curves were called "Wöhler curves" since 1936.[4] 


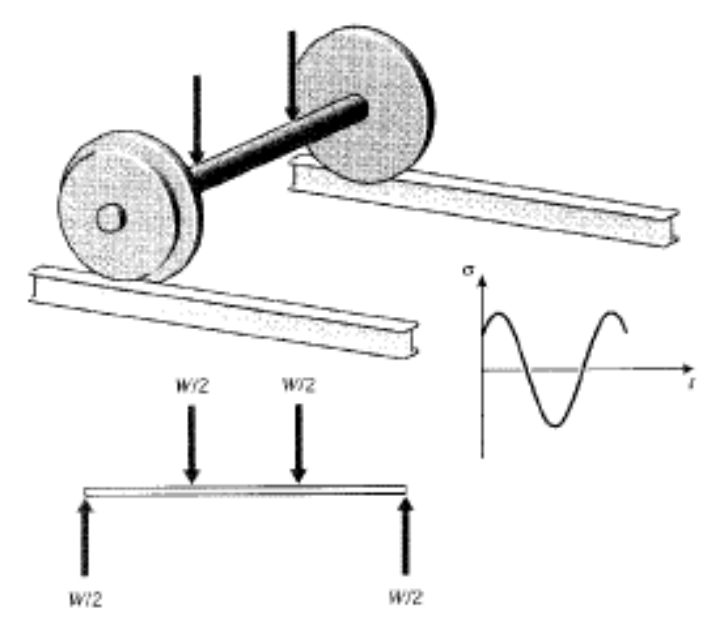

Figure II.1 Fatigue In A Railcar Axle.

\section{II.1.3 1870-1905}

The next name to be mentioned would be Bauschinger, Professor of Mechanics at the Munich Polytechnical Scaool, which is now the Technical University of Munich. The Bauschinger effect, on his words "the change of the elastic limit by often repeated stress cycles", is the basis for the hypotheses of Manson and Coffin which originated in the 1950s and which are still being utilized today in the LFC field and for Fatigue-life prediction according to the concept.[4]

\section{II.1.4 1905-1925}

The first full-scale fatigue test with a large aircraft component was carried out at the Royal Aircraft Establishment in the U.K. In the literature the notch effect on actual components-as apart from that on specimens- is quoted. The term "notch effect" was probably coined by the German Heyn in 1914, but implicitly it was already discussed by Rankinein 1842 and by all his successors including Wöhler. The first experiments to improve the fatigue strength of components probably were carried out in the U.K during the first World War . [4] 


\section{II.1.5 1920-1945 : With Special Emphasis On The German Contribution}

In this period of time the foundations were laid for almost all the fatigue knowledge we enjoy today. The following topics originated or were investigated:

- The "Gestaltfestigkeit" by Thum and Bautz.

- The fatigue strength under variable amplitudes by Gasner.

- The measurement of fatigue loads and stresses, on many components for example by Lehr.

- The measurement of load spectra on automobile springs by Batson and Bradley, on agricultural machinery by Kloth and Stroppel, on aircraft from 1932 onwards by Kaul, Filzek, Freise, etc.

- The realization that higher-strength materials do not result in higher fatigue strengths of components because they always contain notches, by Gassner for aircraft aluminum alloys and by Graf foe welded and riveted joints of structural steels.

- The mechanical methods to improve fatigue strength by inducing compressive residual stresses, like cold-rolling, shot-peening and coining by Föppl, and Thum and coworkers.

- The first book on fatigue in 1924 by Gough in the U.K., 1927 by Moore and Kommers in USA, 1929 by Graf in Stuttgart, 1929 by Föppl in Braunschweig, 1934 by Herold in Vienna, 1937 by Cazaud in France, 1937 by Serensen in Russia, 1941 by the Battella Institute in the USA.

- The damage accumulation hypotheses for fatigue-life prediction under variable amplitudes in 1924 by the Swede Palmgren, 1937 by the American Langer, 1938 by the Russian Serensen and 1945 by the American Miner.

- Inductive strain gages, for example by Lehr, and as a direct counting device giving the spectrum of level crossings by Svenson.

- The electrical wire strain gage in 1939 by the Americans Ruge and de Forest from MIT, and independently by Simmons and Clark from Caltech.

- The statistical scatter of the static strength of materials in 1939 by Weibull.

- Fatigue test with large numbers of specimens and their statistical evaluation by Müller-Stock in Braunschweig. 
- The first crack propagation tests in 1936 by the American de Forest.

- The foundation of fracture mechanics in 1920 by Griffith.

- Seminars and meetings about fatigue by Thum, the VDI, the Lilienthal Gesellschaft, the VDEH, the DGM in Germany, the Institution of Mechanical Engineers in the U.K.[4]

\section{II.1.6 The Period of 1945-1960}

This was the time period in which the harvest of the years 1920-1945 was brought in. In all industrial countries fatigue was investigated. The de Havilland "Comet", designed in about 1948, the first commercial jet aircraft of the Western world, had an operating altitude about twice that of contemporary propeller-driven aircraft. Therefore the pressurized fuselage had to support higher stresses. In 1954 two "Comets" crashed, one near Elba, one near Naples, by failure of the fuselage at a window cutout. In a large research and test programme, the cause was clarified according to the level of knowledge of the day: the full-scale fatigue test had been carried out with a fuselage which had before been pressurized to twice the maximum pressure differential in service. This was done to save a static test aircraft. In the window corners beneficial residual compressive stresses were thereby induced, which obviously were not present in the accident aircraft. Besides, an ultra-highstrength aluminum alloy of the 7000 series had been used, the unfavorable fatigue behavior of which Gassner had already described in 1941. As late as 1987 Swift of the FAA showed, however, that in reality a design fault had been the cause of the accidents: the fuselage frames of the "Comet" were in one piece, whereas in more modern aircraft types they are built up of two independent frames. Therefore, a fast fracture could not been contained in the "Comet" design.

Because of the "Comet" accidents, complex flight-by-flight test with the complete aircraft structure, so called full-scale fatigue test, became the rule, the pressurized aircraft fuselage in a water tank, the wings loaded by servohydraulic cylinders with the ground to air cycle and 10-40 gusts of different magnitude per flight. Earlier aircraft had been tested in a much more simple way and often in parts, the wings for example only by the ground to air cycle and 10 gusts of equal magnitude per flight. 
Countries which had not come to the fore earlier supplied important contributions to the fatigue of aircraft structures, for example Australia: beginning in 1948 and until about 1970, the Aeronautical Research Laboratories carried out fullscale fatigue tests with 180 wings of the P-51 "Mustang", left over from WW II. Topics investigated were the behavior at constant and variable amplitudes, a complete Goodman diagram for wings of 2024-T3 was established, the accuracy of Miner's Rule for the wing structure was investigated and a highly sophisticated statistical treatment of the scatter observed was developed, altogether a very meritorious research programme. The fatigue behavior of other military aircraft of WW II vintage was also investigated.

Besides the "Comet", several other aircraft types suffered fatal crashes due to fatigue. Williams in 1965 gave a compherensive summary; one cause for accidents and incidents cited and again in references was; the high strength aluminum alloys of the 7000 series have unfavorable fatigue properties.

In 1958 two large steam turbine rotors burst during test runs, as well as several "Polaris" rockets during pressure tests. In all cases the cause was crack-like material defects, which in the Polaris rocket were very small because an ultra-high-strength steel was used. Again, the national security of the U.S.A. and of the Western world was threatened. In the same year Irwin of the US Navy had taken up the old ideas of Griffith and had realized that the stress-intensity factor was the determining factor for static strength in the cracked state. If $\mathrm{K}$ reaches a certain critical number depending on the "fracture tougness" of the material in question, instant fast fracture occurs: linear elastic fracture mechanics (LEFM) was born. [4]

$K=S \cdot \sqrt{\pi \cdot a}$

\section{II.1.7 1960 - 1994}

From 1960 onwards the number of fatigue experts and therefore of publications increased still further. This must also be attributed to the rapid development of fracture mechanics, i.e. of fatigue-crack propagation. Paris of Lehigh University, in his Ph.D. Thesis of 1962 and a previous paper established that fatigue-crack propagation could be described by the following equation soon erroneously called a "law": 


$$
\frac{d a}{d n}=C \cdot \Delta K^{n}
$$

This equation soon set out on a veritable triumphant advance around the world. It is almost exclusively used even today, although it contains neither influence of mean stress on crack propagation, nor the static fracture on reaching the fracture toughness $K_{1 c}$, nor the "fracture mechanics fatigue limit" $\Delta K_{0}$, that is the stressintesity range below which no fatigue-crack propagation occurs. The Paris equation therefore can be compared to an S-N curve from a stress amplitude of infinity to one of zero, showing no influence of mean stress nor a fatigue limit. The complex process of crack propagation is undoubtedly described much too simply by this equation; this fact however did not prevent its- partly undiscriminating- use all over the world to this very day. Paris also maintained that the slope of his curve was $n=4.0$ for all materials. This could be compared to all S-N curves of metallic materials having the some slope and for all mean stresses as well.

In 1963 Paris extended his equation to variable amplitudes by inserting a "characteristic" stress " $h$ " instead of the $\Delta \sigma$ in the formula for $\Delta K$. This value $h$ was said to depend on the shape of the stress spectrum only. Paris further stated that the crack propagation curve for constant and variable amplitudes would coincide if both were plotted against this $\mathrm{h}$, this being somewhat similar to the root mean square of the stress amplitudes. Intentionally or unintentionally, Paris thus claimed to have solved the problem of damage accumulation if only for fatigue-crack propagation. Paris' claims were soon proved incorrect. Numerical values for $n$ ranged from 2.0 to 20 in experiments and the problem of damage accumulation, i.e. of the prediction of crack propagation under variable stress amplitudes, has not been conclusively solved even today .

From about 1965 onwards, the Society of Automotive Engineers (SAE) in a large cooperative programme has tried to predict fatigue life using the local-strain approach. Several US automobile makers and many universities were participants. Much too short stress-time histories were employed probably because of the limited computer capacities of the time. Had it been proved that the fatigue life could be predicted with reasonable accuracy, this would not have been useful, because the rare high loads so typical of real service stress time histories did not occur in the 
sequences chosen. However, the programme did not even succeed in correctly predicting fatigue life under these unrealistic sequences. [4]

\section{II.2 FACTORS AFFECTING FATIGUE PERFORMANCE}

Many parameters affect the fatigue performance of components. They include parameters related to stress (load), geometry and properties of the component, and the external environment. The stress parameters include state of stress, stress range, stress ratio, constant or variable loading, frequency and maximum stress.

The geometry and properties of the component include stress (strain) raisers, size, stress gradient, and metallurgical and mechanical properties of the metal. The external environment parameters include temperature and aggressiveness of the environment.

The primary factor that affects the fatigue behavior of component is the fluctuation in the localized stress or strain. Consequently, the most effective methods for increasing the fatigue life significantly are usually accomplished by decreasing the severity of the stress concentration and the magnitude of the applied nominal stress. In many cases, a decrease in the severity of the stress concentration can be easily accomplished by using transition radii in fillet region.[3]

\section{II.3 FATIGUE DAMAGE THEORIES}

Predicting fatigue damage for structural components subjcted to variable loading conditions is a complex issue. The first, simplest, and most widely used damage model is the linear damage. This rule is often referred to as Miner's rule (1945). However, in many cases the linear rule often leads to nonconservative life predictions. The result from this approach do not take into account the effect of load sequence on the accumulation of damage due to cyclic fatigue loading. Since the introduction of the linear damage rule many different fatigue damage theories have been proposed to improve the accuracy of fatigue life prediction. A comprehensive review of many fatigue damage approaches can be found elsewhere.

In engineering applications, the amount of component life spent on crack nucleation and short crack growth is usually called the crack initiation period, 
whereas the component life spent during long crack growth is called the crack propagation period. An exact definition of the transition period from initiation to propagation is usually not possible. However, for steels the size of a crack at the end of the initiation stage, $a_{0}$, is of the order of a couple of grains of the material. This crack size typically ranges from about 0.1 to $1.0 \mathrm{~mm}$. The crack initiation size can be estimated using the linear elastic fracture mechanics approach for smooth specimens by Dowling (1998):

$a_{0}=\frac{1}{\pi}\left(\frac{\Delta K_{t h}}{\Delta S_{e}}\right)^{2}$

Or by 0.1 to 0.2 times the notch-tip radius for notched specimens (Dowling, 1998) or by twice the Peterson empirical material contant for steels (Peterson, 1959):

$a_{0}(m m)=2 \times 0.0254 \times\left(\frac{2079}{S_{u}(M P a)}\right)^{1.8}$

Where $S_{u}$ is the ultimate tensile strength of a material, $\Delta S_{e}$ is the stress range at the fatigue limit, and $\Delta K_{t h}$ is the range of the threshold intensity factor for $\mathrm{R}=-1$.

Typically, the crack initiation period accounts for most of the fatigue life of a component made of steels, particularly in the high-cycle fatigue regime (approximately $>10,000$ cycles). In the low-cycle fatigue regime (approximately $<$ 10,000 cycles), most of the fatigue life is spent on crack propagation.

Once a crack has formed or complete failure has occured, the surface of a fatigue failure can be inspected. A bending or axial fatigue failure generally leaves behind clamshell or beach markings. The name for these markings is shown in Figure II.2. The crack nucleation site, usually in a radial manner. A semielliptical pattern is left behind. In some cases, inspection of the size and location of the beach marks left behind may indicate where a different period of crack growth began or ended.

Within the beach lines are striations. The striations shown in Figure II.2 appear similar to the rings on the cross-section of a tree. These striations represent the extension of the crack during one loading cycle. Instead of a ring for each year of growth, there is a ring for each loading cycle. In the event of a failure, there is a final 
shear lip, which is the last bit of material supporting the load before failure. The size of this lip depends on the type loading, material, and other conditions.

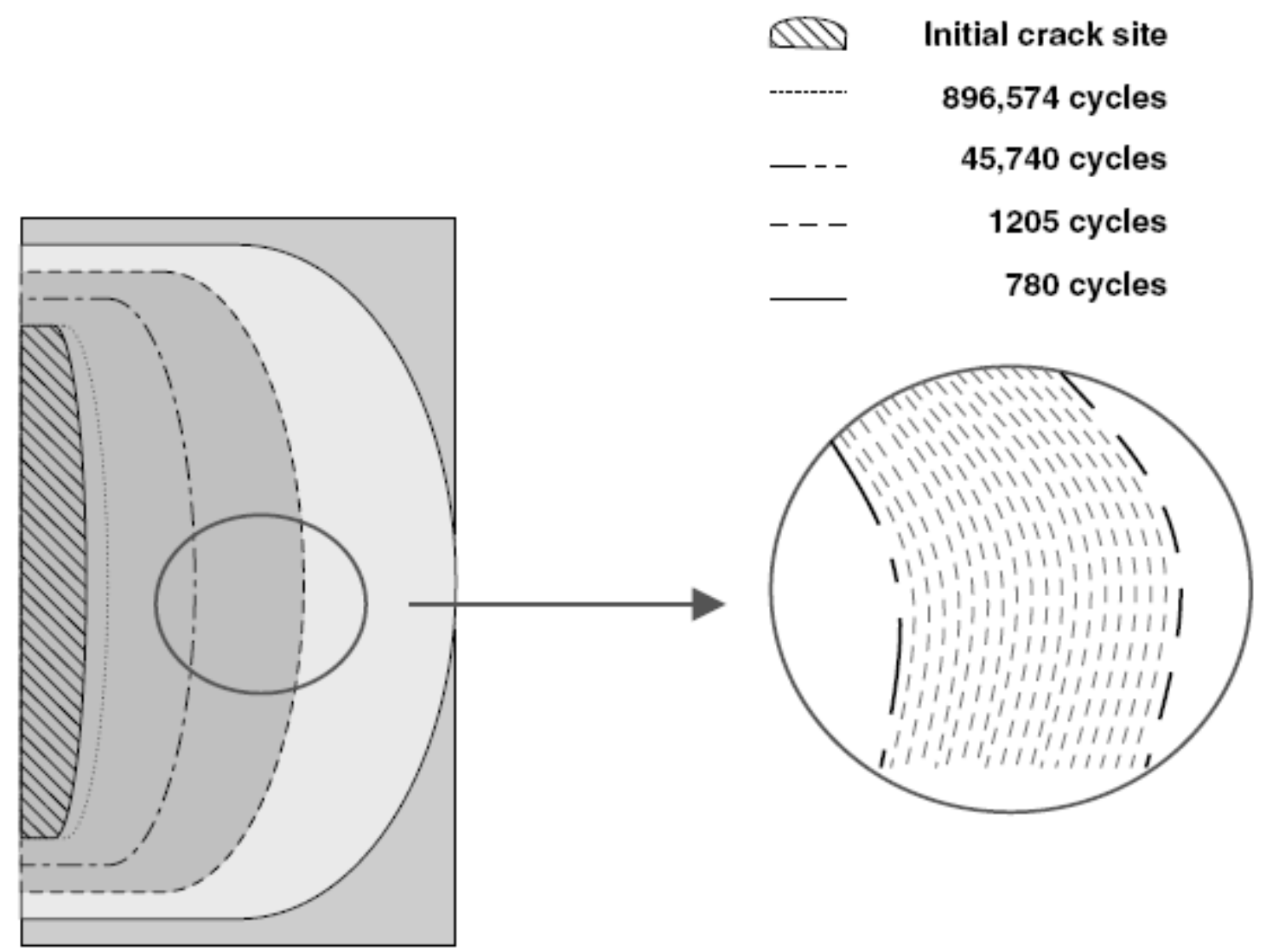

Figure II.2 Fracture Surface Markings And Striations

\section{II.3.1 Cumulative Damage Models - The Damage Curve Approach}

The component's damage can be expressed in terms of an accumulation of the crack length toward a maximum acceptable crack length. For example, a smooth specimen with a crack length at fracture of $a_{f}$ is subjected to cyclic loading that result in a crack length of $a$. The amount of damage, $D$, at a given stress level $S_{1}$, would be the ratio of $a$ to $a_{f}$. To illustrate the cumulative damage concept, a crack growth equation developed by Manson and Halford (1981) is adopted:

$a=a_{0}+\left(a_{f}-a_{0}\right)\left(\frac{n}{N_{f}}\right)^{a_{f}}$ 
Equation II.5 was derived based on early crack growth fracture mechanics and fitted with a large amount of test data for loading with two-step life/stress levels, where $n$ is the number of loading cycles applied to achieve a crack length of $a$, and $a_{0}$ is the initial crack length. The value $N_{f}$ represents the number of cycles applied to achieve the crack length $a_{f}$ at final fracture. The exponent $a_{f}$ is empirically determined and has the following form:

$a_{f}=\frac{2}{3} N_{f}^{0.4}$

Cumulative damage (D) is the ratio of instantaneous to final crack length and can be expressed as follows:

$$
D=\frac{a}{a_{f}}=\frac{1}{a_{f}}\left[a_{0}+\left(a_{f}-a_{0}\right)\left(\frac{n}{N_{f}}\right)^{a_{f}}\right]
$$

This damage equation implies that fatigue failure occurs when $D$ is equal to unity. Consider a two-step high-low sequence loading in Figure II.3, where $n_{1}$ denotes the initial applied load cycles with a higher stress or load level. Note that the subscript 1 and 2 refer to sequence of the applied loading: 1 is the first and 2 is the second load level. The S-N curve is used to obtain the fatigue lives $N_{1, f}$ and $N_{2, f}$ for each load level. Nonlinear damage curves for two different loads are shown schematically in Figure II.4. Each of these curves represents a different loading condition that leads to a different time to failure (or life level). At each load level or life level, the relation between the damage value and the applied cycles ratio follows the power law equation in II.7. If a cycle ratio $n_{1} / N_{1, f}$ is the first applied along the curves representing the life level $N_{1, f}$ to point $\mathrm{OA}$, the damage accumulation process will be represented by the life level curve $N_{1, f}$ from zero to point A. If at this point a new loading level with a life of $N_{2, f}$ is introduced and this loading is applied, the damage process will proceed from point A to point A' from the same damage value.

If the load corresponding to the cycle ratio $n_{2, f} / N_{2, f}$ is applied from A' to B' at the life level $N_{2, f}$, failure takes place if $\mathrm{D}=1.0$ is reached at point $\mathrm{B}$ '. From this figure, it is clear that if a higher load level with a lower life along OA is first applied 
and followed by the lower load magnitude with higher life along A'B', the sum of cycle ratios will be smaller than unity. Thus, the estimated fatigue life depends on the sequence of loading. However, if a lower load level is applied first along OA' and is followed by the higher load level along $\mathrm{AB}$, the summation of the cycle ratios is greater than unity because the cycle ratio AA' is accounted for twice.

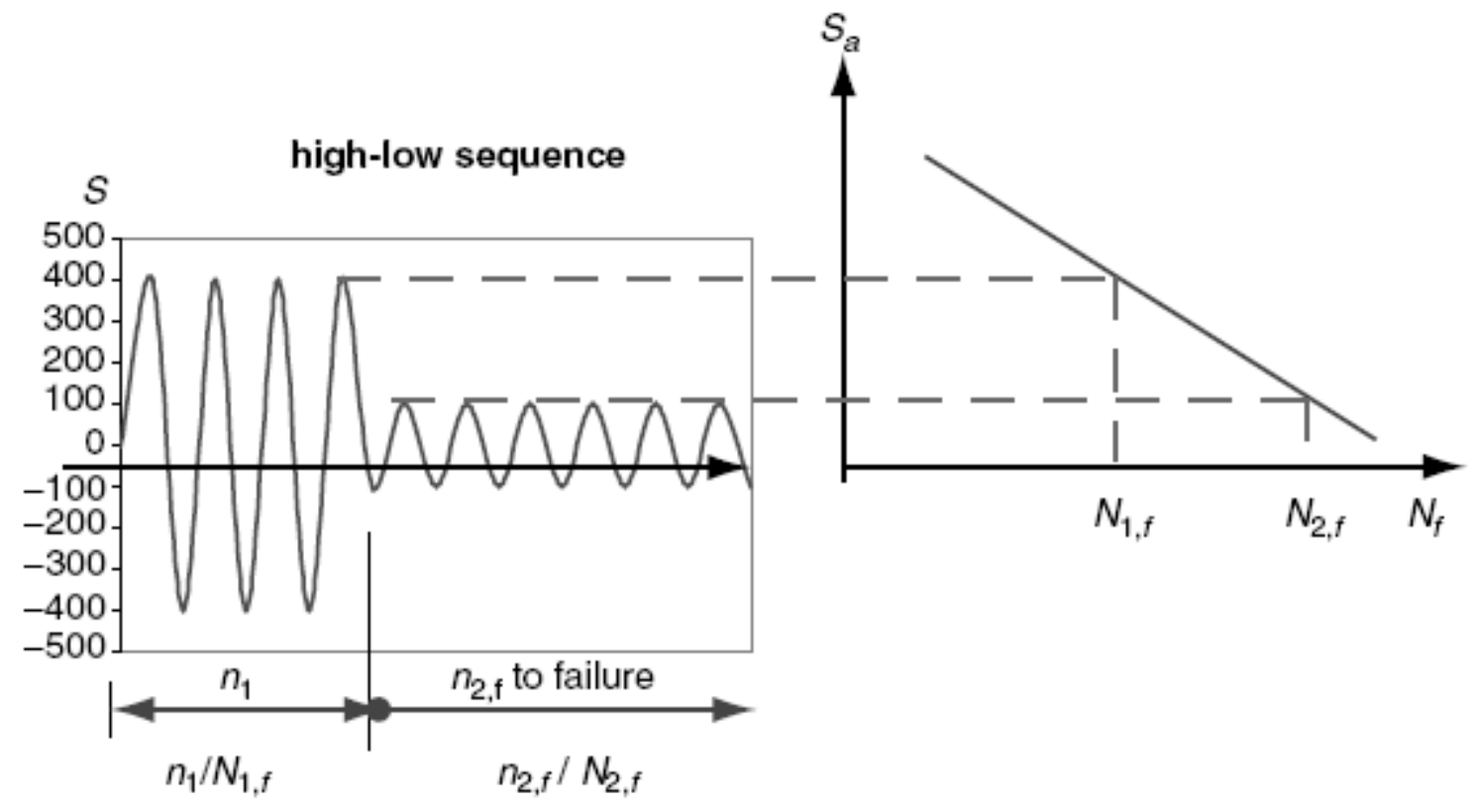

Figure II.3 A Block Of Two-Step High-Low Sequence Loading.

Based on the equal damage at A and A' in Figure II.4 for the two load levels, the following equations hold true for the relation between the cycle ratio $n_{1} / N_{1, f}$ and the equivalent damage cycle ratio $n_{2} / N_{2, f}$ :

$\left(\frac{n_{2, f}}{N_{2, f}}\right)=1-\left(\frac{n_{1}}{N_{1, f}}\right)^{\left(N_{1, f} / N_{2, f}\right)^{0.4}}$

and

$\frac{n_{1}}{N_{1, f}}=1-\left[\frac{n_{2}}{N_{2, f}}\right]^{\left(N_{2, f} / N_{1, f}\right)^{0.4}}$

where $n_{2}$ is the number of cycles at the life level $N_{2, f}$, equivalent damage to the initial cycle ratio $n_{1} / N_{1, f}$. 
It is clear that Equation II.9 is independent of material and geometric parameters (e.g., $a_{0}, a_{f}$, and $\alpha_{f}$ ) that were introduced in the damage accumulation equation (Equation II.7). Thereby, a nonlinear damage curve for a reference life level $\left(N_{1, f}\right)$ can be linearized by replacing $a_{0}$ by zero and $2 / 3$ by $\left(1 / N_{1, f}\right)^{0.4}$. Thus, the damage function for the reference life level can be simplified as a linear line connecting $(0,0)$ with $(1,1)$, i.e.,

$$
D_{1}=\frac{n_{1}}{N_{1, f}}
$$
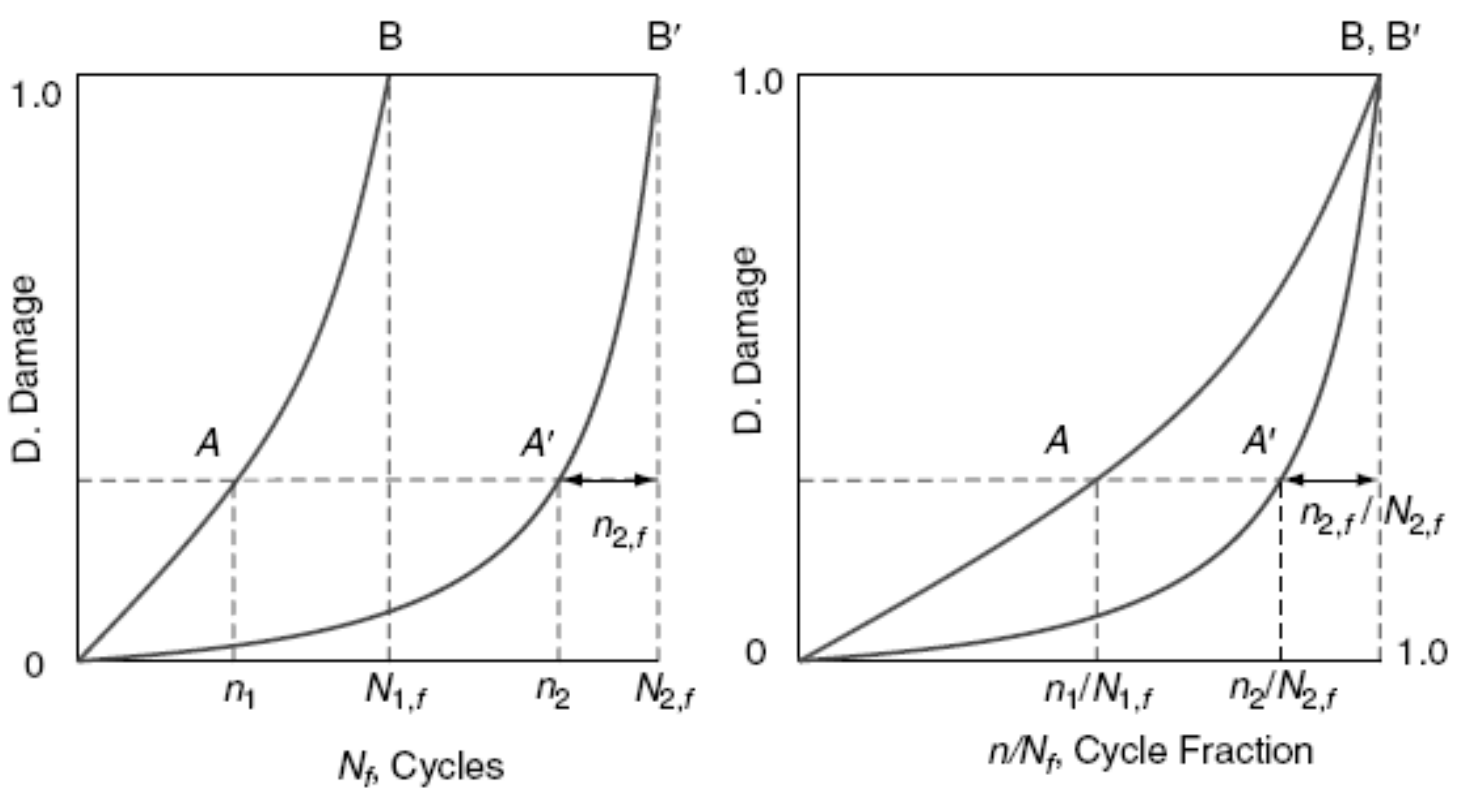

Figure II.4 Nonlinear Damage Accumulation.

Therefore, the damage curve for another life level $\left(N_{2, f}\right)$ is then given by the power law damage equation defined as:

$D_{2}=\left[\frac{n_{2}}{N_{2, f}}\right]^{\left(N_{2, f} / N_{1, f}\right)^{0.4}}$

For multiple life levels (e.g., $N_{1, f}<N_{2, f}<\ldots<N_{n, f}$ ), the damage curves can be constructed expeditiously by letting the damage curve for the lowest life level be the reference life. Two other methods have been developed to determine the power law damage equation. Based on the experimental observations that the equivalent 
damage S-N lines converge to the fatigue limit, Subramanyan (1976) calculated damage by referring to the reference stress amplitude $S_{r e f}$ and the fatigue limit $S_{e}$ as follows:

$D_{N}=\left[\frac{n_{n}}{N_{n, f}}\right]^{\left(S_{n}-S_{e}\right) /\left(S_{r e f}-S_{e}\right)}$

On the other hand, Hashin (1980) expressed this differently by using the fatigue life $\mathrm{Ne}$ at the fatigue limit Se:

$D_{N}=\left[\frac{n_{n}}{N_{n, f}}\right]^{\log \left(N_{n, f} / N_{e}\right) / \log \left(N_{r e f} / N_{e}\right)}$

The power law accumulation theories using the three different methods are compared with the experimental data by Manson et al. (1967). The high to-low (H-L) step-stress series was applied to smooth components made of SAE 4130 steel with a soft heat treatment. The two stress levels are 881 and $594 \mathrm{MPa}$, which correspond to fatigue lives of 1700 and 81,250 cycles, respectively. A fatigue limit of $469 \mathrm{MPa}$ was also determined at 800,000 cycles. By applying Equations II.11-II.13, the three power law exponent values are obtained (i.e., 0.213 on Manson and Halford, 0.303 on Subramanyan, and 0.372 on Hashin).

\section{II.3.2 Linear Damage Models}

If the damage curves in the cycle $N_{i, f}$ coordinate are linearized, the linear damage rule is developed by reducing the damage curves to a single line in the cycle ratio $n_{i} / N_{i, f}$ domain, as shown in Figure II.5. In this case, the fatigue damage has a unique, linear relation with the cycle ratio regardless of the stress levels. Hence, at a given level of damage, the cycle ratio for two different damage curves will be the same. This is illustrated by Figure II.5, in which two linear damage curves plotted on a graph of damage versus cycles to failure are equal to each other when plotted on a graph of damage versus cycle ratio. 

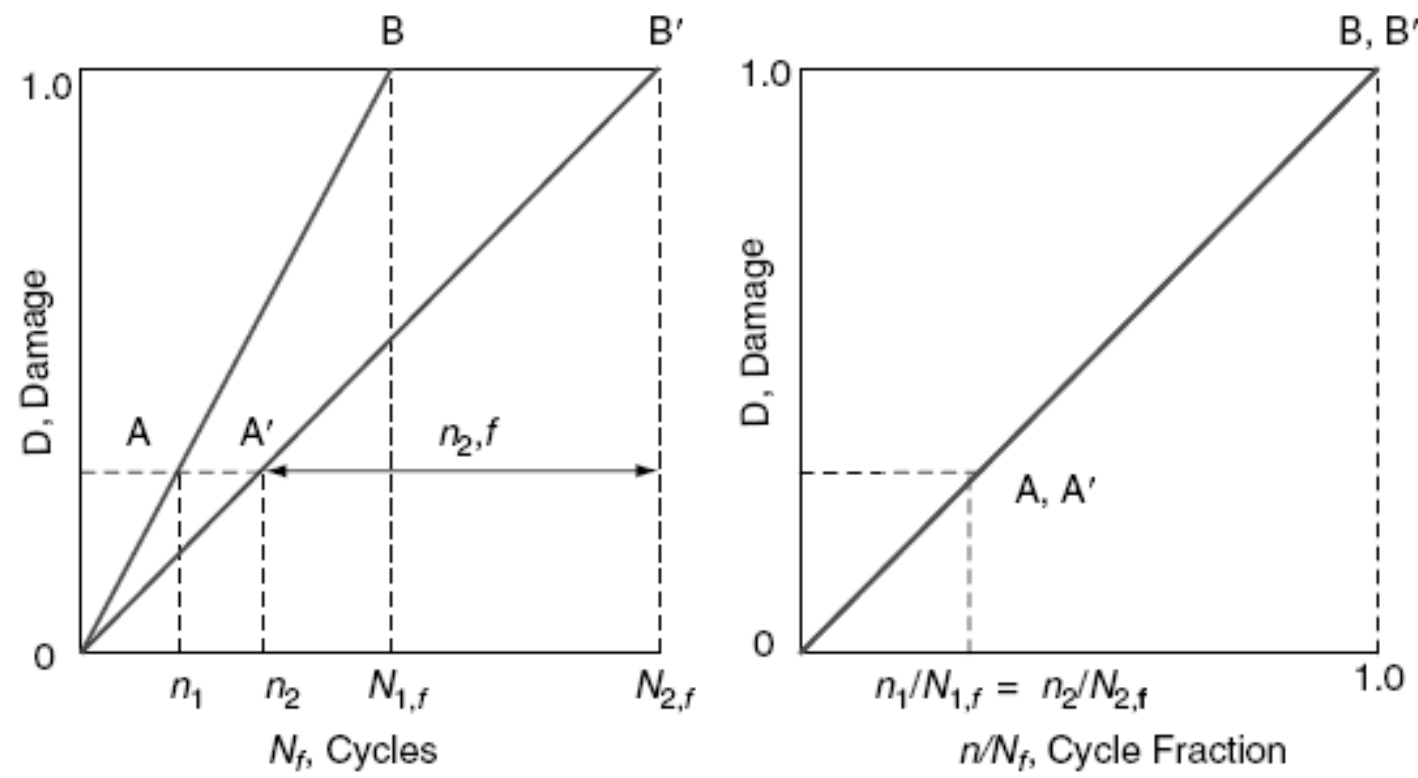

Figure II.5 Linear Damage Accumulation.

Failure will occur when the sum of the ratios at each stress level reaches a value of 1.0. In terms of mathematics, the linear damage rule can be expressed as follows:

$D_{i=} \frac{n_{i}}{N_{i, f}}$

Failure is predicted when

$\sum D_{i=} \sum \frac{n_{i}}{N_{i, f}} \geq 1.0$

The universally used linear damage assessment model was first proposed by Palmagren (1924) for application to the Swedish ball bearing industry. Langer (1937), working for Westinghouse in the electric power generation area, independently proposed a similar linear rule for pressure vessel and piping components made of steel. Miner (1945) of Douglas Aircraft built on Langer's work and applied the linear damage rule to tension-tension axial fatigue data for aircraft skin material (aluminum alloy 24S-T ALCLAD). Miner demonstrated excellent agreement between the predictions from the linear damage rule and his experimental results. This success led to the strong association between Miner and the linear damage rule, and the linear damage rule is commonly referred to as Miner's linear damage rule. 


\section{II.3.3. Double Linear Damage Rule by Manson and Halford}

The tedious iteration process using the nonlinear damage theory and the deficiency in damage assessment using the simple linear damage rule have motivated researchers to look for a better way to overcome the disadvantages of each method. Based on the observation that fatigue is at least a two-phase process - crack initiation and crack propagation - the models for the damage curves can be assumed to be bilinear. Examples of such curves are shown in Figure II.6. The bilinear model represents an equivalent damage model to the damage curve accumulation rule.

Manson and Halford (1981) derived the required criteria to determine the coordinates of the knee point, i.e., the intersection between the two straight lines of the bilinear curves. It is suggested that the straight line connecting $(0,0)$ and $(1,1)$ be the reference damage line for the lowest life level. Because of the nonlinear nature of damage and the accumulation of damage being modeled as a bilinear process, the two regions of damage are identified. The region of damage from the origin to the level of AA' is designated as Phase I $\left(D_{I}\right)$, and the region of damage from AA' to $\mathrm{BB}^{\prime}$ is defined as Phase II $\left(D_{I I}\right)$. Using an approach similar to the method presented to normalize the cycle ratio for linear damage accumulation, the cycle ratios for Phase I and Phase II damage accumulations are constructed in a linear fashion, as shown in Figure II.7.

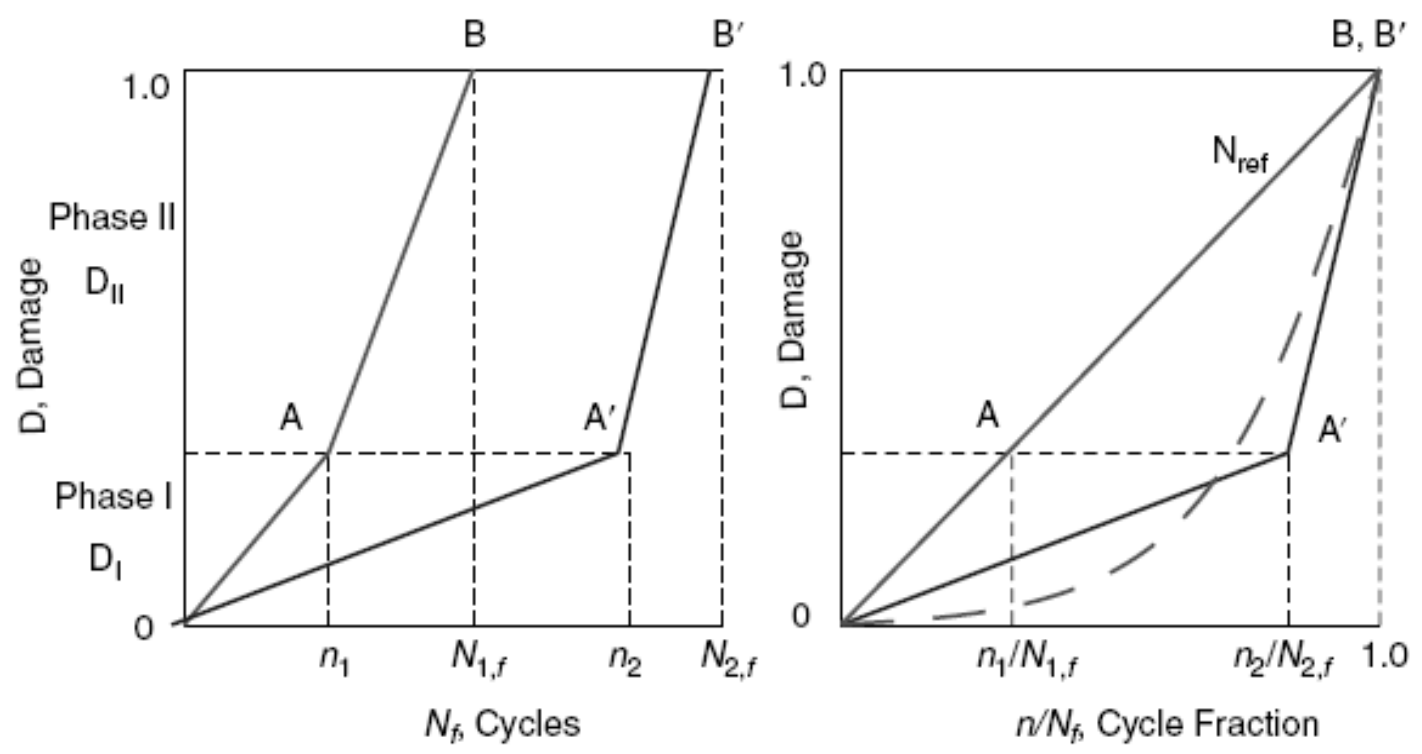

Figure II.6 Double Linear Damage Accumulation. 

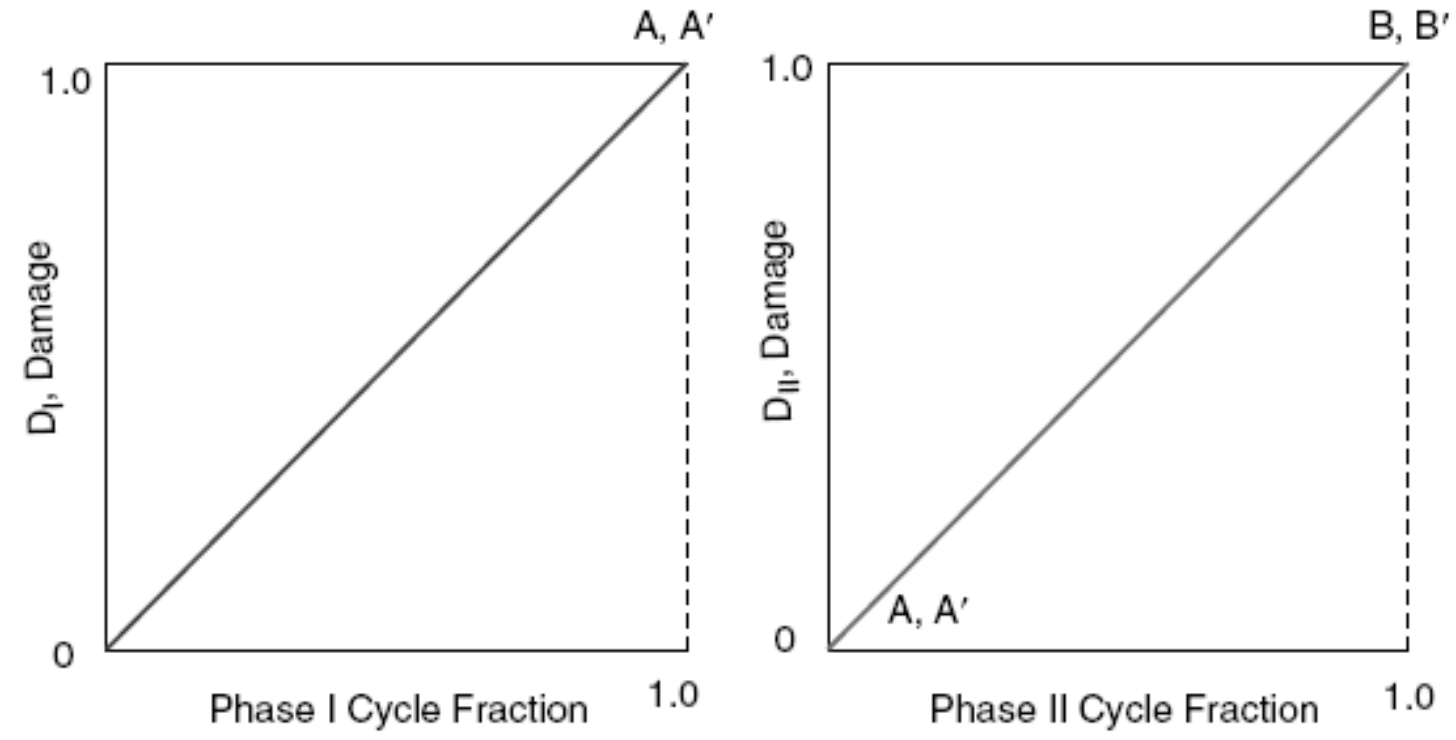

Figure II.7 Phase I And Phase II Linear Damage Rules.

Figure II.6 illustrates that the total damage can be decomposed into Phase I damage $\left(D_{I}\right)$ and Phase II damage $\left(D_{I I}\right)$. The Phase I linear damage accumulation rule states that prior to reaching the damage $D_{I}$, the cycle ratios can be summed linearly and are independent of the loading sequence (i.e., from OA to OA' or from $\mathrm{OA}^{\prime}$ to $\mathrm{OA}$ ). When the sum of the cycle ratios reaches unity, Phase I damage is completed. After the total damage beyond $D_{I}$, the Phase II linear damage accumulation rule applies. Regardless of the loading sequence, the damage accumulation depends only on the total sum of cycle fractions at each level. Based on the considerable amount of test data developed for two-step loading on many materials, Manson and Halford discovered that the knee point between Phase I and Phase II damage depends on the ratio of $N_{1, f} / N_{2, f}$ instead of the physical significance of crack initiation and crack propagation. Figure II.8 shows the linear damage rule for the H-L step stress loading with the initial applied cycle fraction $n_{1} / N_{1, f}$ and the remaining cycle fraction $n_{2, f} / N_{2, f}$. Figure II.8 illustrates the double linear damage rule and damage curve accumulations for the two-step loading and the relationship between $n_{1} / N_{1, f}$ and $n_{2, f} / N_{2, f}$. Equation II.8 is the mathematical model for the description of the relationship between $n_{1} / N_{1, f}$ and 
$n_{2, f} / N_{2, f}$. To meet the condition that the bilinear model is equivalent to the damage curve accumulation rule, the knee point coordinates were derived and are found to depend on the ratio of $N_{1, f} / N_{2, f}$. Figure II.9 shows that the test data on the knee point coordinates correlates well with $N_{1, f} / N_{2, f}$. The coordinates of the knee point are empirically determined as follows:

$\left[\frac{n_{1}}{N_{1, f}}\right]_{\text {knee }}=0.35 \times\left(\frac{N_{1, f}}{N_{2, f}}\right)^{0.25}$
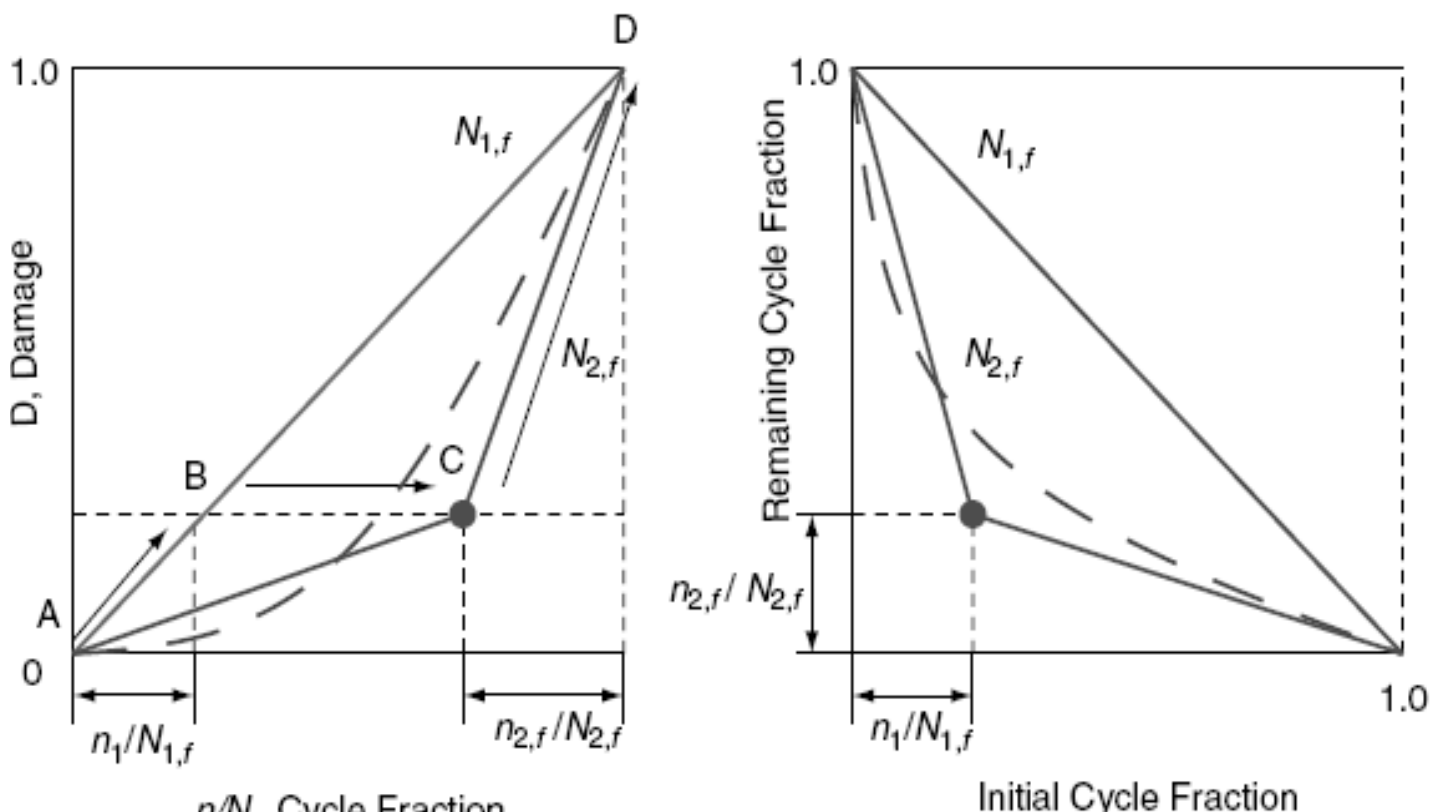

$n / N_{f}$, Cycle Fraction

Initial Cycle Fraction

Figure II.8 Double Linear Damage And Damage Curve Accumulations For Two-Step Loading.
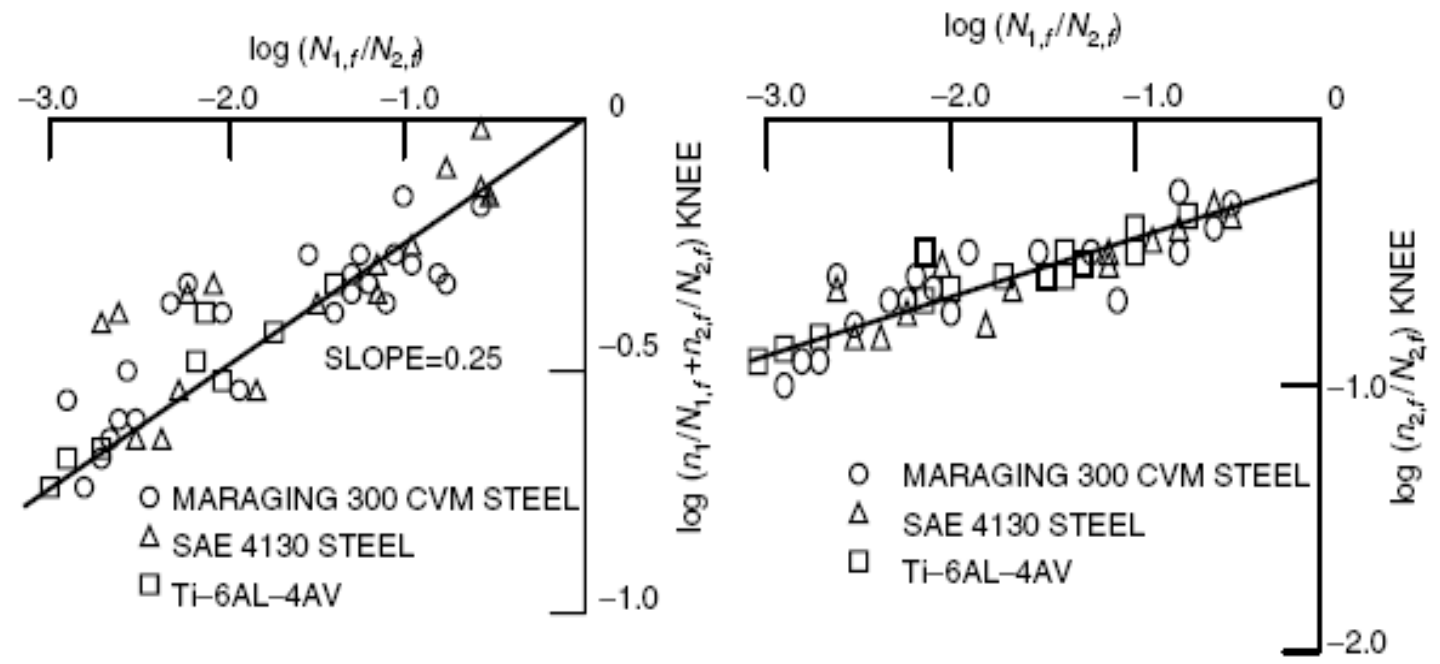

Figure II.9 Two Knee Point Coordinates For The Double Linear Damage Rules. 
$\left[\frac{n_{2, f}}{N_{2, f}}\right]_{\text {knee }}=0.65 \times\left(\frac{N_{1, f}}{N_{2, f}}\right)^{0.25}$

It is important to note that the knee coordinates are independent of the specific material. Hence, the knee points would be the same for all materials. Their location is dependent only on maximum and minimum lifes. [2]

\section{II.4. STRESS BASED FATIGUE ANALYSIS AND DESIGN}

Since the mid-1800's, a standard method of fatigue analysis and design has been the stress-based approach. This method is also referred to as the stress- life or the $\mathrm{S}-\mathrm{N}$ approach and is distinguished from other fatigue analysis and design techniques by several features:

. Cyclic stresses are the governing parameter for fatigue failure

. High-cycle fatigue conditions are present

- High number of cycles to failure

- Little plastic deformation due to cyclic loading

During fatigue testing, the test specimen is subjected to alternating loads until failure. The loads applied to the specimen are defined by either a constant stress range $\left(S_{r}\right)$ or a constant stress amplitude $\left(S_{a}\right)$. The stress range is defined as the algebraic difference between the maximum stress $\left(S_{\max }\right)$ and minimum stress $\left(S_{\min }\right)$ in a cycle:

$S_{r}=S_{\max }-S_{\min }$

The stress amplitude is equal to one-half of the stress range:

$S_{a}=\frac{S_{r}}{2}=\frac{\left(S_{\max }-S_{\min }\right)}{2}$ 
Typically, for fatigue analysis, it is a convention to consider tensile stresses positive and compressive stresses negative. The magnitude of the stress range or amplitude is the controlled (independent) variable and the number of cycles to failure is the response (dependent) variable. The number of cycles to failure is the fatigue life $\left(N_{f}\right)$, and each cycle is equal to two reversals $\left(2 N_{f}\right)$. The symbols of stresses and cycles mentioned previously are illustrated in Figure II.10. Most of the time, S$\mathrm{N}$ fatigue testing is conducted using fully reversed loading. Fully reversed indicates that loading is alternating about a zero mean stress. The mean stress $\left(S_{m}\right)$ is defined as:

$S_{m}=\frac{\left(S_{\max }+S_{\min }\right)}{2}$

Exceptions exist when stress-life testing is performed for specimens for which this type of loading is physically not possible or is unlikely. One example is the fatigue testing of spot welded specimens. Cyclic loading varying from zero to tension is used in fatigue testing on specimens with a single spot weld, because compression may cause local buckling of the thin sheet metal. Actual structural components are usually subjected to alternating loads with a mean stress. Two parameters, the stress ratio $(\mathrm{R})$ and the amplitude ratio $(\mathrm{A})$, are often used as representations of the mean stress applied to an object. [2]. The stress ratio is defined as the ratio of minimum stress to maximum stress:

$$
R=\frac{S_{\min }}{S_{\max }}
$$

The amplitude ratio is the ratio of the stress amplitude to mean stress:

$$
A=\frac{S_{a}}{S_{m}}=\frac{1-R}{1+R}
$$




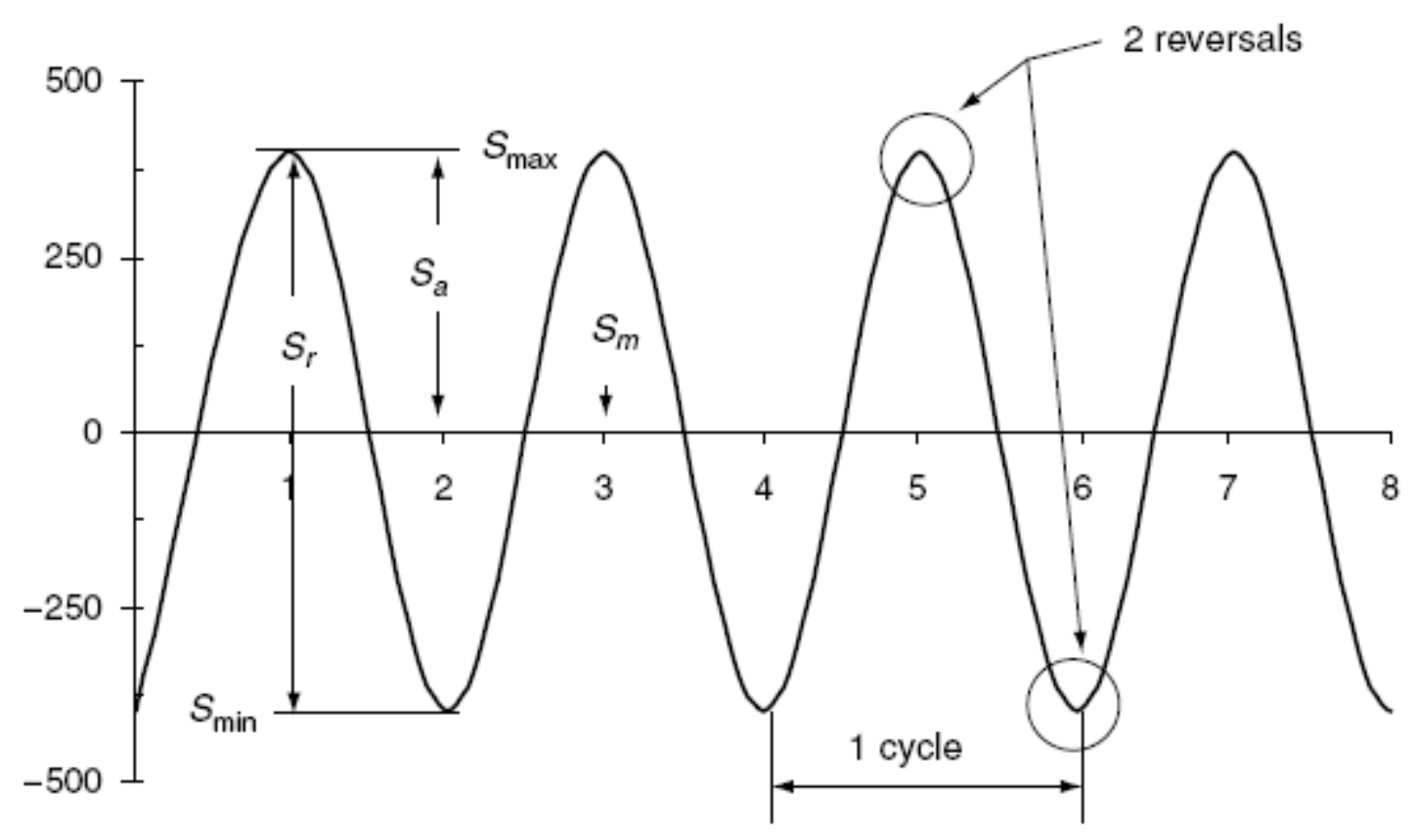

Figure II.10 Symbols Used With Cyclic Stresses And Cycles

\section{II.4.1 S-N Curves}

The basis of the stress-life method is the Wöhler S-N curve, that is a plot of alternating stress, $\mathrm{S}$, versus cycles to failure, N. The data which results from these tests can be plotted on a curve of stress versus number of cycles to failure. This curve shows the scatter of the data taken for this simplest of fatigue tests. A typical S-N material data can be seen in Figure II.11. The arrows imply that the specimen had not failed in $10^{7}$ cycles. [5]

The most important concept is the S-N diagram, such as those shown in Fig. II.12, in which a constant cyclic stress amplitude $\mathrm{S}$ is applied to a specimen and the number of loading cycles $\mathrm{N}$ until the specimen fails is determined. Milions of cycles might be required to cause failure at lower loading levels, so the abscissa in usually plotted logarithmically. [1] 


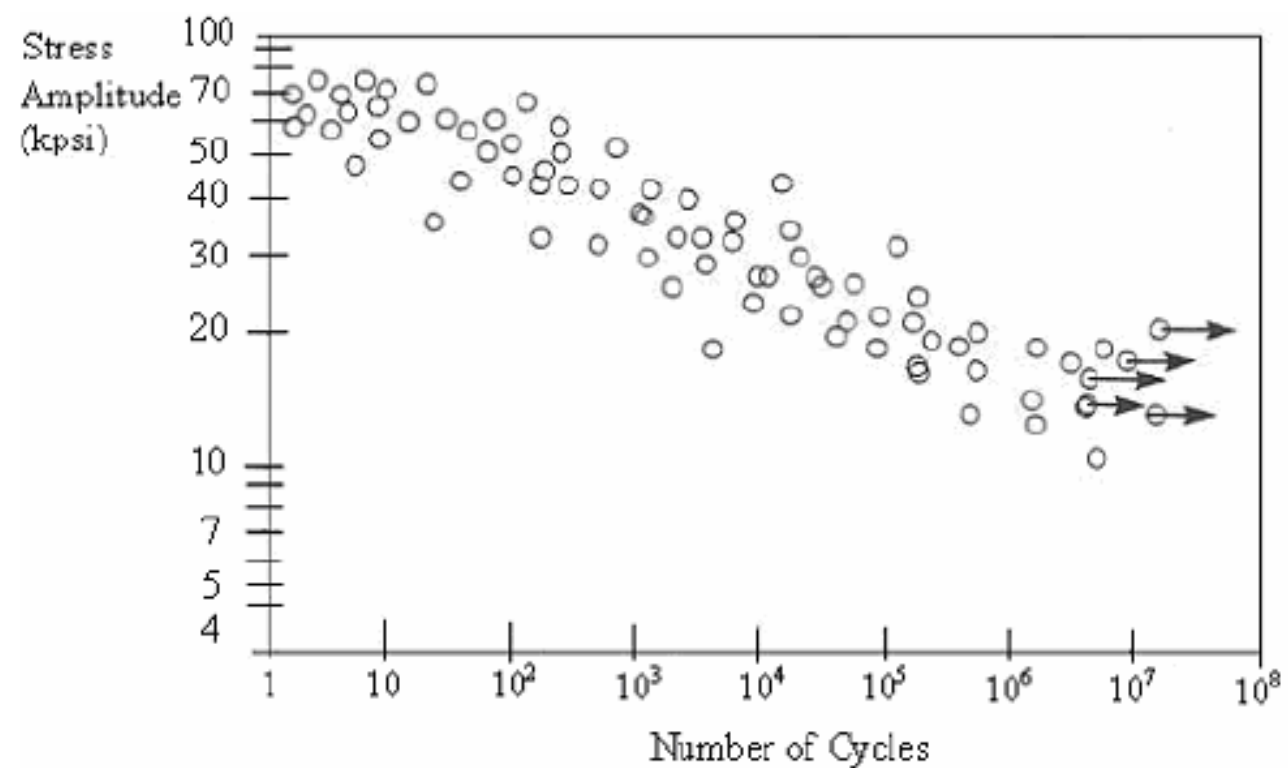

Figure II.11. A Typical S-N Material Data [5]

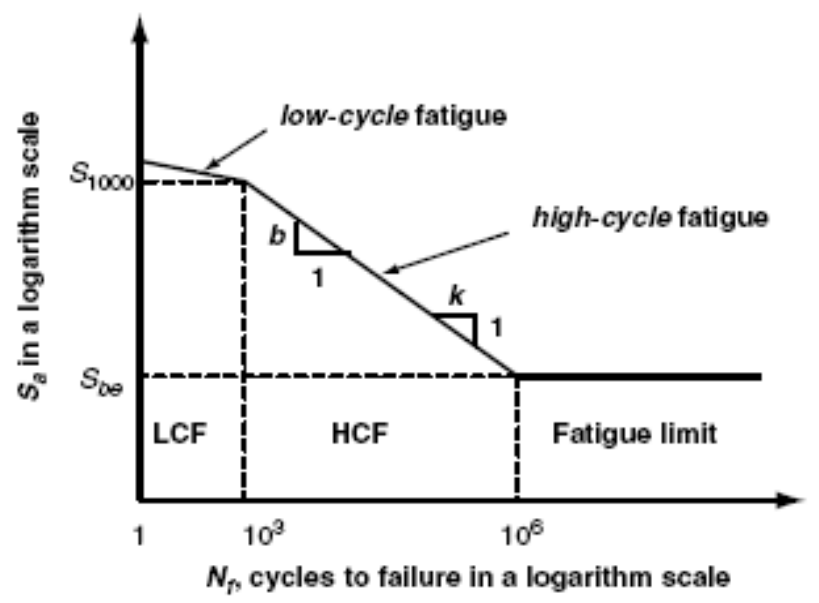

Figure II.12 Schematic Of An S-N Curve For Steels [2] .

The S-N curve derived on the standart specimens under fully reversed bending loads can be constructed as a piecewise- continuous curve consisting of three distinct linear region when plotted on log-log coordinates. As shown schematically in Figure II.12, there are two inclined linear segments and one horizontal segment in a typical $\log$-log S-N curve. The two inclined linear segments represent the low-cycle fatigue and high-cycle fatigue regions and the horizontal asymptote represents the bending fatigue limit. The boundary between low ang high-cycle fatigue cannot be defined by a spesific number of cycles. For specimens made of steels, the fatigue strength values at $1,10^{3}, 10^{6}$ cycles define an $\mathrm{S}-\mathrm{N}$ curve. 
An S-N curve can be generated for standard smooth material specimens, for individual manufactured structural components, for subassemblies or for complete structures. Standard smooth specimens can be flat or cylindrical unnotched precision machined coupons with polished surfaces so as to minimize surface roughness effects. The material $\mathrm{S}-\mathrm{N}$ curve provides the baseline fatigue data on a given geometry, loading condition, and material processing for use in subsequent fatigue life and strength analysis. This baseline data can be adjusted to account for realistic component conditions such as notches, size, surface finish, surface treatments, temperature, and various types of loading. Other than from testing, there is no rational basis for determining these correction factors. The $\mathrm{S}-\mathrm{N}$ curve for real components, subassemblies, or structures represents the true fatigue behavior of production parts structures including all the aforementioned variables. However, if a design has changed, it is necessary to regenerate the $\mathrm{S}-\mathrm{N}$ curve to incorporate the change effect. This adds cost and time to the fatigue design process. In general, a limitation of the $\mathrm{S}-\mathrm{N}$ method is that it can not predict local plasticity and mean stress effect. [2]

The approach known as stress-based approach continues to serve as a wides preadused tool for the design of the aluminum structures. Comparing the stress-time history at the chosen critical point with the S-N curve allows a life estimate for the component to be made. Stress-life approach assumes that all stresses in the component, even local ones, stay below the elastic limit at all times. It is suitable when the applied stress is nominally within the elastic range of the material and the number of cycles to failure is large. The nominal stress approach is therefore best suited to problems that fall into the category known as high-cycle fatigue. High cycle fatigue is one of the two regimes of fatigue phenomenon that is generally considered for metals and alloys. It involves nominally linear elastic behavior and causes failure after more than about $10^{4}$ to $10^{5}$ cycles. This regime associated with lower loads and long lives, or high number of cycles to produce fatigue failure. As the loading amplitude is decreased, the cycles-to-failure increase. [5] 


\section{II.4.2 Material Properties}

Historically, fatigue tests have been conducted in rotating bending. Today, it is often common to find test data for axial loading as well. The fatigue limit, $S_{F L}$, is the stress which failures do not occur in the laboratory. [6]

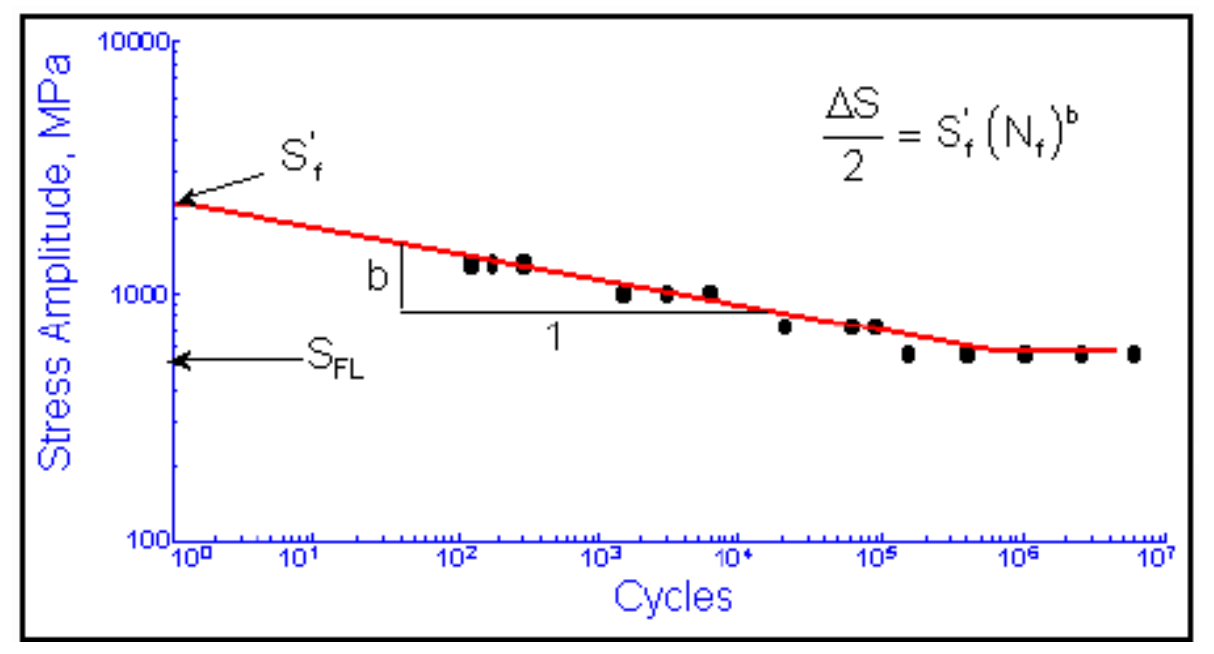

Figure II.13 Represent The S-N Curve With Fatigue Limit Data.

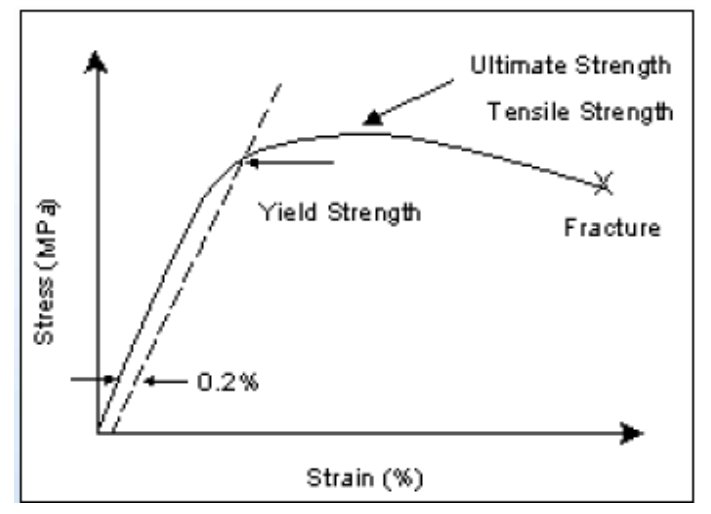

Figure II.14 Ultimate Strength Is Also Called The Tensile Strength.

Wöhler called this a safe stress level for design. Today we know that failures will occur below the safe stress level but it will take a very large number of cycles, longer than the $10^{6}$ or $10^{7}$ cycles used in normal fatigue testing. The finite life portion of the curve is fit to a power function relating the stress amplitude, $\Delta S / 2$, and fatigue life in cycles, $N_{f}$. Be careful, some people use reversals, $2 N_{f}$, instead of cycles for plotting fatigue data. There are 2 reversals in one cycle. The intercept at 1 cycle, $S_{f}{ }^{\prime}$, and slope, $\mathrm{b}$, are taken as material constants. Many times the fatigue 
behaviour of a material are unknown and must be estimated from the tensile properties. There is a strong correlation between fatigue strength and tensile strength. The fatigue limit is approximated as one half of the tensile strength.

The ultimate strength, $S_{u}$, is also called the tensile strength. It is the maximum stress reached in an engineering stress strain diagram. [7]

$S_{F L}=0.5 S_{u}$

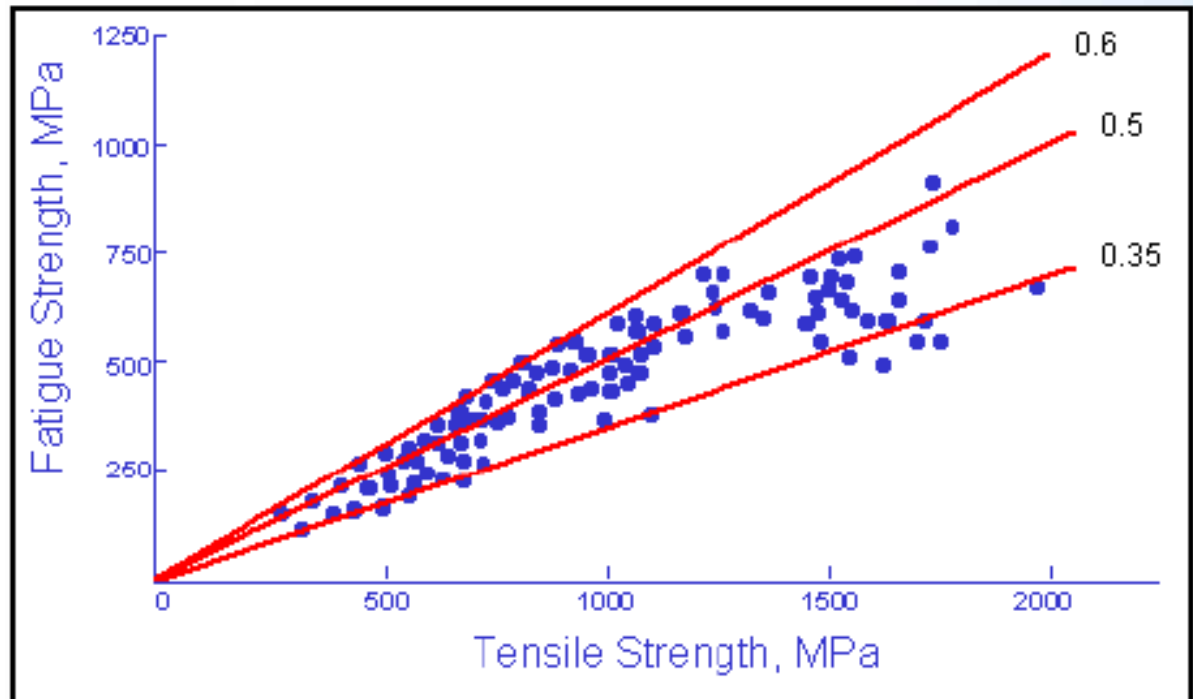

Figure II.15 Tensile Strength Vs. Fatigue Strength.

Many metal alloys are heat treatable and the hardness rather than the tensile strength are known. Another well known approximation, with just as much scatter as shown above, is that the tensile strength is approximately one half of the Brinell hardness, BHN. Combining these two approximation provides an estimate of the fatigue strength from the hardness.

$$
S_{F L}=0.25(B H N)
$$

It has been observed that the fatigue strength at 1000 cycles is approximately $0.9 S_{u}$. This gives two points on the S-N curve, both in terms of hardness that can be used to estimate the entire S-N curve.

$S_{a}=\frac{\Delta S}{2}=1.62 S_{u}\left(N_{f}\right)^{-0.085}$ 


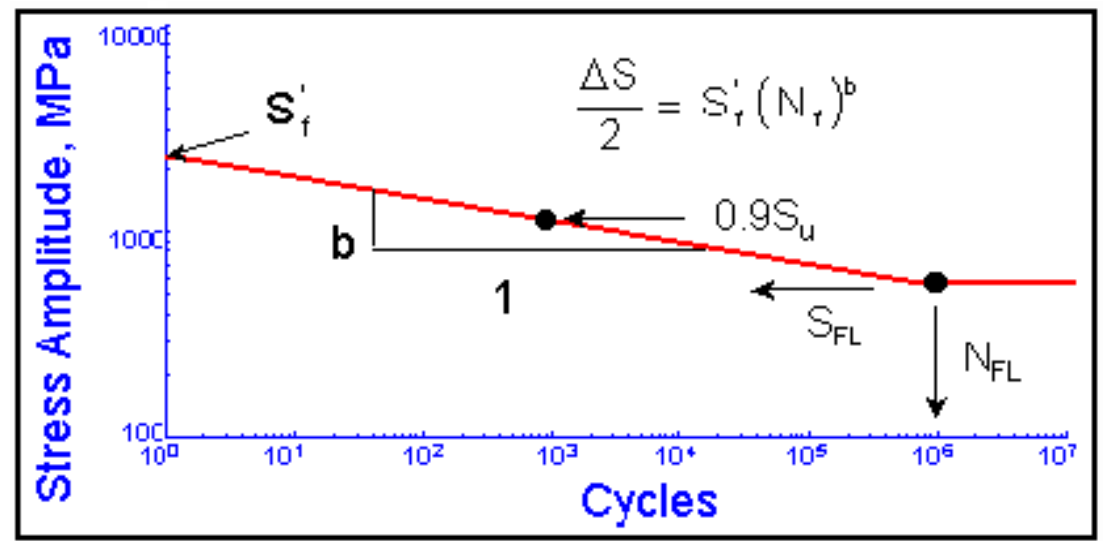

Figure II.16 Related Between Material Parameters.

Four material parameters are used to describe the materials stress life curve, $S_{f}{ }^{\prime}$, b, $S_{F L}$ and $N_{F L}$, only three of which are independent. Leaving any one of the parameters blank will result in the fourth one being directly computed. If all four are entered, $S_{F L}$ will be ignored. [7]

\section{II.4.3 Modifying Factors}

In general, if fatigue behaviour is dominated by the crack propagation mechanism (e.g., welded joints or sharp notched components, etc.), the S-N curve often has a steep slope ( $b \approx-0.3 ; k \approx 3$ ). If fatigue behavior is controlled by the crack initiation mode (e.g., smooth and blunt notched components), the S-N curve has a flatter slope $(b \approx-0.15 ; k \approx 7)$. Through many years of experience and testing, empirical relationships that relate fatigue strength data and the ultimate tensile strength, $S_{u}$, have been developed. These relationships are not scientifically based but are simple and useful engineering tools to estimate the fatigue lives of components in the highcycle fatigue region. Thus, the estimated fatigue strength corresponding to the two fatigue lifes (e.g., $10^{3}$ cycles and $10^{6}$ cycles) for the baseline test specimens are discussed. If a component or loading condition deviates from the standard test setup used to generate the aforementioned $\mathrm{S}-\mathrm{N}$ data, it is necessary to modify the baseline S-N curve to account for the differences. Such adjustments are accomplished through the use of modifying factors. Figure II.16 illustrates the effects of modifying factors on a baseline S-N curve. [2] 


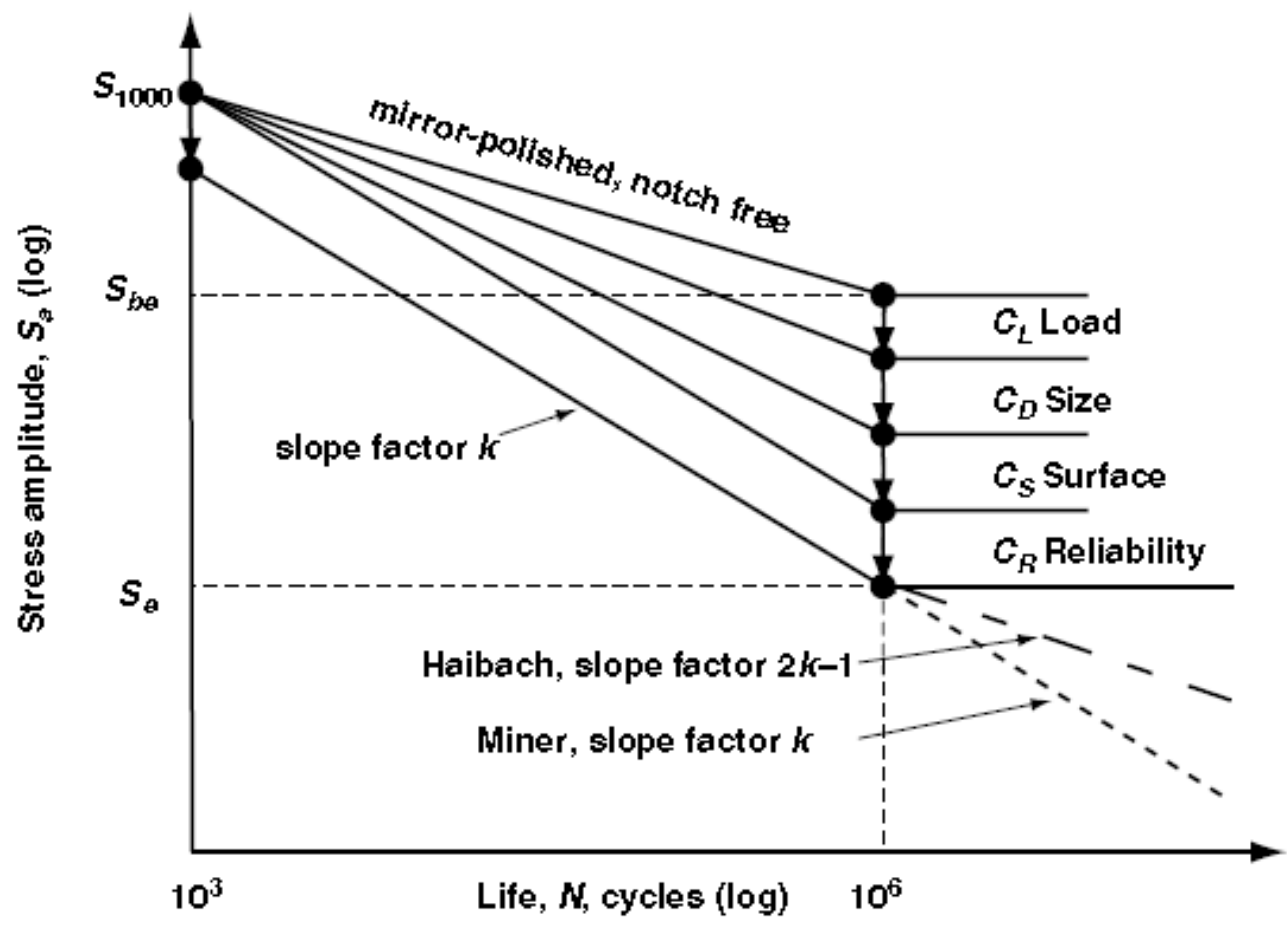

Figure II.17 Modified S-N Curves For Smooth Components Made Of Steels. [2]

Materials, as they are tested, are always in a different condition (surface finish, residual stress, etc.) from the materials as they are actually used. An important part of the analysis is to "correct" the basic materials data to obtain an estimate of the fatigue limit of the material in the component or structure of interest. Fatigue cracks usually nucleate on the surface so that the condition of the surface plays a major role in the fatigue resistance of a component. Test specimens are polished to eliminate the effects of surface finish. The degree of surface damage depends not only on the processing but also on the strength of the material. Higher strength materials are more susceptible to surface damage. To account for this in the analysis the material fatigue limit is reduced by a surface finish factor, $K_{S F}$. [7] 


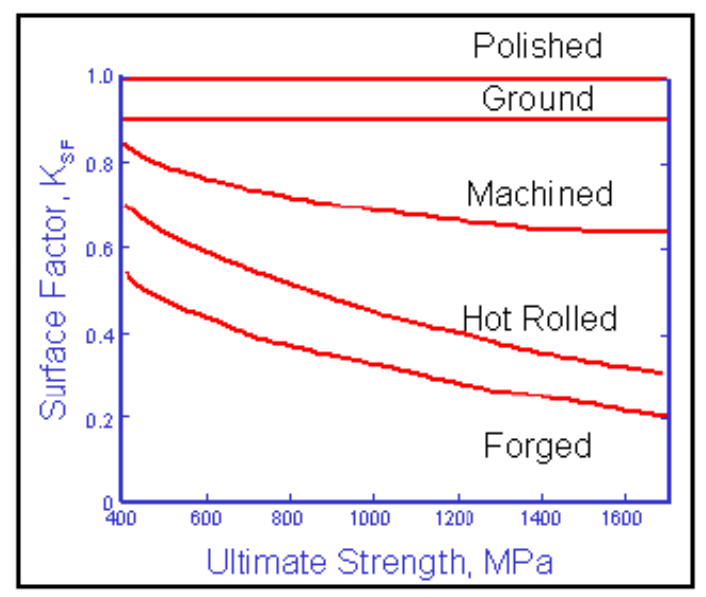

Figure II.18 Effect Of Surface Factor.

The original data for constructing this curve is shown below. The factors tend to provide conservative estimates for fatigue lifes. [7]

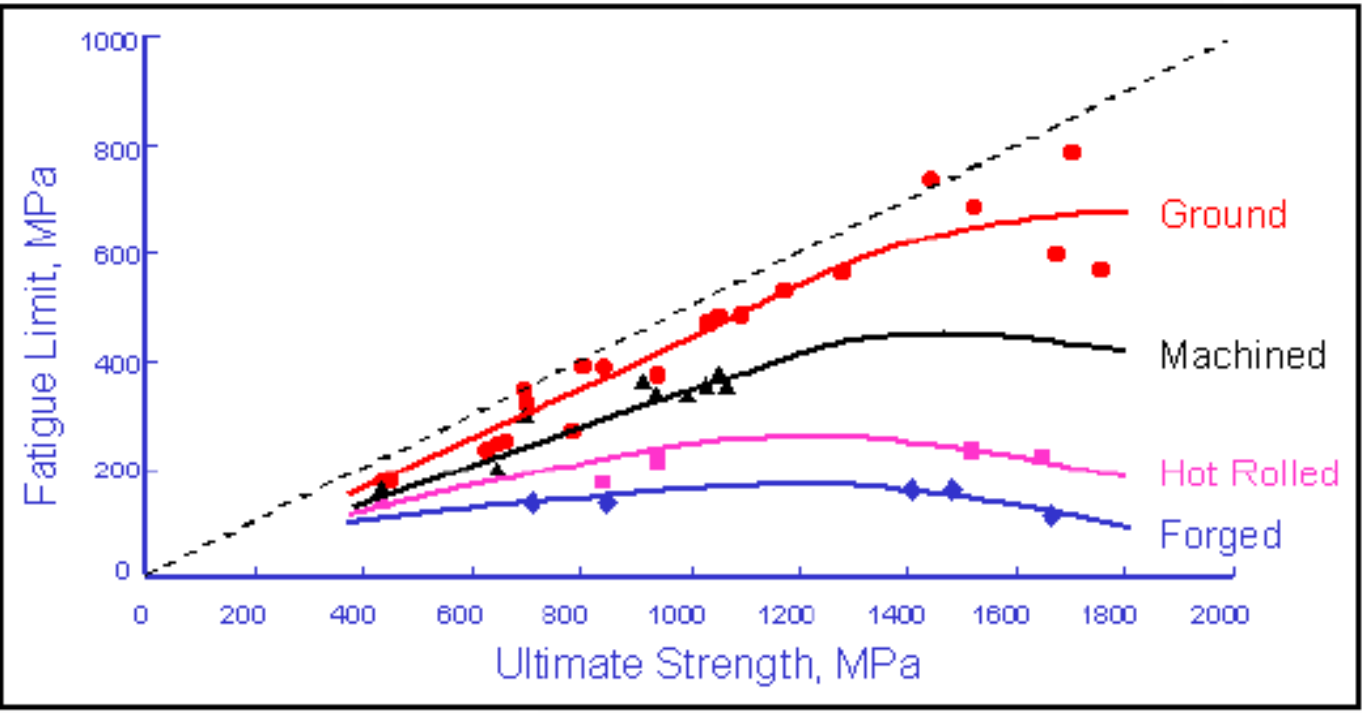

Figure II.19 Effect Of Surface Factor On Fatigue Limit.

These data are fit to a simple power function to obtain an estimate of the surface factor for any hardness steel.

$$
k_{S F}=\alpha \cdot S_{u}^{\beta}
$$

Table II. $1 \alpha$ and $\beta$ Coefficient

\begin{tabular}{|c|c|c|}
\hline & $\alpha$ & $\beta$ \\
\hline Ground & 1,58 & $-0,085$ \\
\hline Machined & 4,51 & $-0,265$ \\
\hline Hot Rolled & 57,7 & $-0,718$ \\
\hline Forged & 272,000 & $-0,995$ \\
\hline
\end{tabular}


Fatigue limits have historically been determined from small specimens, $6 \mathrm{~mm}$ in diameter, tested in rotating bending. High strength materials tested in tension tend to have lower fatigue limits. An empirical load factor $k_{L}$, is introduced for other types of loading.

Table II. $2 \mathrm{k}_{\mathrm{L}}$ coefficient

\begin{tabular}{|l|c|}
\hline & $\mathrm{k}_{\mathrm{L}}$ \\
\hline Tension, Su $<=1500 \mathrm{Mpa}$ & 0,92 \\
\hline Tension, Su $>1500 \mathrm{Mpa}$ & 1,0 \\
\hline Bending & 1,0 \\
\hline Torsion & 0,58 \\
\hline
\end{tabular}

Experiments show that smaller components tend to have higher fatigue limits than larger ones. This is accommodated in the analysis by introducing a size factor, $\mathrm{k}_{\text {size }}$. Some people call this a gradient factor. One of the most widely used corrections is based on the diameter of a bar.

$k_{\text {size }}=\left(\frac{d}{7.62}\right)^{-0.1133} 3 \leq d \leq 50$

One of the problems associated with this simple approximation is what to do when the section is not round. This problem is overcome by defining an effective diameter. The volume of material subjected to $95 \%$ of the maximum stress in any shaped cross section is equated to a round bar of the same highly stressed volume. When these volumes are equated, the length canceled and the ratio becomes one of the relative areas. If we define the cross sectional area of a non-circular section sujected to $95 \%$ of the maximum stress as $\mathrm{A}_{0.95}$, then the effective diameter is given by

$$
d=\sqrt{\left(\frac{A_{0.95}}{0.077}\right)}
$$

Once these correction factors are determined, the fatigue limit of the machine component in the condition that it is being used in can be evaluated from the standard test specimen. 
$S_{F L}($ component $)=S_{F L}($ material $) k_{S F} \cdot k_{L} \cdot k_{\text {size }}$

These generalized empirical factors have the greatest confidence when applied to steel because they were all derived from on extensive database on steel accumulated from over 100 years of testing. The figures above have shown considerable scatter in the test data so that the factors must be regarded as approximate and are no substitute for actual test data for a critical application. That said, they provide a good first approximation when no test data is available. [7]

\section{II.4.4 Notch Effect}

Fatigue failure of a component typically occurs at a notch on a surface where the stress level increases due to the stress concentration effect. The term notch is defined as a geometric discontinuity that may be introduced either by design, such as a hole, or by the manufacturing process in the form of material and fabrication defects such as inclusions, weld defects, casting defects, or machining marks. For a component with a surface notch, the maximum elastic notch stress $\left(\sigma^{e}\right)$ can be determined by the product of a nominal stress (S) and the elastic stress concentration factor $\left(K_{t}\right)$ :

$\sigma^{e}=S \times K_{t}$

The maximum elastic notch stress can be calculated from an elastic finite element analysis and is sometimes referred to as the pseudo-stress if the material at a notch is actually inelastic. Because notch stresses and strains are controlled by net section material behavior, the nominal stress for determination of $K_{t}$ is defined by an engineering stress formula based on basic elasticity theory and the net section properties that do not consider the presence of the notch. The elastic stress concentration factor is a function of the notch geometry and the type of loading. For the cases in which the component geometry and loading conditions are relatively simple and the nominal stress can be easily defined, elastic stress concentration factors are often available in the references (Peterson, 1974; Pilkey, 1997). However, because of complexities of the geometry and loads in most real components, the value of $\sigma^{e}$ can be directly obtained from the elastic finite element analysis. [2]

\section{II.4. 5 Stress Concentrations}

Stress concentrations are one of the most important factors affecting the fatigue life of any component or structure. These stress concentrations may be 
intentional in the design or unintentional such as deep machining marks or other processing related flaws. It seems reasonable to directly compare the maximum stress at a stress concentration to the estimated fatigue limit for that component.

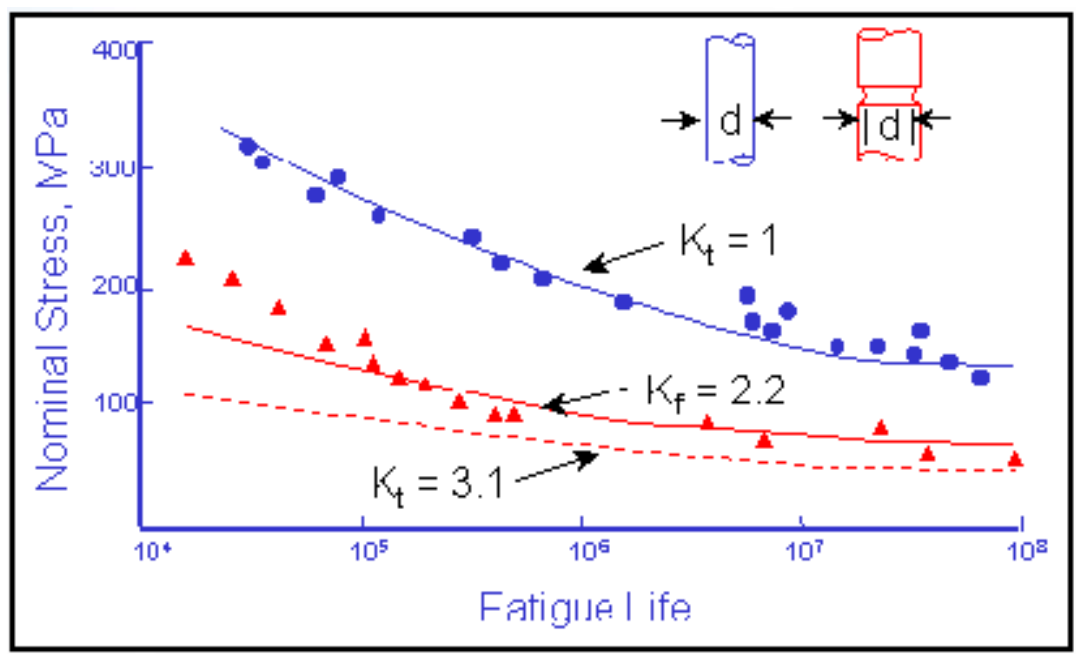

Figure II.20 Effect Of Stress Concentration Factor

Test data for an unnotched bar, such as the one above pictured are plotted as circles. This geometry has a stress concentration factor, $K_{t}$ equal to 1 . The dashed line represents estimated data for a geometry that has a stress concentration factor of 3.1. The presence of the notch reduces the allowable nominal stress amplitude at any fatigue life by a factor equal to $K_{t}$. Notice that all of the actual test data, triangles, lie above this estimate. This is because the effective stress concentration in fatigue is less than that predicted by the stress concentration factor, $K_{t}$. This effctive stress concentration factor is called the fatigue notch factor, $K_{f}$. The variation between $K_{f}$ and $K_{t}$ is dependant on the size of the notch and strength of the material. A material that is very sensitive to notches will have $K_{f}$ equal to $K_{t}$. If the material is very insensitive to notches, $K_{f}$ will be close to 1 . A notch sensitivity factor, q, is introduced to quantify this sensitivity. 


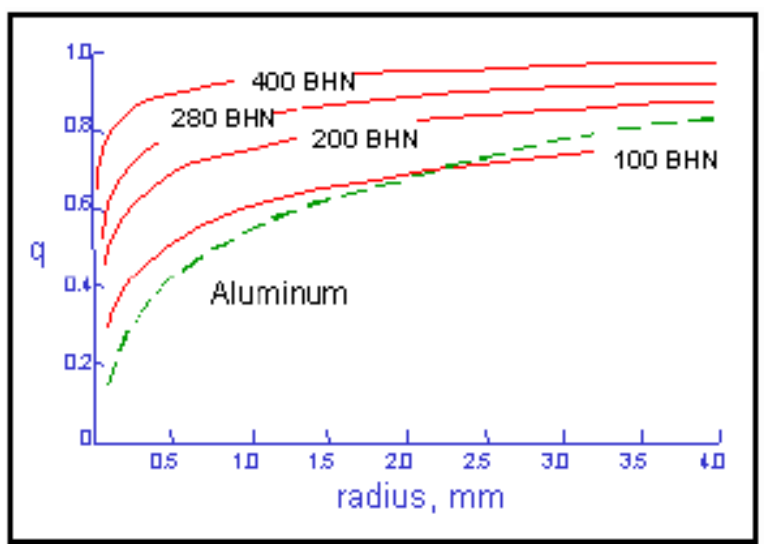

Figure II.21 Radius Versus Notch Sensitivity Factor.

Smaller radii are less effective in fatigue than larger ones. Fatigue notch factors can be computed from $K_{t}$ and q.

$K_{f}=1+\left(K_{t}-1\right) q$

Peterson fit the available test data for steel and aluminum to obtain an expression for $K_{f}$ in terms of ultimate strength, $S_{u}$, and notch radius,q in $\mathrm{mm}$.

$$
K_{f}=1+\frac{K_{t}-1}{1+\frac{\left(\frac{2070 M p a}{S_{u}}\right)^{1.8}}{q}} \text { for steel }
$$

$$
K_{f}=1+\frac{K_{t}-1}{1+\frac{0.5 m m}{q}} \text { for aluminum }
$$

Plastic deformation reduces the effect of a stress concentration at shorter lives. The fatigue notch factor becomes smaller as the lives become shorter. In ductile materials, stress concentrations play only a small role in determining the overall strength of the structure. One unfortunate consequence of this is that static strength testing often provides little information about the likely fatigue performance of a component. An estimate of the notched component S-N curve may be obtained dividing the materials fatigue strength, including any modify factors, at $10^{6}$ cycles by $K_{f}$ and drawing a line to the unnotched fatigue strength at 1 cycle. 


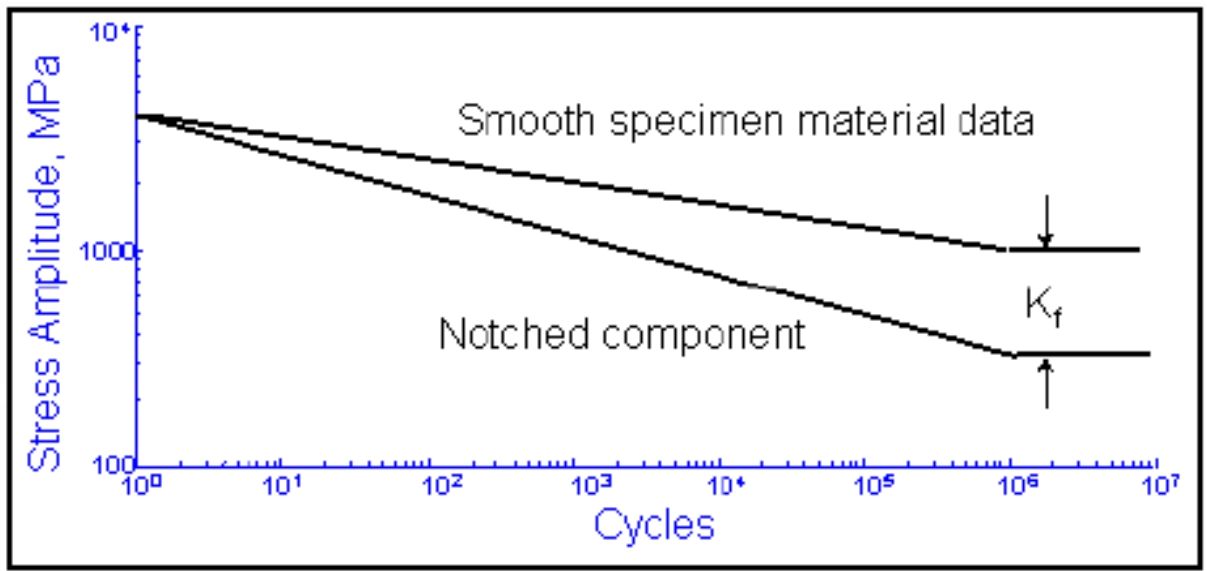

Figure II.22 Notching Effect In Fatigue Life.

This has the effect of changing the slope of the material's S-N curve and leaving the intercept unchanged. If we include the modifying factors this new slope, $b_{\text {notch }}$, can be computed as:

$b_{\text {notch }}=b-\frac{\log \left(\frac{K_{f}}{k_{S F} k_{L} k_{\text {size }}}\right)}{\log \left(N_{F L}\right)}$

and the new notched S-N curve will be given by: [7]

$S_{a}=\frac{\Delta S}{2}=S_{f}{ }^{\prime}\left(N_{f}\right)^{b_{\text {notch }}}$

\section{II.4.6 Mean Stresses}

From the perspective of applied cyclic stresses, fatigue damage of a component correlates strongly with the applied stress amplitude or applied stress range and is also influenced by the mean stress (a secondary factor). In the high-cycle fatigue region, normal mean stresses have a significant effect on fatigue behavior of components. Normal mean stresses are responsible for the opening and closing state of microcracks. Because the opening of microcracks accelerates the rate of crack propagation and the closing of microcracks retards the growth of cracks, tensile normal mean stresses are detrimental and compressive normal mean stresses are beneficial in terms of fatigue strength. The shear mean stress does not influence the opening and closing state of microcracks, and, not surprisingly, has little effect on 
crack propagation. There is very little or no effect of mean stress on fatigue strength in the low-cycle fatigue region in which the large amounts of plastic deformation erase any beneficial or detrimental effect of a mean stress. [2]

Tensile mean stresses are known to reduce the fatigue strength of a component. Compressive mean stresses increase the performance and are frequently used to increase the fatigue strength of a manufactured part. The most common method for accounting for mean stresses is the Goodman Diagram. It was first proposed in 1890. Goodman writes ".. whether the assumptions of the theory are justifiable or not .... We adopt it simply because it is the easiest to use, and for all practical purposes, represents Wöhlers data." The fatigue limit for zero mean stress is plotted on one axis and the ultimate strength on the other.

- Gerber's mean stress correction

$$
S_{e}=\frac{S_{a}}{1-\left(\frac{S_{m}}{S_{u}}\right)^{2}}
$$

- Goodman's mean stress correction

$$
S_{e}=\frac{S_{a}}{1-\left(\frac{S_{m}}{S_{u}}\right)}
$$

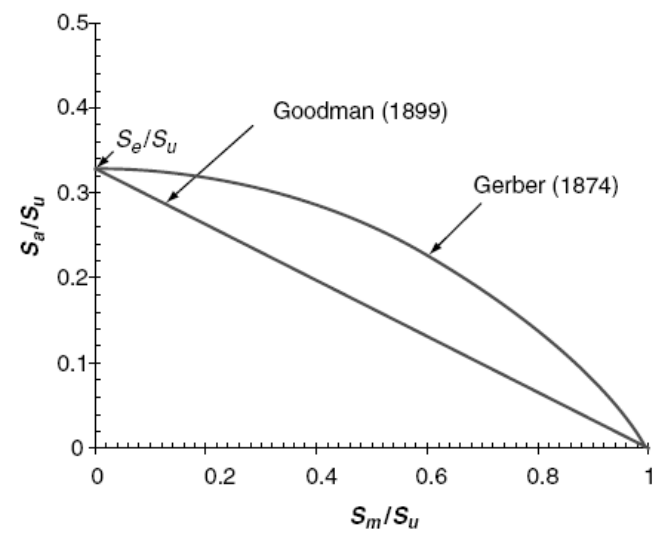

Figure II.23 Haigh's Plot For Gerber's and Goodman's Diagrams.

- Soderberg's mean stress correction

$$
S_{e}=\frac{S_{a}}{1-\left(\frac{S_{m}}{S y}\right)}
$$


Stress concentration effects can be directly included in the Goodman diagram.

$$
\frac{K_{f} S_{a}}{S_{F L}}+\frac{K_{f} S_{m}}{S_{u}}=\frac{1}{n}
$$

For finite lifes, an equivalent completely reversed stress, Seq, is computed and compared with the component S-N curve.

$$
\mathrm{S}_{\mathrm{eq}}=\frac{\mathrm{S}_{\mathrm{a}}}{1-\frac{\mathrm{K}_{\mathrm{f}} \cdot \mathrm{S}_{\mathrm{m}}}{\mathrm{S}_{\mathrm{u}}}}
$$

Here $K_{f}$ is used to modify the mean stress but not the stress amplitude because stress concentration effects are already included in the component SN curve.

Direct use of these equations poses problems for situations involving high mean stresses or in situations that result in short fatigue lives. This problem is caused by the calculated elastic stress being higher than the actual stress and in some cases even higher than the ultimate strength. A preloaded bolt is a good example. A common way to overcome this problem is to apply the stress concentration factor only to the alternating stress and not to the mean stress. This has the potential to lead to nonconservative estimates at long lives with moderate mean stresses. Plastic deformation limits the stress around a stress concentration to some value between the yield and ultimate strength of the material. A more reasonable method is to apply the stress concentration factor to both mean and alternating stresses and then made a correction to the maximum stress $K_{f}\left(S_{a}+S_{m}\right)$ when it exceeds the material's yield strength. The maximum stress should be limited to about $80 \%$ of the ultimate strength. [7]

\section{II.5 STRAIN BASED FATIGUE ANALYSIS AND DESIGN}

Most components may appear to have nominally cyclic elastic stresses, but notches, welds, or other stress concentrations present in the component may result in local cyclic plastic deformation. Under these conditions, another approach that uses the local strains as the governing fatigue parameter (the local strain-life method) was 
developed in the late 1950's and has been shown to be more effective in predicting the fatigue life of a component. The local strain-life method is based on the assumption that the life spent on crack nucleation and small crack growth of a notched component can be approximated by a smooth laboratory specimen under the same cyclic deformation at the crack initiation site. This is illustrated in Figure II.24. By using this concept it is possible to determine the fatigue life at a point in a cyclically loaded component if the relationship between the localized strain in the specimen and fatigue life is known. This strain-life relationship is typically represented as a curve of strain versus fatigue life and is generated by conducting strain controlled axial fatigue tests on smooth, polished specimens of the material. Strain-controlled axial fatigue testing is recommended because the material at stress concentrations and notches in a component may be under cyclic plastic deformation even when the bulk of the component behaves elastically during cyclic loading.

The local strain-life method can be used proactively for a component during early design stages. Fatigue life estimates may be made for various potential design geometries and manufacturing processes prior to the existence of any actual components provided the material properties are available. This will result in a reduction in the number of design iterations by identifying and rejecting unsatisfactory designs early in the design process. This reduces the design cycle and gets product to market quickly. The local strain-life approach is preferred if the load history is irregular or random and where the mean stress and the load sequence effects are thought to be of importance. This method also provides a rational approach to differentiate the high-cycle fatigue and the low-cycle fatigue regimes and to include the local notch plasticity and mean stress effect on fatigue life. Because the material data used are only related to the laboratory specimen, the fabrication effects in the actual component, such as surface roughness/finish, residual stress, and material properties alteration due to cold forming, and welding, may not appropriately be taken into account in the local strain-life approach. The effect of surface finish may be included by testing laboratory specimens with the same surface condition, but the extra cost and time involved may decrease the benefit of using the local strain-life approach. [2] 


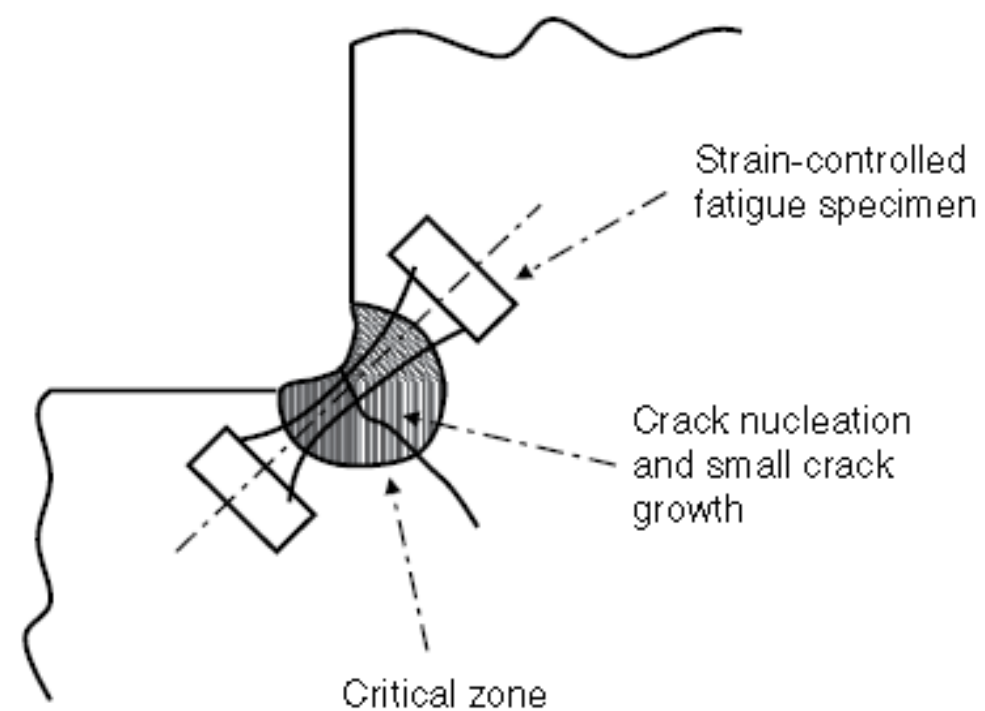

Figure II.24 Concept Of The Local Strain Life Approach. [2]

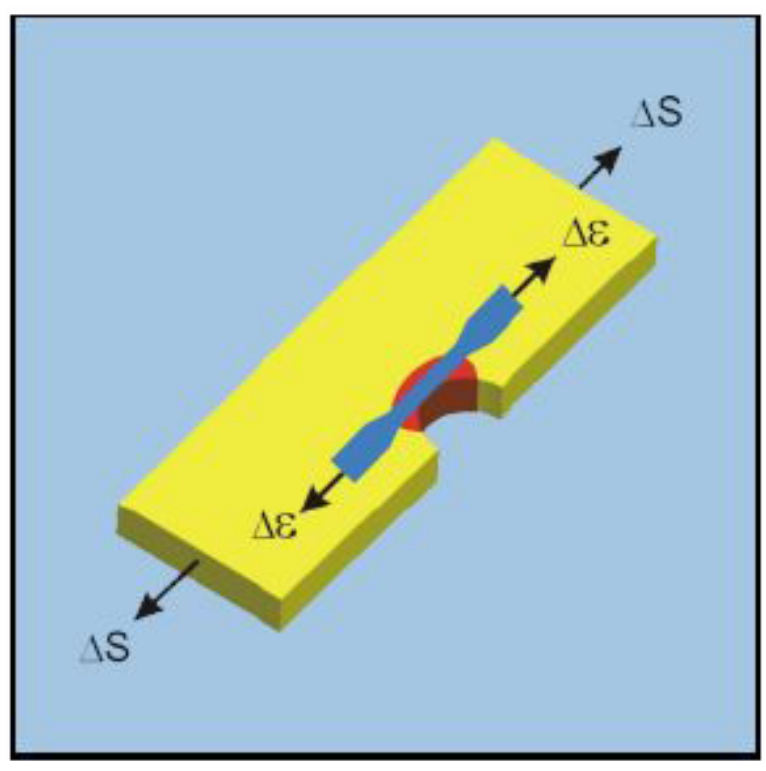

Figure II.25 Test Specimen.

The local plastic strains are controlled by the elastic deformation of the surrounding elastic material. Even though external loads are applied, the local region is strain or deformation controlled. The strain resistance of the material is a better measure of the fatigue performance than the stress resistance. [8] 


\section{II.5.1 Cyclic Material Properties}

Strain controlled tests are always conducted in axial loading. Deflections are controlled and converted into strain. The resulting forces are measured to compute the applied stress. Metals undergo transient behavior when they are first cycled. [8]

\section{II.5.1.1 Transient Cyclic Response}

The transient cyclic response of a material describes the process of change in the resistance of a material to deformation due to cyclic loading. If a material is repeatedly cycled under fully reversed strain-controlled loading, the material may respond in one of the following ways: cyclic hardening, cyclic softening, remaining stable, or some combination of these responses. Figures II.26 demonstrate transient cyclic hardening and transient cyclic softening, respectively, under strain-controlled loading. In transient cyclic hardening, the stress developed in each successive strain reversal increases as the number of cycles increases. In transient cyclic softening, the stress decreases as the number of cycles increases. In both cases, the rate of change of the applied stress will gradually reduce and the stress magnitude will reach a stable level (a steady-state condition) and remain stable for the rest of the fatigue life until the detection of the first fatigue crack. The transient cyclic behavior is handled by using the cyclically stable behavior in the local strain-life approach since the percentage of the number of cycles spent on this transient response is relatively small compared to the total fatigue life. [2]

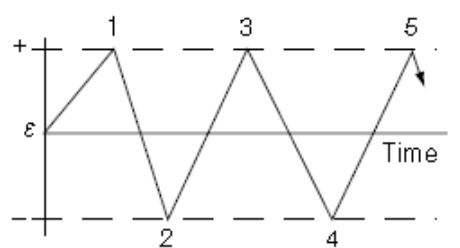

(a)

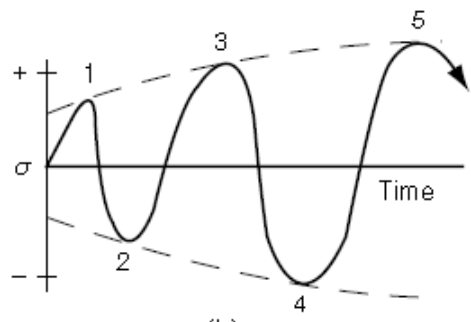

(b)

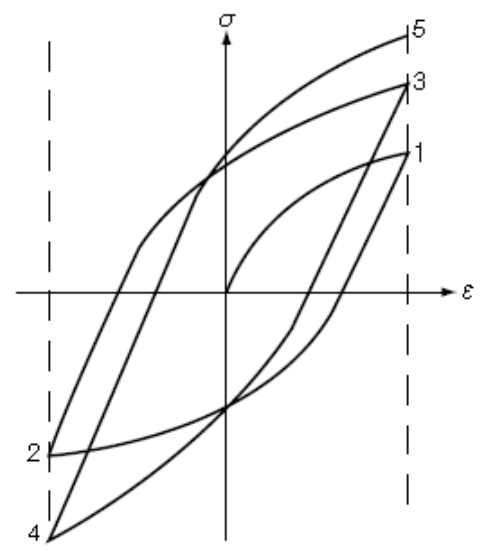

(c)

Figure II.26 Transient Behavior - Cyclic Hardening 


\section{II.5.1.2 Steady-State Cyclic Stress-Strain Behavior}

The properties determined from the steady-state cyclic stress-strain response are the following:

$\sigma_{y}^{l}=0.2 \%$ Offset cyclic yield strength

$K^{l}=$ Cyclic strength coefficient

$n^{l}=$ Cyclic strain hardening exponent

Fatigue life can be characterized by the steady-state behaviour because for constant strain-amplitude controlled testing, the stress-strain relationship becomes stable after rapid hardening or softening in the initial cycles corresponding to the first several percent of the total fatigue life. The cyclic stable stress-strain response is the hysteresis loop and is identified in Figure II.27. The hysteresis loop defined by the total strain range $(\Delta \varepsilon)$ and the total stress range $(\Delta \sigma)$ represents the elastic plus plastic work on a material undergoing loading and unloading. Usually, the stabilized hysteresis loop is taken at half of the fatigue life. [2]

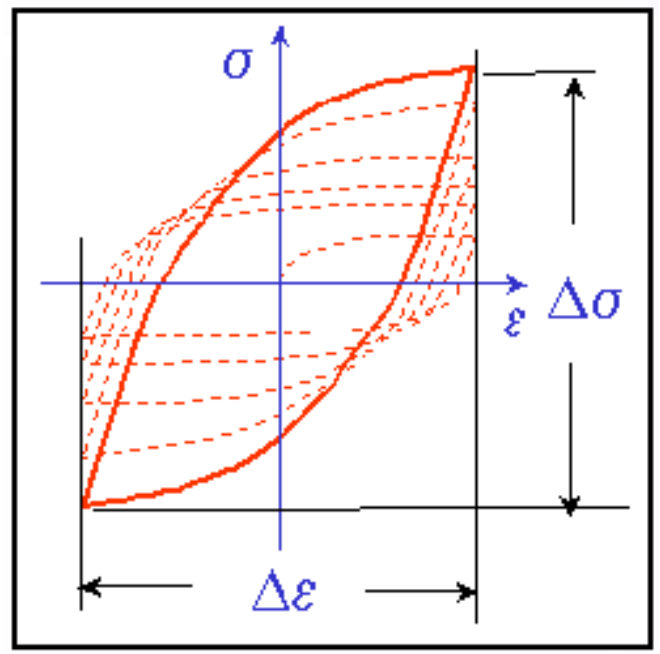

Figure II.27 Hysterisis Diagram.

In this example the material becomes stronger with each loading cycle into the plastic range. Other materials loose strength when they are repeatedly plastically deformed. After the initial transient behavior most materials have steady state behavior described by the hysteresis loop. During the fatigue test the strain range, $\Delta \varepsilon$, is controlled and the resulting stabilized stress range, $\Delta \sigma$, is recorder along with the cycles to failure. In strain life testing cycles to failure is converted to reversals to failure. One cycle has two reversals and a symbol $2 N_{f}$ is used. 
Before plotting the strain vs. fatigue life, the total strain that was controlled during the test is divided into the elastic and plastic part. The elastic strain is computed as the stress range divided by the elastic modulus. Plastic strain is obtained by subtracting the elastic strain from the total strain.

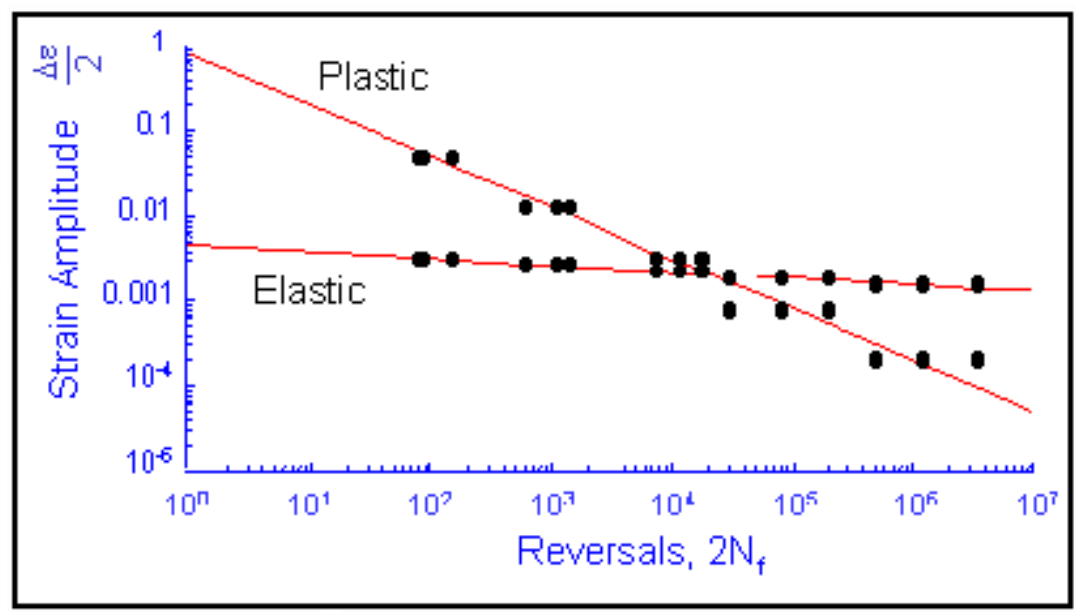

Figure II.28 Strain Versus Fatigue Life.

Test data is then fit to a simple power function to obtain the material constants; fatigue ductility coefficient, $\varepsilon_{f}^{\prime}$, fatigue ductility exponent, c , fatigue strength coefficient, $\sigma_{f}^{\prime}$, and fatigue strength exponent, $b$.

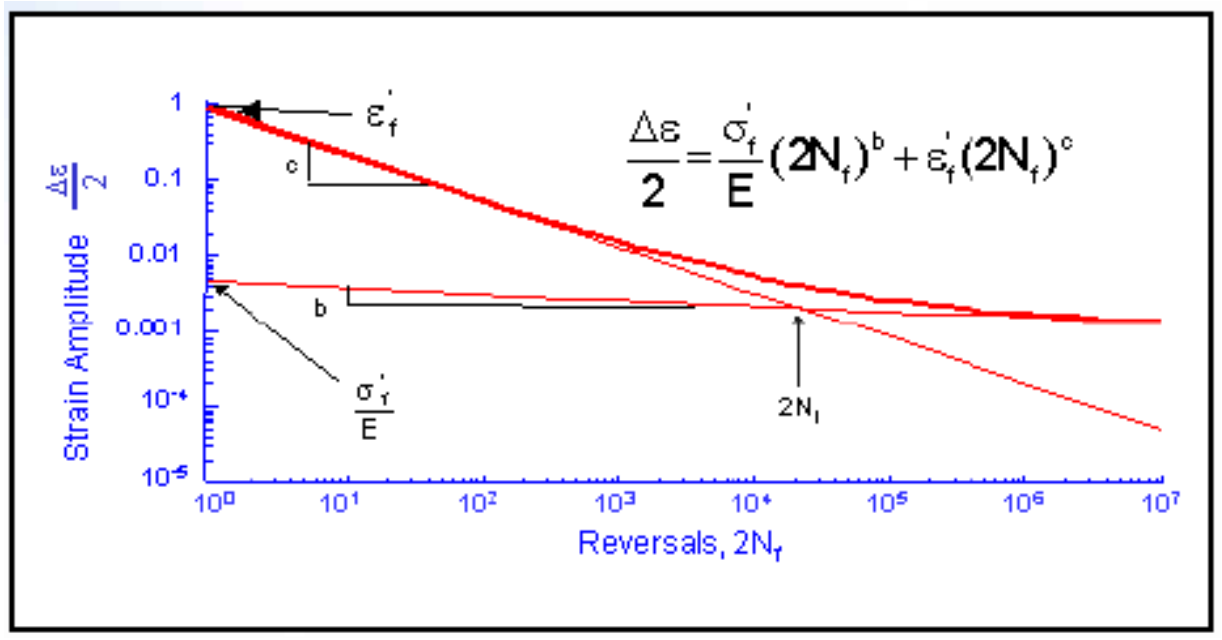

Figure II.29 Fatigue Ductility Coefficient, Fatigue Ductility Exponent, Fatigue Strength Coefficient And Fatigue Strength Exponent.

The total strain is then obtained by adding the elastic and plastic portions of the strain to obtain a relationship between the applied strain and the fatigue life. 


$$
\frac{\Delta \varepsilon}{2}=\frac{\sigma_{f}^{\prime}}{E}\left(2 N_{f}\right)^{b}+\varepsilon_{f}^{\prime}\left(2 N_{f}\right)^{c}
$$

The materials deformation during a fatigue test is measured in the form of a hysteresis loop. After the initial transient behavior the material stabilizes and the same hysteresis loop is obtained for every loading cycle. Each strain range tested will have a corresponding stress range that is measured. The cyclic stress strain curve is a plot of all of this data.

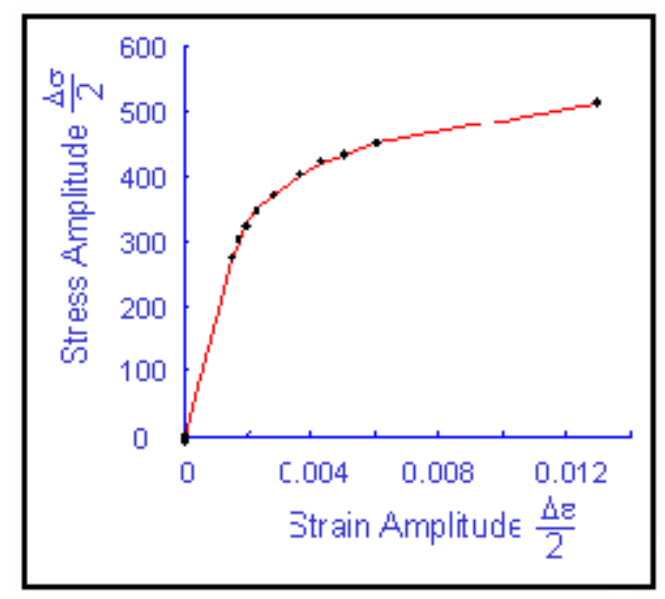

Figure II.30 Stress Amplitude Versus Strain Amplitude.

The cyclic stress strain curve describes the behavior of the material after it has been plastically deformed in service a few times. You can think of the traditional stress strain curve as describing the behavior of the material as it was manufactured. A simple power function is fit to this curve to obtain three material properties; cyclic strength coefficient, $K^{\prime}$, cyclic strain hardening exponent, $n^{\prime}$, and elastic modulus, $E$.

$$
\frac{\Delta \varepsilon}{2}=\frac{\Delta \sigma}{2 E}+\left(\frac{\Delta \sigma}{2 K^{\prime}}\right)^{1 / h^{\prime}}
$$

\section{II.5.2 Stress Concentrations}

Stress concentrations are one of the most important factors affecting the fatigue life of any component or structure. These stress concentrations may be intentional in the design or unintentional such as deep machining marks or other processing related flaws. It seems reasonable to directly compare the maximum stress at a stress concentration to the fatigue limit estimated for that component. 


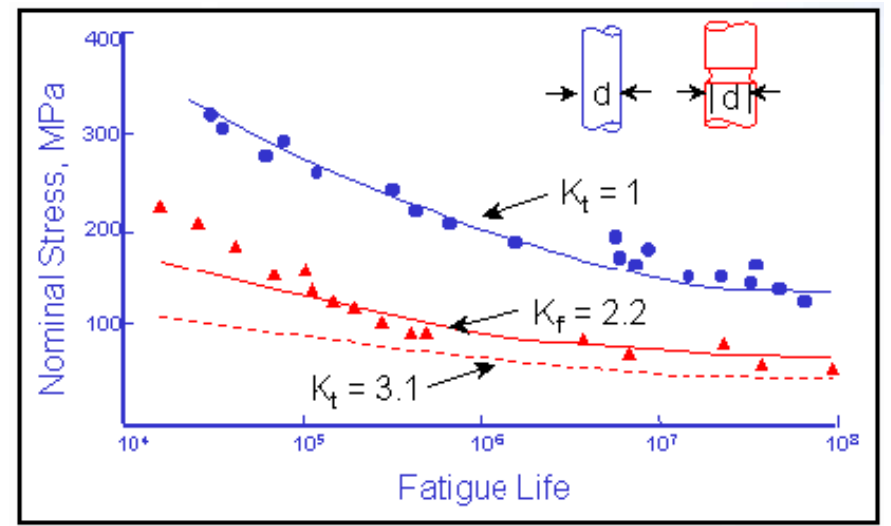

Figure II.31 Stress Concentration Factor In Fatigue Life.

The notched bar in this data has a stress concentration factor $K_{t}$ of 3.1 and the effect of this notch should reduce the allowable nominal stress amplitude at any fatigue life by an amount equal to $K_{t}$. All of the test data lie above this estimate. The effective stress concentration in fatigue is less than the stress concentration factor, $K_{t}$. This reduction factor is called the fatigue notch factor, $K_{f}$, but it is the best thought of as the effective stress concentration in fatigue. The variation between $K_{f}$ and $K_{t}$ is dependant on the size of the notch and strength of the material. A material that is very sensitive to notches will have $K_{f}=K_{t}$. A notch sensitivity factor, q, is introduced to quantify this effect.

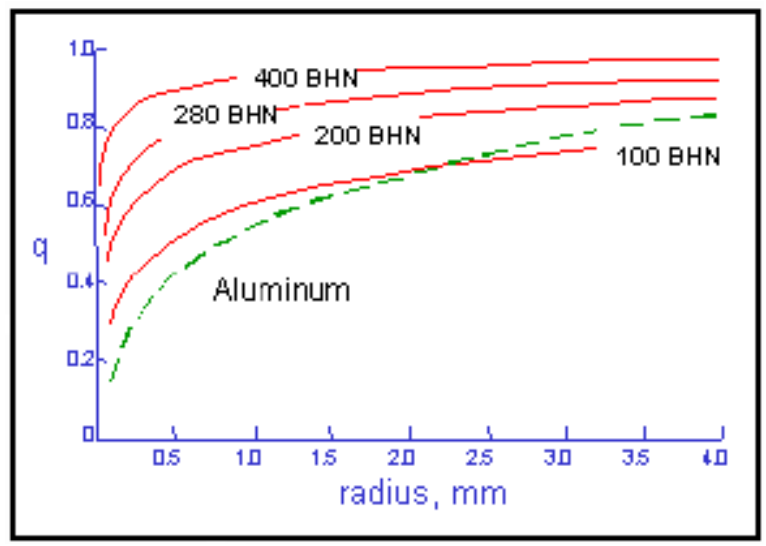

Figure II.32 Radius Versus Notch Sensitivity Factor.

Smaller radii are less effective in fatigue than larger ones. Fatigue notch factors can be computed from $K_{t}$ and $q$.

$K_{f}=1+\left(K_{t}-1\right) q$ 
Peterson fit the available test data for steel and aluminum to obtain an expression for $K_{f}$ in terms of ultimate strength, $S_{u}$, and notch radius, $\mathrm{r}$ in $\mathrm{mm}$.

$$
\begin{gathered}
K_{f}=1+\frac{\left(K_{t}-1\right)}{1+\frac{\left(\frac{2070}{S_{u}}\right)^{1.8}}{\rho}} \quad \text { for steel } \\
K_{f}=1+\frac{\left(K_{t}-1\right)}{1+\frac{0.5 m m}{\rho}} \quad \text { for aluminum }
\end{gathered}
$$

The stress concentration, $K_{t}$ or $K_{f}$, describes the elastic deformation around a notch. But in the strain approach, the plastic strains must be determined. Neuber's rule is used to convert an elastically computed stress or stain into the real stress or strain when plastic deformation occurs. For example, we may compute a stress with elastic assumptions at a notch to be $K_{t} S$ and this stress exceeds the strength of the material. The real stress will be somewhere on the materials stress-strain curve at some point $\sigma$.

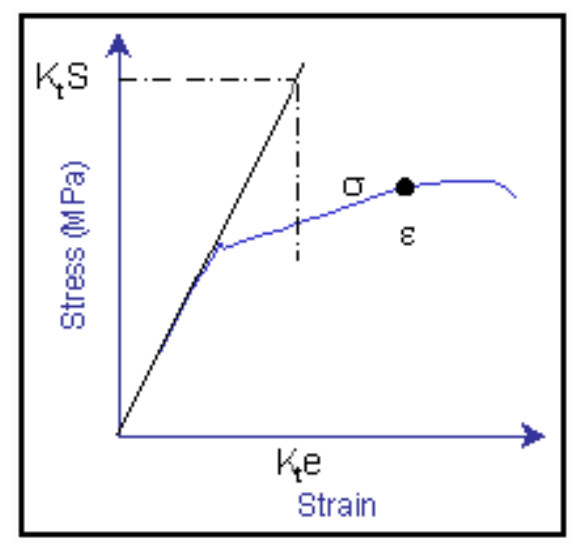

Figure II.33 Real Stress Positions According To Neuber's Rule.

Neuber's rule states, with some mathematical proof, that the product of the elastic solution is equal to the product of the real elastic plastic solution. Mathematically this is expressed as:

$K_{t} S . K_{t} e=\sigma . \varepsilon$ 
Nominal stresses are usually assumed to be elastic so that Neuber's rule can be written in terms of only the applied nominal stres;

$$
\left(K_{t} S\right)^{2}=E . \sigma \cdot \varepsilon
$$

In cyclic loading the stress is replaced by the stress amplitude resulting in the more commonly used form of Neuber's rule.

$$
K_{t} \frac{\Delta S}{2}=\sqrt{\left(\frac{\Delta \sigma}{2}\right)^{2}+E \frac{\Delta \sigma}{2}\left(\frac{\Delta \sigma}{2}\right)^{\frac{1}{n^{l}}}}
$$

This expression is then combined with the materials cyclic stress strain curve to compute the stress at the notch root $\Delta \sigma$. Once $\Delta \sigma$ is known, $\Delta \varepsilon$ can be directly computed from the cyclic stress strain curve. [8]

$K_{t} \frac{\Delta S}{2}=\sqrt{E \frac{\Delta \sigma}{2} \frac{\Delta \varepsilon}{2}}$

\section{II.5.3 Mean Stresses}

Tensile mean stresses are known to reduce the fatigue strength of a component. Compressive mean stresses increase the performance and are frequently used to increase the fatigue strength of a manufactured part.

\section{II.5.3.1 Morrow’s Mean Stress Correction Method}

Morrow has proposed the following relationship when a mean stress present:

$$
\varepsilon_{a}=\frac{\sigma_{f}^{\prime}-\sigma_{m}}{E}\left(2 N_{f}\right)^{b}+\varepsilon_{f}^{\prime}\left(2 N_{f}\right)^{c}
$$

This equation implies that mean normal stress can be taken into account by modifying the elastic part of the strain-life curve by the mean stress $\left(\sigma_{m}\right)$. As illustrated in Figure II.34, the model indicates that a tensile mean stress would reduce the fatigue strength coefficient $\sigma_{f}^{\prime}$ whereas a compressive mean stress would increase the fatigue strength coefficient. This equation has been extensively cited for steels and used with considerable success in the long-life regime when plastic strain amplitude is of little significance. [2] 


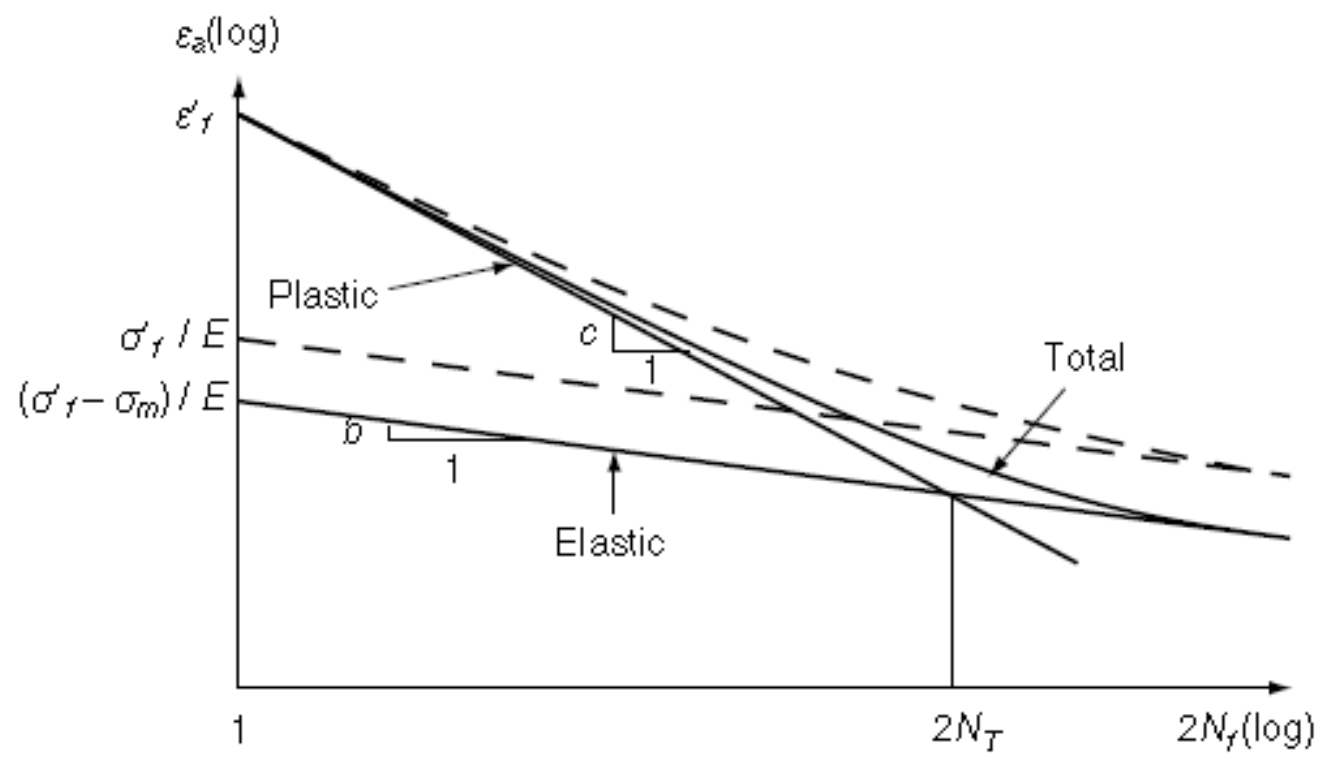

Figure II.34 Morrow’s Mean Stress Correction Model. [2]

\section{II.5.3.2 Smith-Watson-Topper (SWT) Model}

The Smith-Watson-Topper (SWT) parameter is used to account for the effect of mean stresses in the strain approach. The major variables are the maximum stress, $\sigma_{\max }$, and strain range, $\Delta \varepsilon$, of the stable hysteresis loop.

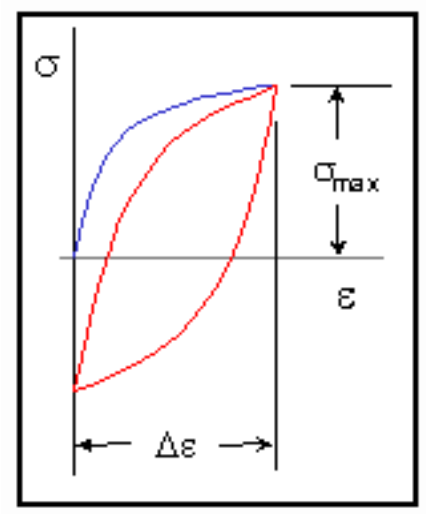

Figure II.35 Smith-Watson-Topper Model.

The strain range provides the driving force for growing small micro cracks and the higher the maximum stress the easier it is for these micro cracks to grow. They proposed a simple damage parameter, $P_{S W T}$, of

$P_{S W T}=\sigma_{\max } \frac{\Delta \varepsilon}{2}$ 
Any combination maximum stress and strain range of that has the same $P_{S W T}$ will have the same fatigue damage. A loading cycle with high maximum stress and small cycles strain ranges can do as much damage as a cycle with low maximum stresses and high cyclic strains. The SWT damage parameter can be related to the constant amplitude material properties generated without a mean stress. In a materials test the maximum stress is equal to the stress amplitude for the zero mean stress strain range.

$$
P_{S W T}=\sigma_{\max } \frac{\Delta \varepsilon}{2}=\left(\frac{\Delta \sigma}{2}\right)_{R=-1}\left(\frac{\sigma_{f}^{\prime}}{E}\left(2 N_{f}\right)^{b}+\varepsilon_{f}^{\prime}\left(2 N_{f}\right)^{c}\right)
$$

This expression requires an iterative solution because the stress range, $\Delta \sigma$, is a complex function of $2 N_{f}$.

Fatigue damage is dependant on the local stresses and plastic strains around stress concentrators. Local mean stresses can be larger or smaller than the nominal mean stress depending on how much plastic deformation occurs around the stress concentration. Local stress strain response for nominal zero to tension loading is shown below. The maximum stress in the hysteresis loop will always be on the materials cyclic stress strain curve shown by the blue line in the figure.

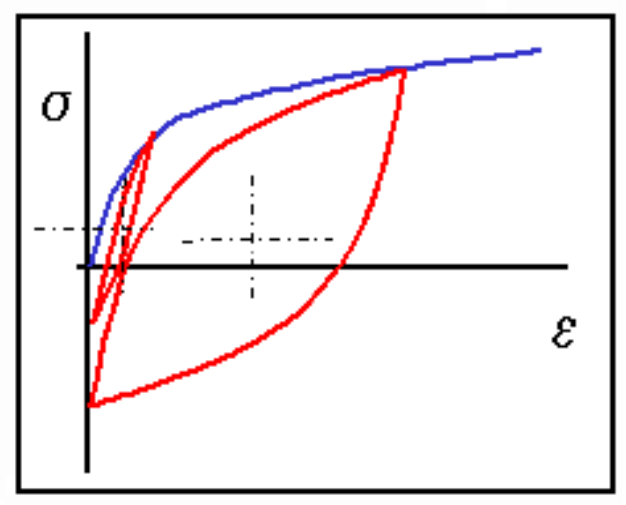

Figure II.36 The Maximum Stress In The Hysteresis Loop.

The local strain range increases with an increase in the nominal stress range as shown by the two hysteresis loops in the drawing. Compressive stresses are formed around the stress concentration upon unloading even though the external nominal stresses were all in tension. Local mean stresses do not increase because the maximum stress is on the flat portion of the cyclic stress strain curve. [8] 


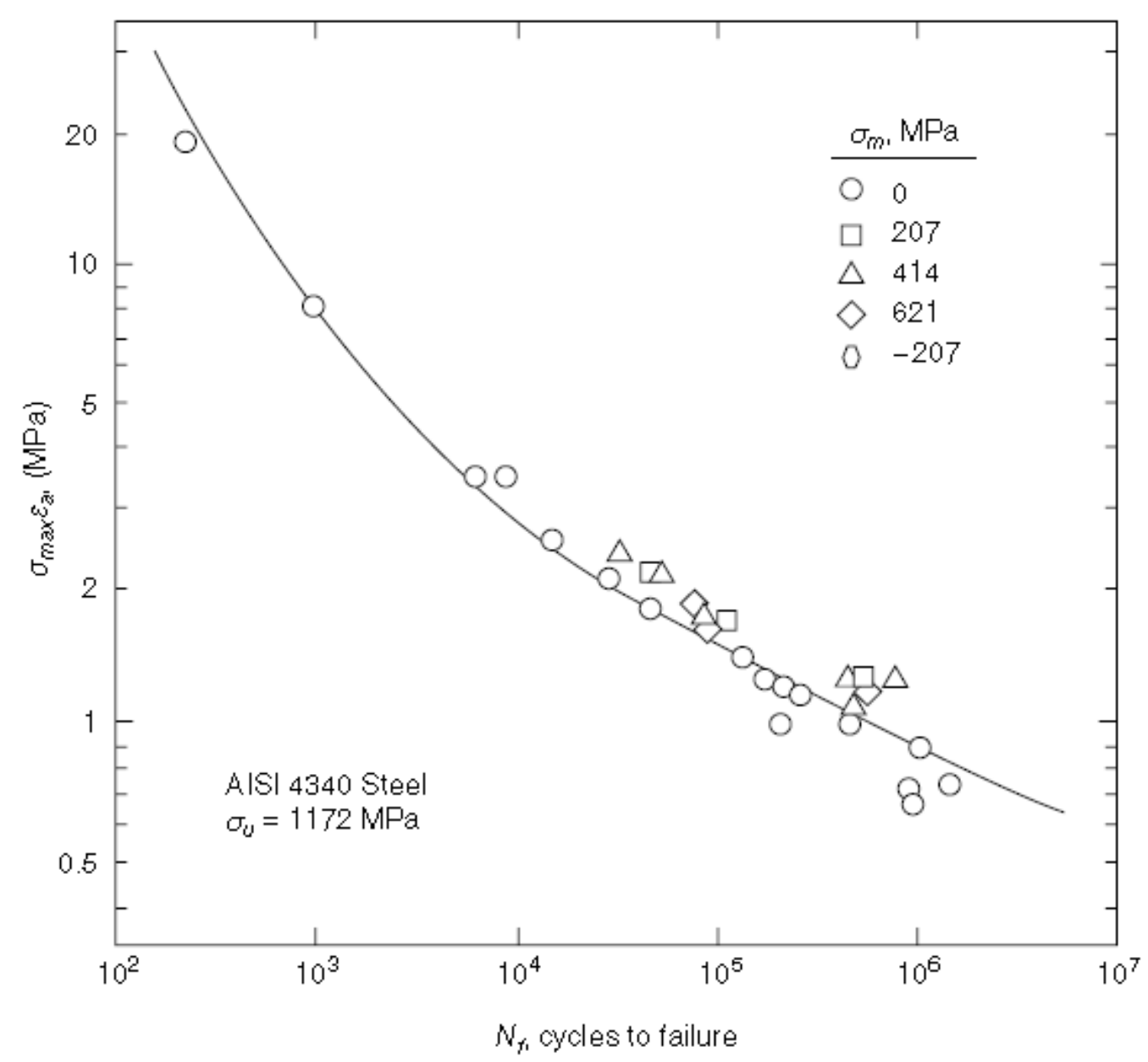

Figure II.37 The SWT Mean Stress Correction Model. Reprinted By Permission Of Pearson Education, Inc.,Upper Saddle River, NJ, From "Mechanical Behavior Of Materials,'” 2nd Edition By Dowling (1998). [2]

\section{II.5.4 Notch Analysis}

Notch analysis is used to relate the nominal stress or strain changes in a component to the local stress and strain response at a notch. This can be used to predict the crack initiation life of notched components by using fatigue life data from smooth laboratory specimens.

Neuber (1961) first analyzed a grooved shaft subjected to monotonic torsional loading and derived a rule for nonlinear material behavior at the notch root. Neuber observed, as illustrated in Figure II.38, that after local yielding occurs, the local true notch stress $(\sigma)$ is less than the stress predicted by the theory of elasticity $\left(\sigma^{e}\right)$ whereas the local true notch strain $(\varepsilon)$ is greater than that estimated by the theory of elasticity. Normalizing the local true notch stress with respect to the nominal stress (S) and the true notch strain to the nominal strain (e) leads to the true stress 
concentration $\left(K_{\sigma}\right)$ and the true strain concentration $\left(K_{\varepsilon}\right)$ factors, respectively. Figure II.39 schematically illustrates the relation of three concentration factors ( $\left.K_{t}, K_{\sigma}, K_{\varepsilon}\right)$ versus the true stress with regard to the yield stres. [2]
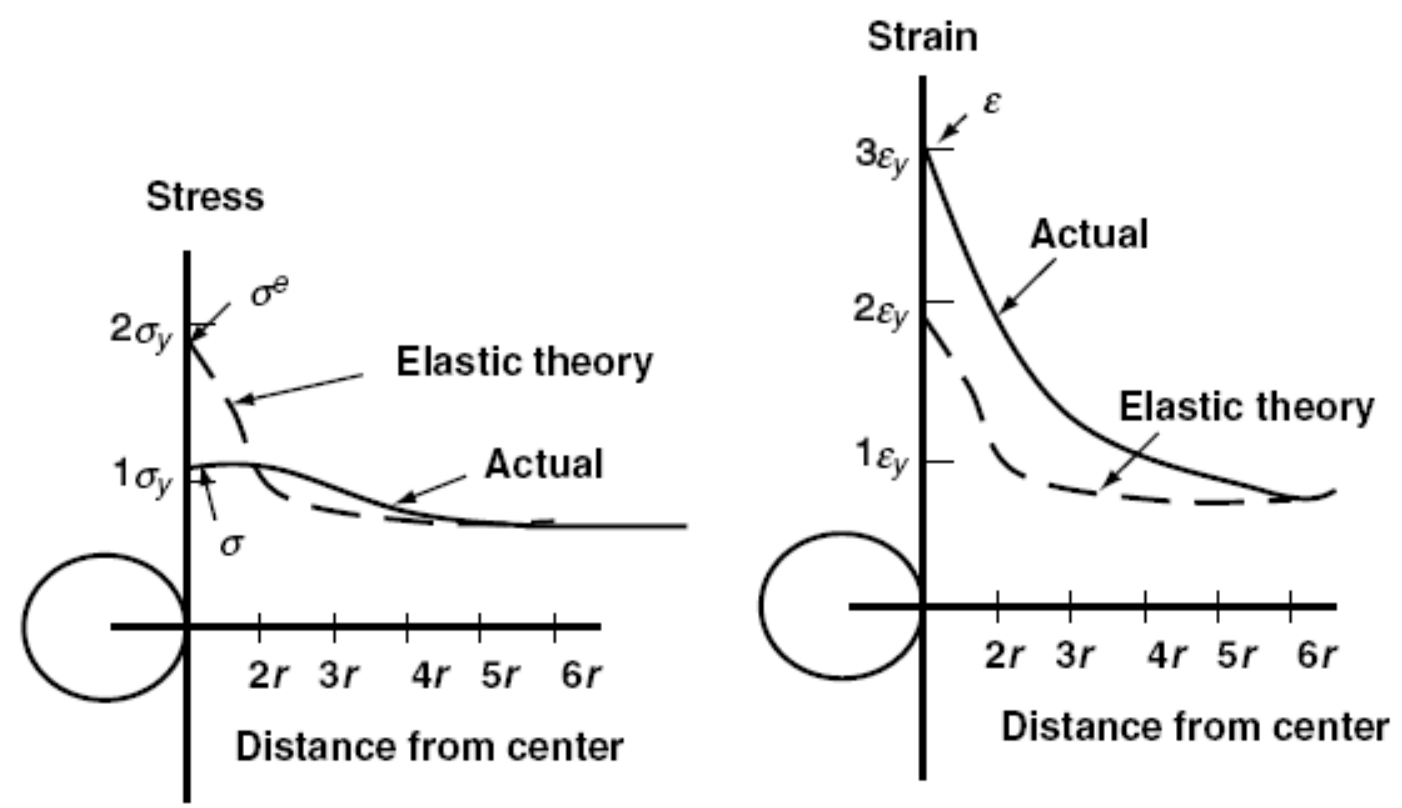

Figure II.38 Stresses And Strains At A Notch.

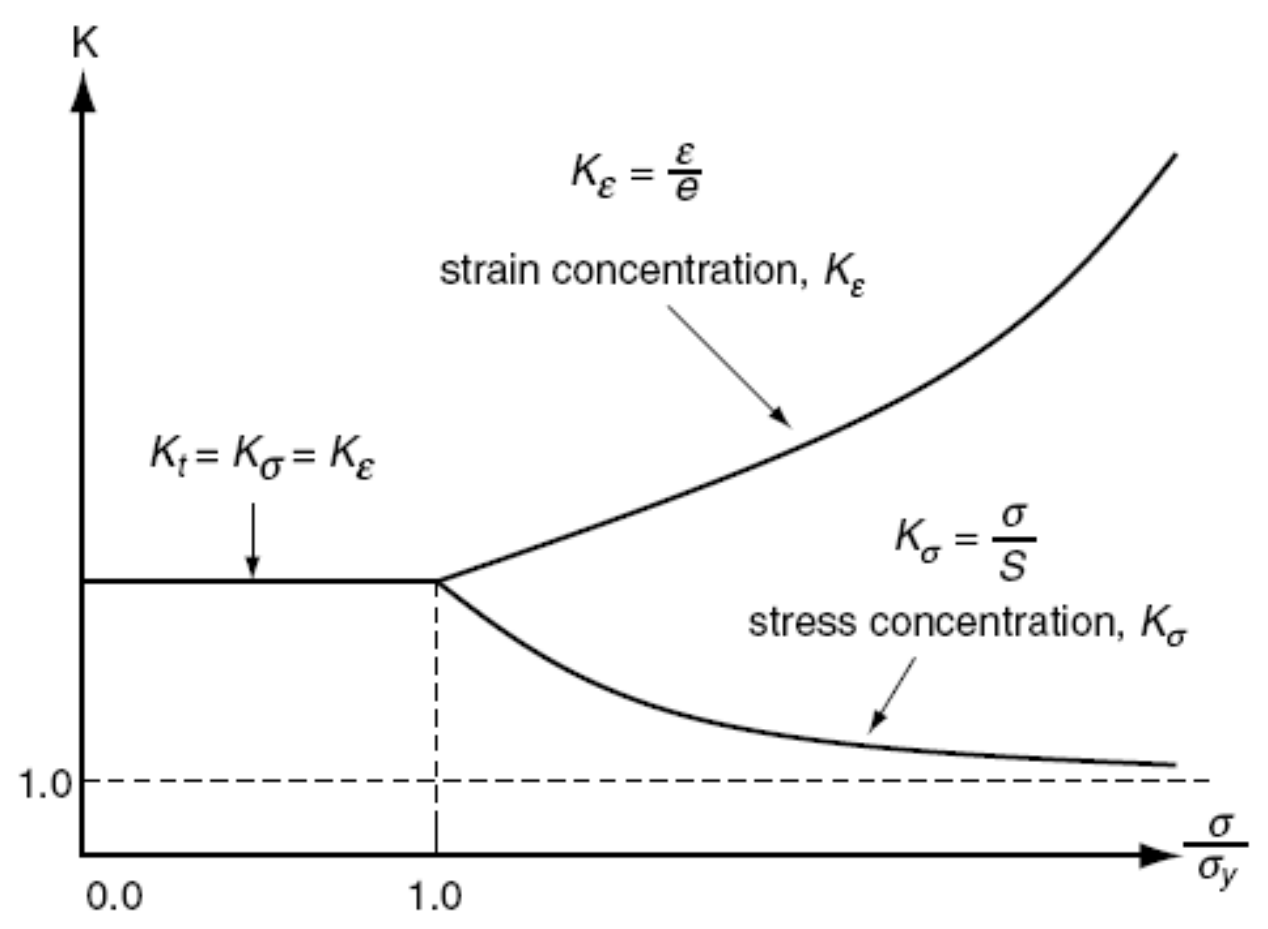

Figure II.39 Schematic Of Concentration Factors. 


\section{II.6 FATIGUE ANALYSIS IN THE FREQUENCY DOMAIN}

Fatigue analysis is often performed in the time domain, in which all input loading and output stress or strain response are time-based signals. In this case, the response time history can be calculated either by the static stress analysis (or inertia relief method) (Lee et al., 1995) or by the modal transient analysis (Crescimanno and Cavallo, 1999; Vellaichamy, 2002). In the static stress analysis, stress can be obtained by superimposing all stress influences from the applied loads at every time step. In the modal transient analysis, stress can be calculated by using the modal stress and the modal coordinates. The modal transient analysis is recommended if resonant fatigue is of primary concern; that is, the loading frequencies appear closer to the system natural frequencies. In some situations, however, response stress and input loading are preferably expressed as frequency-based signals, usually in the form of a power spectral density (PSD) plot. In this case, a system function (a characteristic of the structural system) is required to relate an input PSD of loading to the output PSD of response. The PSD techniques for dynamic analysis have been widely used in the offshore engineering field. PSD represents the energy of the time signal at different frequencies and is another way of denoting the loading signal in time domain. The Fast Fourier Transform (FFT) of a time signal can be used to obtain the PSD of the loading, whereas the Inverse Fourier Transform (IFT) can be used to transform the frequency-based signal to the time-based loading. The transform of loading history between the time domain and frequency domain is subject to certain requirements, as per which the signal must be stationary, random, and Gaussian (normal).

\section{II.6.1 A Random Sample Time History}

A system produces a certain response under excitation. If the excitation or the response motion, $X(t)$, is unpredictable, the system is in random vibration because the exact value of $X(t)$ cannot be precisely predicted in advance. It can only be described probabilistically.

The probability density function (PDF) of a time history $X(t)$ can be obtained by calculating its statistical properties. Figure II.40 shows a sample time history for a random process, $x(t)$, during the time interval $T$, where $X(t)$ exits between the values 
of $x$ and $x+d x$ for a total time of $\left(d t_{1}+d t_{2}+d t_{3}+d t_{4}\right)$. The probability that $x \leq X(t) \leq x+d x$ is therefore given by

$P[x \leq X(t) \leq x+d x]=\frac{d t_{1}+d t_{2}+d t_{3}+d t_{4}}{T}$

If the duration $T$ is long enough, the PDF $f_{x}(x)$ is given by

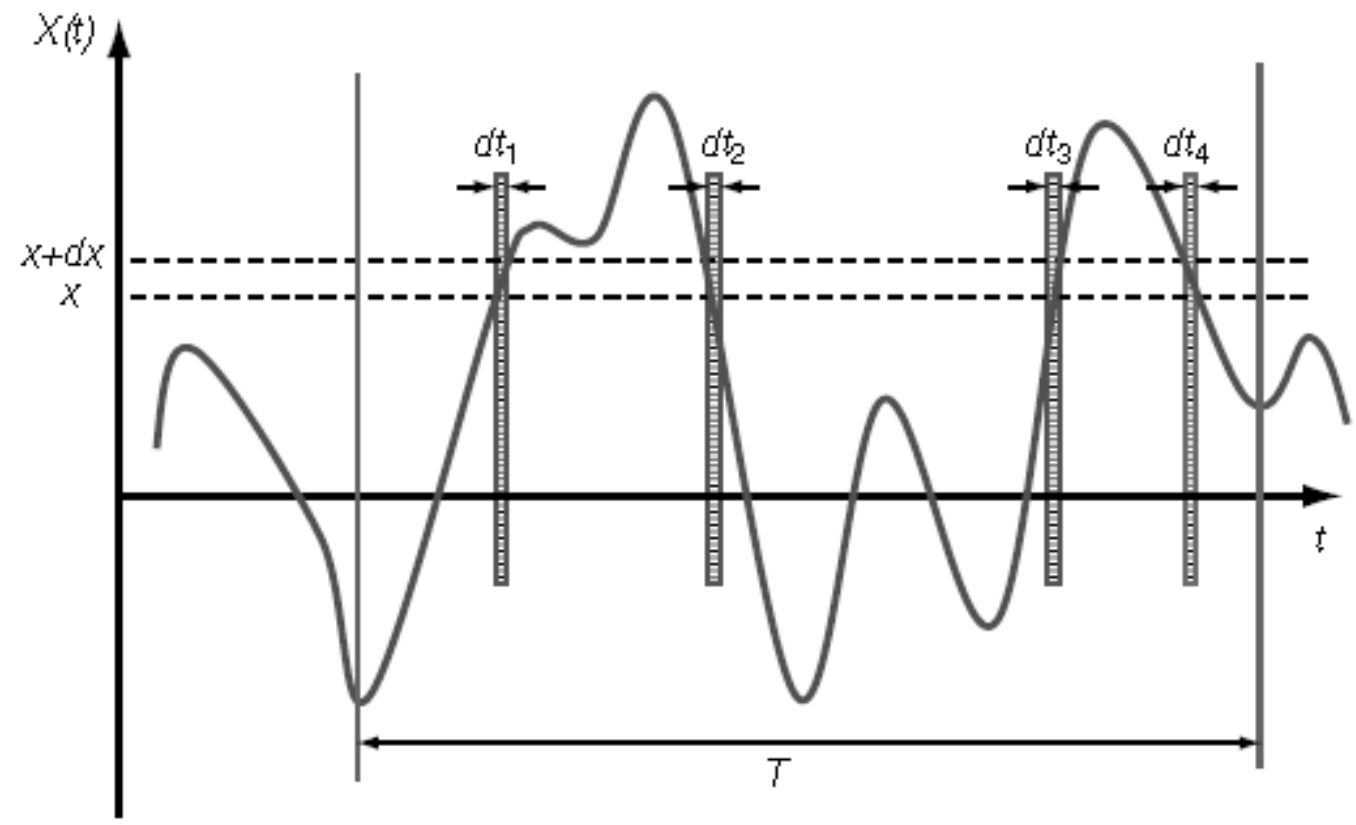

Figure II.40 Probability Density Function (PDF) For A Random Process X(T).

$f_{X}(x)=P[x \leq X(t) \leq x+d x]=\frac{\sum_{i-1}^{k} d t_{i}}{T}$

Equation II.54 is correct if the time duration $T$ goes to infinity, and implies that the sample time history continues forever. Measurement of the time segments, $\sum d t_{i}$, for the PDF $f_{X}(x)$ in Equation II.54 is very cumbersome. Alternatively, the PDF can be determined by the fraction of the total number of samples in the band between $\mathrm{x}$ and $x+d x$. This can be done by digitizing the time history at a certain sampling rate in the time interval T. As shown in Figure II.41, $f_{X}(x)$ is then given by 


$$
f_{X}(x)=P[x \leq X(t) \leq x+d x]=\frac{\text { sample }_{\text {band }}}{\text { sample }_{T}}=\frac{6}{69}
$$

With a given PDF $f_{X}(x)$, some statistical properties of the random process $X(t)$ can be obtained. The mean, $\mu_{x}$, and the variance, $\sigma_{x}^{2}$, of the process can be calculated as

$$
\begin{aligned}
& \mu_{X}=\int_{\infty}^{+\infty} x f_{X}(x) d x \cong \frac{1}{T} \int_{0}^{T} X(t) d t \\
& \sigma_{X}^{2}=\int_{\infty}^{+\infty}[x-\mu x] f_{X}(x) d x \cong \frac{1}{T} \int_{0}^{T}\left[X(t)-\mu_{X}\right] d t
\end{aligned}
$$

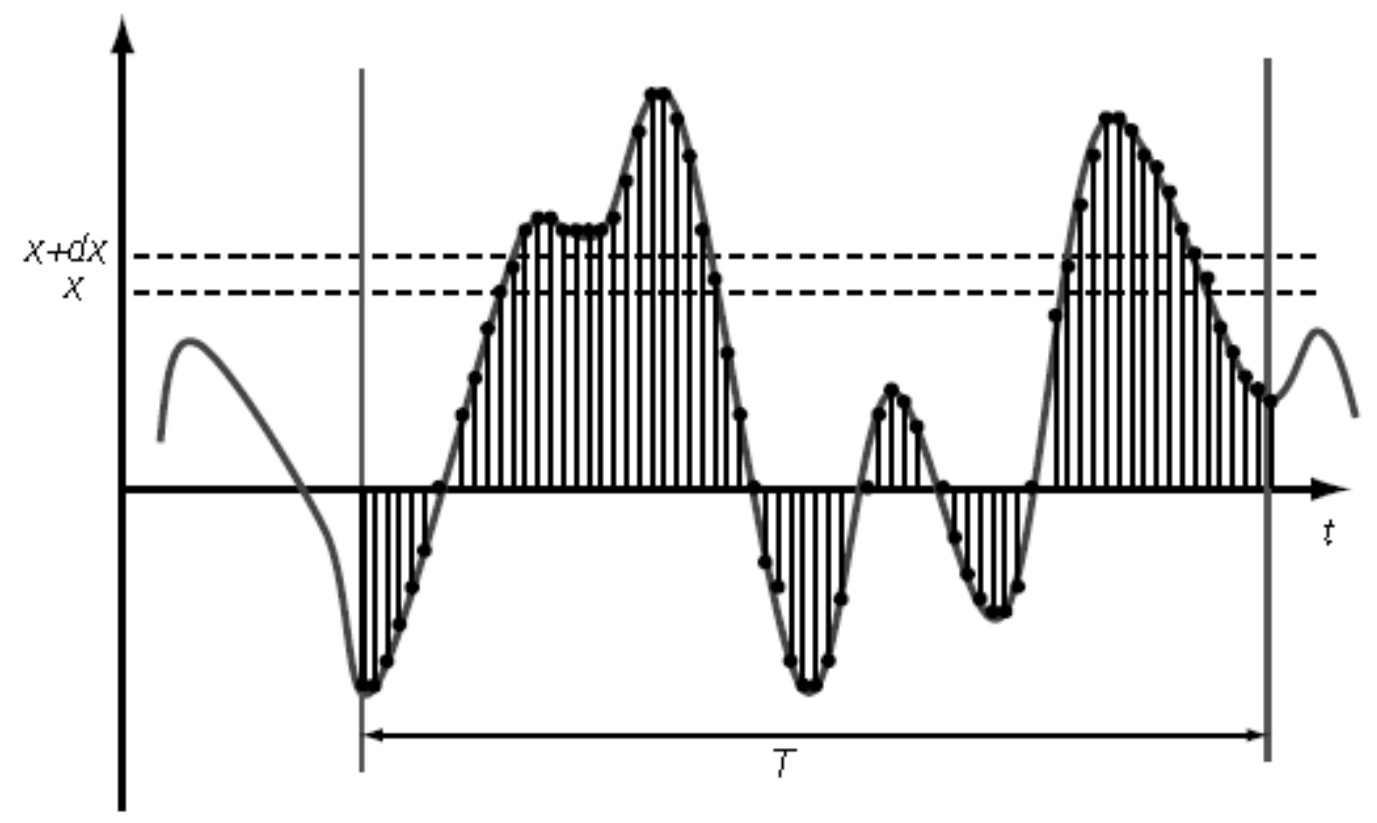

Figure II.41 PDF For A Digitized Random Process $X(T)$. 


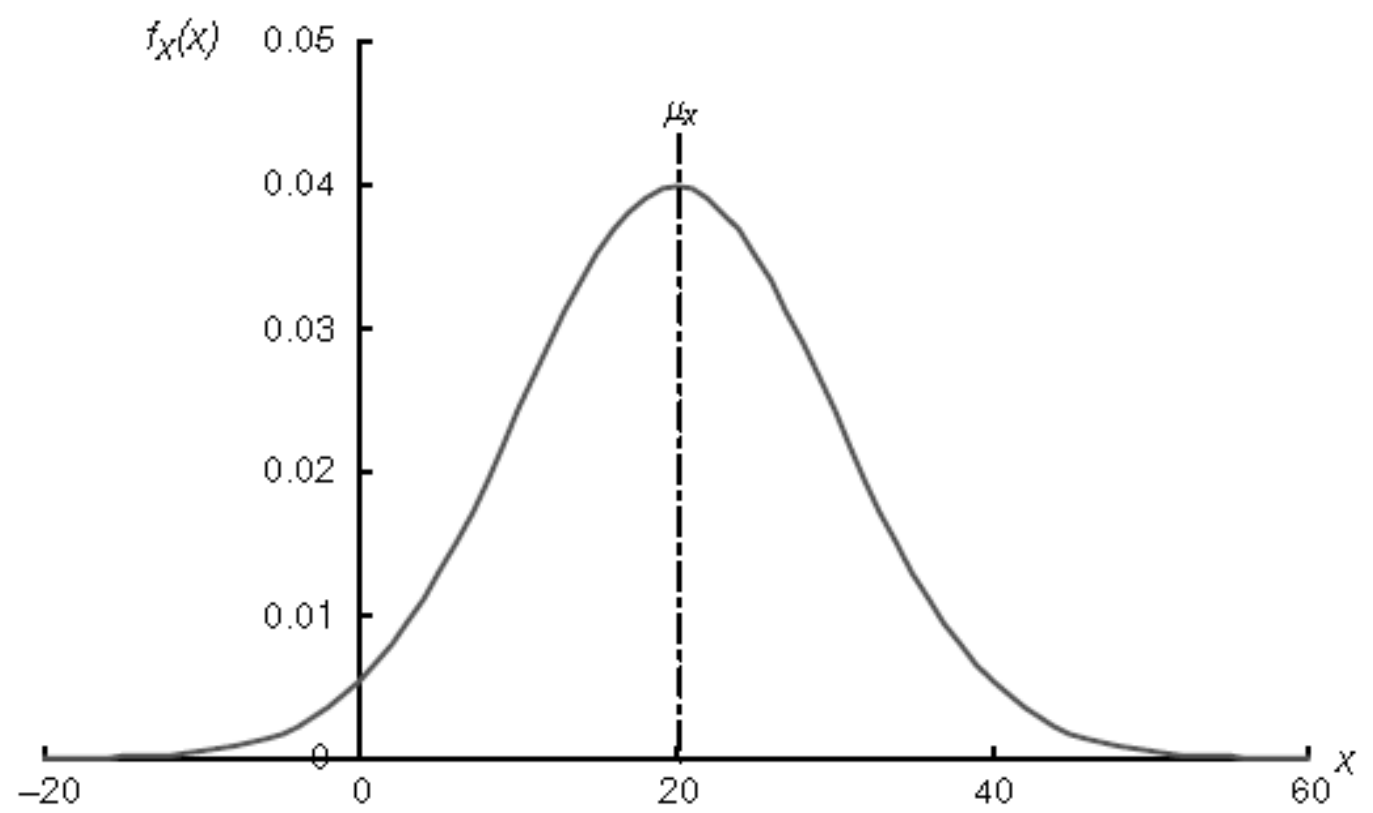

Figure II.42. PDF For A Gaussian Process.

where $\mathrm{T}$ is the record length. When $\mu_{X}=0, \sigma_{X}$ is the root mean square RMS) of the random process $X(t)$. The RMS is a measure of the amplitude $f$ the process. The process $X(t)$ is called Gaussian if its PDF $f_{x}(x)$ follows he bell-shape distribution of Figure II.42. The PDF is given by

$f_{X}(x)=\frac{1}{\sqrt{2 \pi} \sigma_{x}} \exp \left[-\frac{1}{2}\left(\frac{x-\mu_{x}}{\sigma_{x}}\right)^{2}\right] \quad-\infty<x<+\infty$

where $\mu_{x}$ and $\sigma_{x}$ are the mean and standard deviation of the process, respectively.

\section{II.6.2 A Random Process}

A collection of an infinite number of sample time histories, such as $X 1(t), X 2(t)$, and $X 3(t)$ makes up the random process $X(t)$ as shown in Figure II.43. Each time history can be generated from a separate experiment. For example, the front axle shaft torque of a vehicle is of interest. It is necessary to learn how the torque varies during long-distance driving. A large number of time histories for various road and weather conditions must be recorded. In engineering, the ensemble of a sufficiently large number of sample time histories approximates the infinite collection 
representing a random process. Instead of being measured along a single sample, the ensemble statistical properties are determined across the ensemble, as shown in Figure II.44. For a Gaussian random process, the ensemble probability density at each time instant and at any two time units must be Gaussian. A random process is said to be stationary if the probability distributions for the ensemble remain the same (stationary) for each time instant. This implies that the ensemble mean, standard deviation, variance, and mean square are time invariant. A stationary process is called ergodic if the statistical properties along any single sample are the same as the properties taken across the ensemble. That means each sample time history completely represents the ensemble. Note that if a random process is ergodic, it must be stationary. However, the converse is not true: a stationary process is not necessary ergodic.

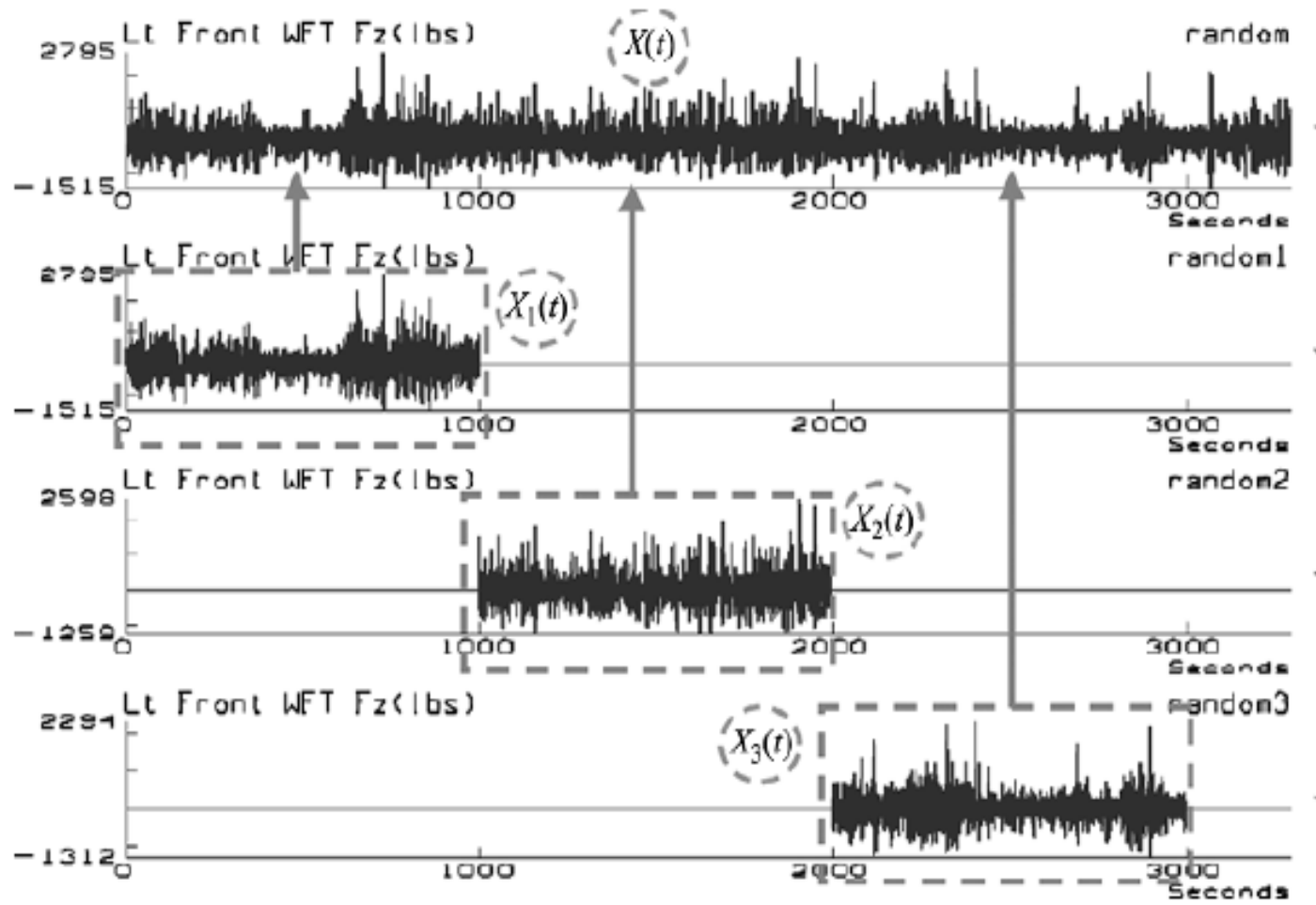

Figure II.43 Random Process_-Ensemble Of Random Sample Time Histories. 


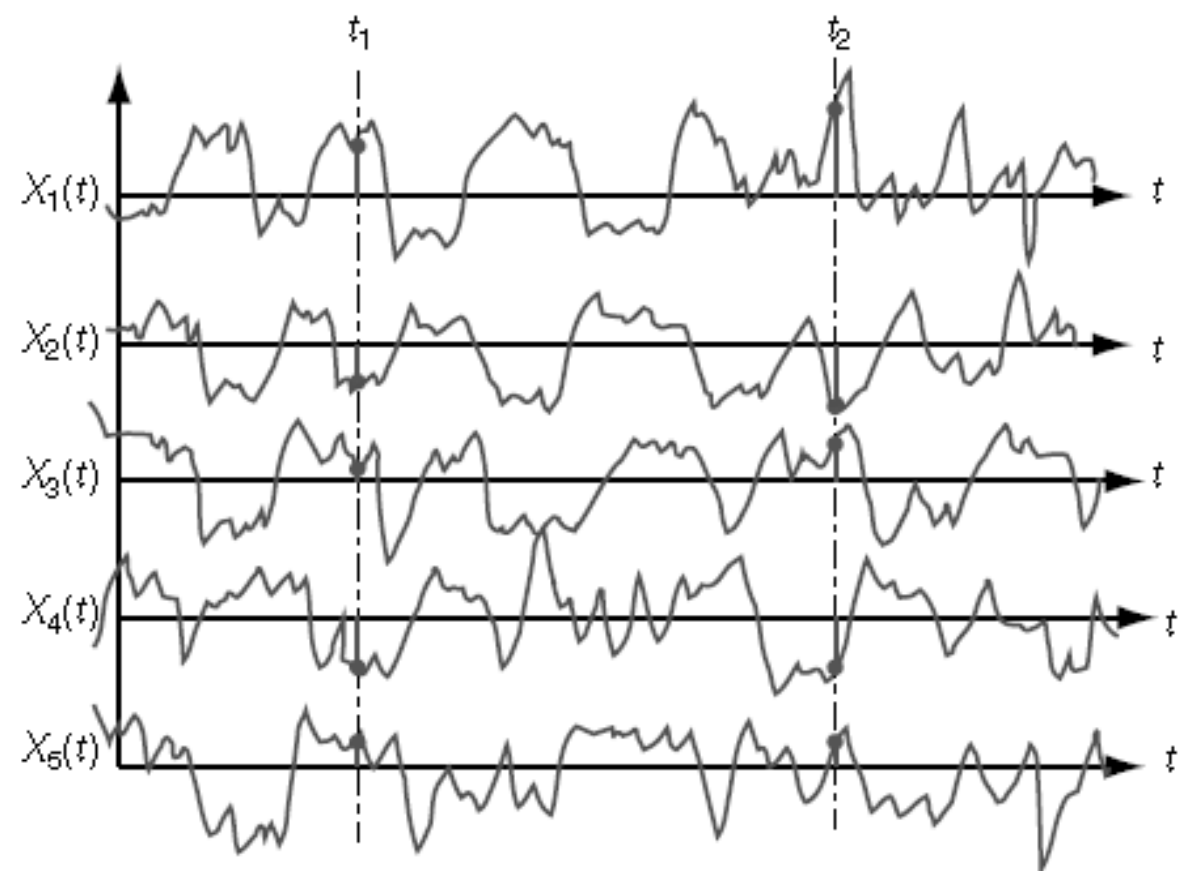

Figure II.44 Illustration Of Ensemble Statistical Data.

The autocorrelation function of a random process is the mean value of the product $X\left(t_{1}\right) X\left(t_{2}\right)$, and is denoted by $\mathrm{E}\left[X\left(t_{1}\right) X\left(t_{2}\right)\right]$. It can be approximated by the average value of the product $X\left(t_{1}\right) X\left(t_{2}\right)$, which can be obtained by sampling the random variable $x$ at times $t_{1}$ and $t_{2}$. For a stationary random process, the value of $\mathrm{E}\left[X\left(t_{1}\right) X\left(t_{2}\right)\right]$ is time invariant. However, it depends only on the time difference $\tau=\left|t_{2}-t_{1}\right|$. Therefore, the autocorrelation function of $X(t)$, denoted by $R(\tau)$, is actually a function of $t$. It is expressed as

$R(\tau)=E\left[X\left(t_{1}\right) X\left(t_{2}\right)\right]$

Also, because $X(t)$ is stationary, its mean and standard deviation are independent of t. Thus,

$E\left[X\left(t_{1}\right)\right]=E\left[X\left(t_{2}\right)\right]=\mu . X$

$\sigma_{X}\left(t_{1}\right)=\sigma_{X}\left(t_{2}\right)=\sigma \cdot x$

The correlation coefficient, $\rho$, for $X\left(t_{1}\right)$ and $X\left(t_{2}\right)$ is given by

$\rho=\frac{R_{X}(\tau)-\mu_{x}^{2}}{\sigma_{x}^{2}}$ 
If $\rho= \pm 1$, there is perfect correlation between $X\left(t_{1}\right)$ and $X\left(t_{2}\right)$, and if $\rho=0$, there is no correlation. Because the value of $\rho$ lies between -1 and 1 , it has

$$
\mu_{x}^{2}-\sigma_{x}^{2} \leq R_{x}(\tau) \leq \mu_{x}^{2}+\sigma_{x}^{2}
$$

Figure II.45 shows the properties of the autocorrelation function $R(\tau)$ of a stationary random process $X(t)$. When the time interval approaches infinity, the random variables at times $t_{1}$ and $t_{2}$ are not correlated. That means

$$
R_{X}(\tau \rightarrow \infty) \cong \mu_{X} \text { and } \rho \rightarrow 0
$$

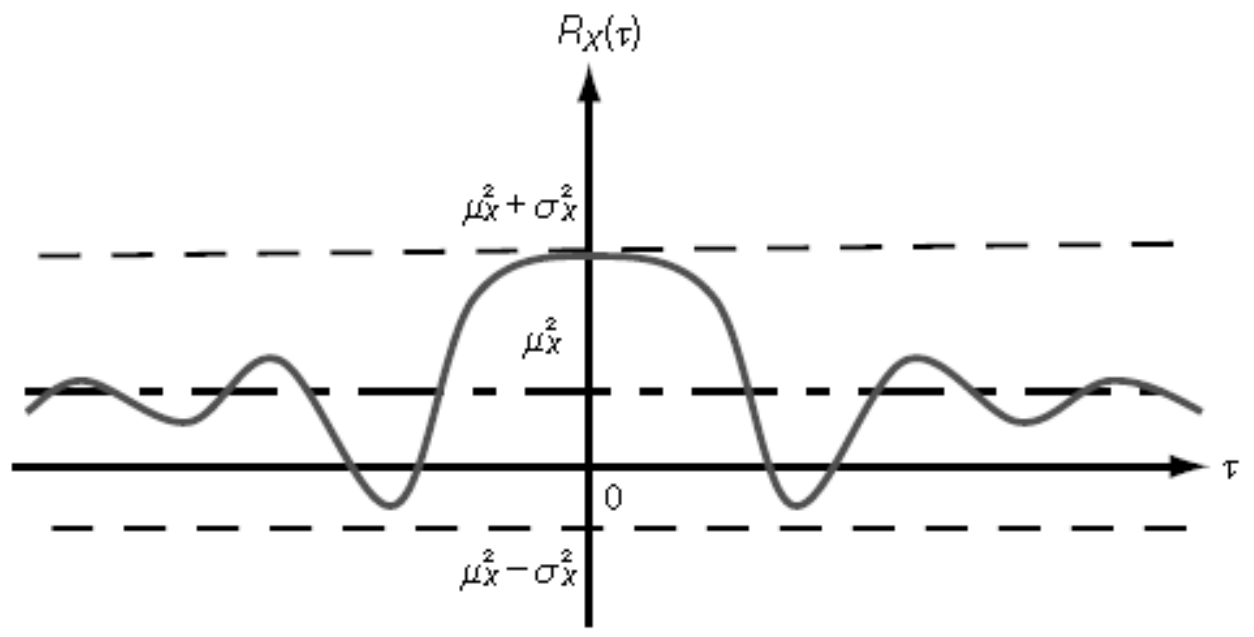

Figure II.45 Autocorrelation Function $R_{X}(\tau)$ Of A Stationary Random Process.

When the time interval is zero,

$R_{X}(\tau=0)=\mu_{X}^{2}+\sigma_{X}^{2}=E\left\lfloor X^{2}\right\rfloor$

and $R(0)$ becomes the mean square value of the process. Also, for a stationary random process, $R(\tau)$ is an even function, i.e.,

$R_{X}(\tau)=R_{X}(-\tau)$

\section{II.6.3 Fourier Analysis}

Any periodic time history can be represented by the summation of a series of sinusoidal waves of various amplitude, frequency, and phase. If $X(t)$ is a periodic 
function of time with a period $T, X(t)$ can be expressed by an infinite trigonometric series of the following form:

$$
X(t)=A_{0}+\sum_{k-1}^{\infty}\left(A_{k} \cos \frac{2 \pi k t}{T}+B_{k} \sin \frac{2 \pi k t}{T}\right)
$$

The Fourier series can be also expressed by using complex coefficients as

$$
X(t)=\sum_{k-1}^{\infty} C_{k} e^{i 2 \pi k t / T}
$$

where the complex coefficients $C_{k}$ are given by

$$
C_{k}=\frac{1}{T} \int_{T / 2}^{T / 2} X(t) e^{i 2 \pi k t / T} d t
$$

The Fourier transform can be considered as the limit of the Fourier series of $X(t)$ as $T$ approaches infinity. This can be illustrated as follows by rewriting Equation II.68 with infinite T:

$$
X(t)=\lim _{T \rightarrow \infty} \sum_{k-\infty}^{\infty}\left(\frac{1}{T} \int_{T / 2}^{T / 2} X(t) e^{-i 2 \pi k t / T} d t\right) e^{i 2 \pi k t / T}
$$

If the frequency of the $k$ th harmonic, $\omega_{k}$, in radians per second, is

$$
\omega_{k}=\frac{2 \pi k}{T}
$$

and the spacing between adjacent periodic functions, $\Delta \omega$, is

$$
\Delta \omega=\frac{2 \pi}{T}
$$

Equation II.70 becomes

$$
X(t)=\lim _{T \rightarrow \infty} \sum_{k=\infty}^{\infty}\left(\frac{\Delta \omega}{2 \pi} \int_{T / 2}^{T / 2} X(t) e^{-i k \Delta \omega t} d t\right) e^{i k \Delta \omega t}
$$


As $T$ goes to infinity, the frequency spacing, $\Delta \omega$, becomes infinitesimally small, denoted by $d \omega$, and the sum becomes an integral. As a result, Equation II.73 can be expressed by the well-known Fourier transform pair $X(t)$ and $X(\omega)$ :

$X(\omega)=\frac{1}{2 \pi} \int_{-\infty}^{\infty} X(t) e^{-i \omega t} d t$

$X(t)=\int_{-\infty}^{\infty} X(\omega) e^{i \omega t} d \omega$

The function $X(\omega)$ is the forward Fourier transform of $X(t)$, and $X(t)$ is the inverse Fourier transform of $X(\omega)$. The Fourier transform exists if the following conditions are met:

1. The integral of the absolute function exists, i.e., $\int_{-\infty}^{\infty}|\mathrm{X}(\mathrm{t})| \mathrm{dt}<\infty$

2. Any discontinuities are finite.

\section{II.6.4 Spectral Density}

The Fourier transform of a stationary random process $X(t)$ usually does not exist because the condition

$\int_{-\infty}^{\infty}|X(t)| d t<\infty$

is not met. However, the Fourier transform of the autocorrelation function $R_{X}(\tau)$ always exists. If the stationary random process $X(t)$ is adjusted (or normalized) to a zero-mean value, i.e.,

$R_{X}(\tau \rightarrow \infty)=0$

the condition

$\int_{-\infty}^{\infty}\left|R_{x}(\tau)\right| d t<\infty$

is met. In this case, the forward and inverse Fourier transforms of $R_{X}(\tau)$ are given by 
$S_{x}(\omega)=\frac{1}{2 \pi} \int_{-\infty}^{\infty} R_{x}(\tau) e^{-i \omega \tau} d \tau$

$R_{x}(\tau)=\int_{-\infty}^{\infty} S_{x}(\omega) e^{i \omega \tau} d \omega$

where $S_{X}(\omega)$ is the spectral density of the normalized stationary random process $X(t)$. If $\tau=0$, Equation II.80 reduces to

$$
E\left[X^{2}\right]=R_{x}(0)=\int_{-\infty}^{\infty} S_{x}(\omega) d \omega=\sigma_{x}^{2}
$$

This means that the square root of the area under a spectral density plot $S_{X}(\omega)$ is the RMS of a normalized stationary random process. $S_{X}(\omega)$ is also called mean square spectral density and is illustrated in Figure II.46.

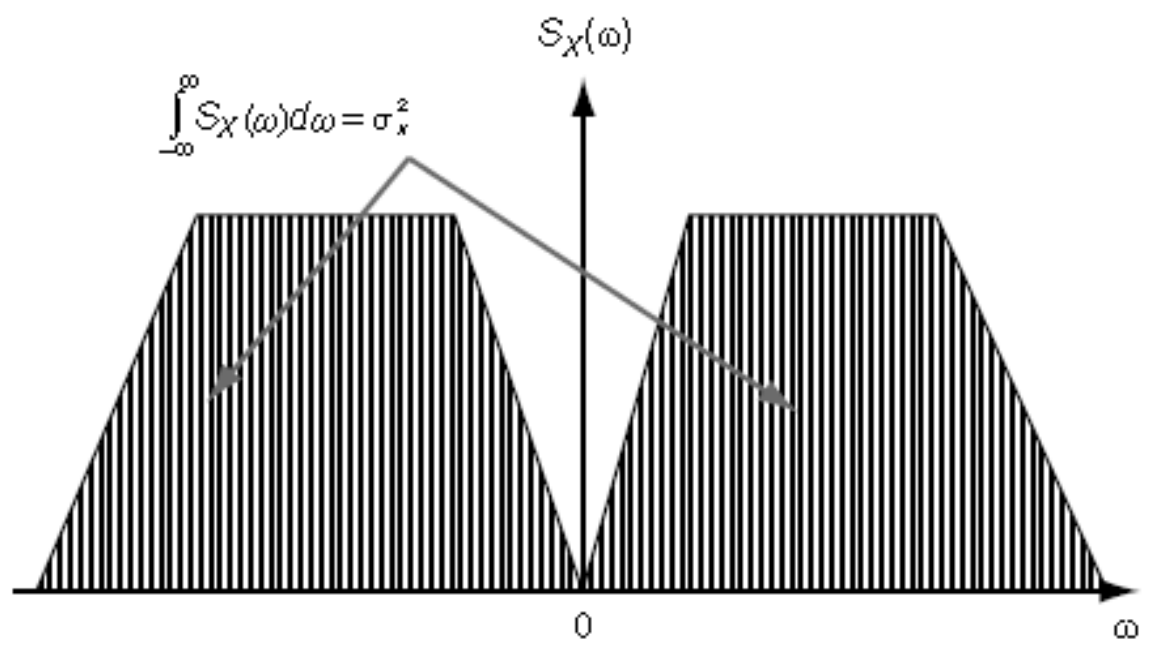

Figure II.46 Relationship Between The Spectral Density And Root Mean Square Of A Normalized Stationary Random Process.

The idea of a negative frequency has been introduced for mathematical completeness. However, it has no physical meaning. It is common practice to consider the frequency from zero to infinity and to have the frequency expressed in hertz (cycle/second) rather than radians/second. Therefore, the two-sided spectral density, $S_{X}(\omega)$, can be transformed into an equivalent one-sided spectral density $W_{x}(f)$ as follows: 
$E\left[X^{2}\right]=\sigma_{X}^{2}=\int_{0}^{\infty} W_{X}(f) d f$

Where

$W_{x}(f)=4 \pi S_{x}(\omega)$

is the PSD and

$$
f=\frac{\omega}{2 \pi}
$$

The following spectral density relationships exist for first and second derivatives of a stationary random process $X(t)$ :

$$
\begin{aligned}
& S_{x}(\omega)=\omega^{2} S_{X}(\omega) \\
& W_{x}(f)=(2 \pi)^{2} f^{2} W_{x}(f) \\
& \sigma_{\mathrm{x}}^{2}=\int_{-\infty}^{\infty} \mathrm{S}_{\mathrm{x}}(\omega) \mathrm{d} \omega=\int_{-\infty}^{\infty} \omega^{2} \mathrm{~S}_{\mathrm{x}}(\omega) \mathrm{d} \omega=(2 \pi)^{2} \int_{0}^{\infty} \mathrm{f}^{2} \mathrm{~W}_{\mathrm{x}}(\mathrm{f}) \mathrm{df} \\
& S_{x}^{\ddot{x}}(\omega)=\omega^{4} S_{X}(\omega) \\
& W_{x}^{\ddot{*}}(f)=(2 \pi)^{4} f^{4} W_{x}(f) \\
& \sigma_{\ddot{x}}^{2}=\int_{-\infty}^{\infty} S_{x}{ }_{x}(\omega) \mathrm{d} \omega=\int_{-\infty}^{\infty} \omega^{4} S_{x}(\omega) \mathrm{d} \omega=(2 \pi)^{4} \int_{0}^{\infty} f^{4} W_{x}(f) d f
\end{aligned}
$$

A random process is called a narrow-band process if its spectral density has only a narrow band of frequencies. In contrast, a broad-band process is a process whose spectral density covers a broad band of frequencies. White noise is a broad-band process. Figure II.47 shows examples of a narrow-band process, a wide-band process, and white noise.

The PSD function is usually presented on a log-log scale. An octave (oct) is a doubling of frequency. The increase in octaves from $f_{1}$ to $f_{2}$ is 
oct $=\frac{1}{\log _{10} 2} \log \frac{f_{2}}{f_{1}}$

A bel is the common logarithm of the ratio of two measurements of power. A decibel

$(\mathrm{db})$ is one-tenth of a bel and is defined by ;
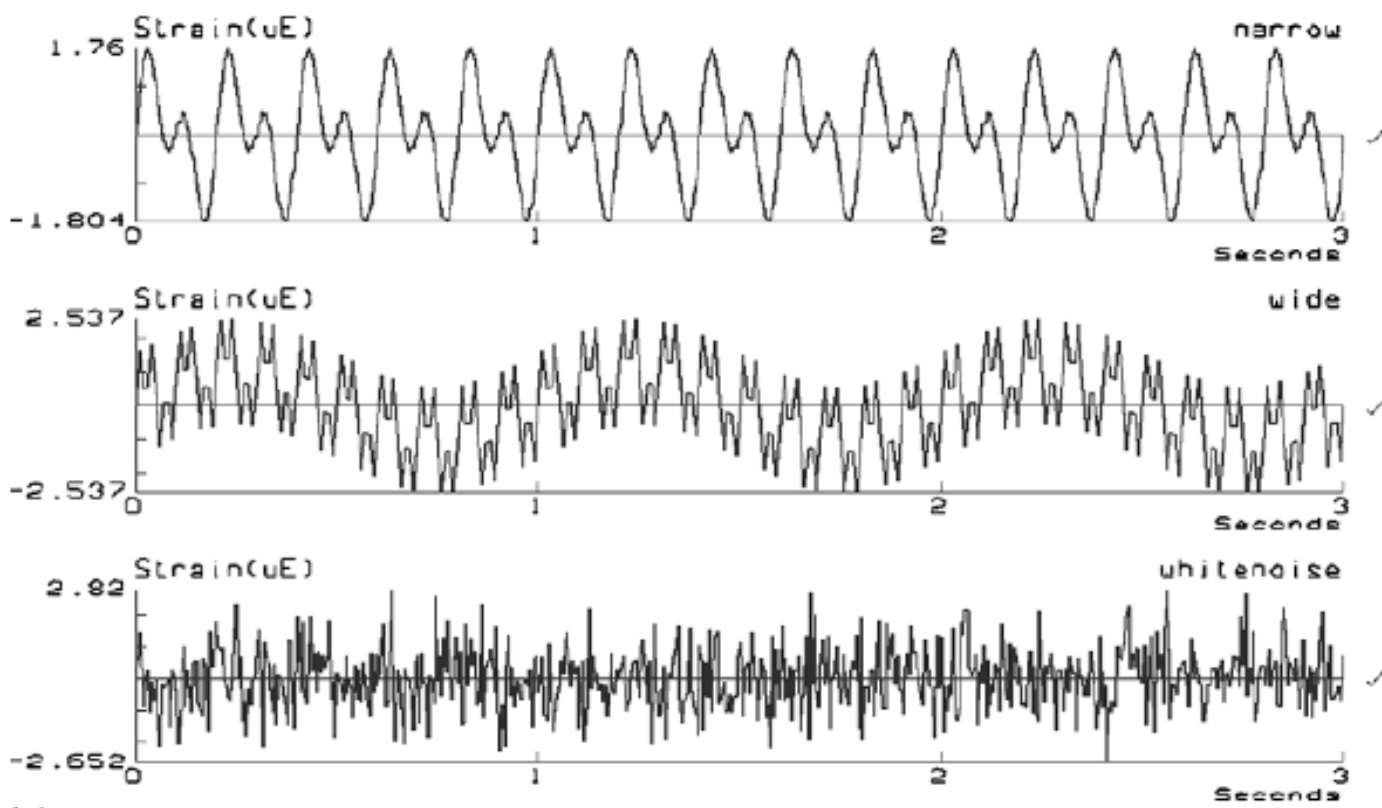

(a)

2. 256 PMS Fower (UE $\left.{ }^{\wedge} 2 . H_{2}^{\wedge}-1\right)$

nerrow
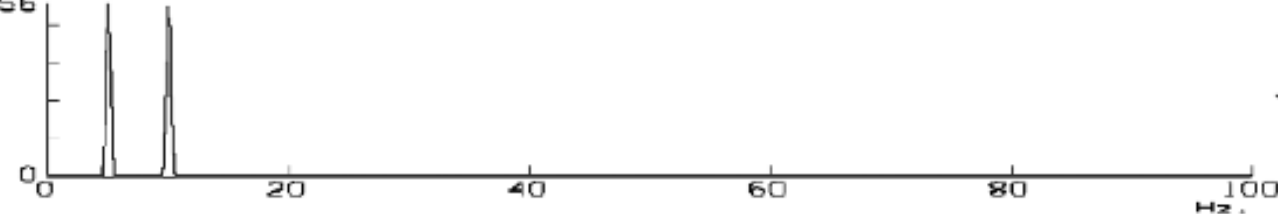

$6 .>7$ RMS Power (uE^2. $\left.\mathrm{H}_{2}^{\wedge}-1\right)$

wi de

(b)

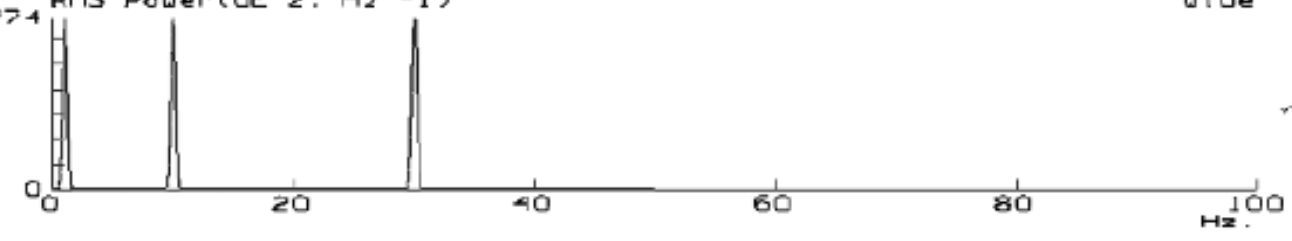

0.2333 FMS Fower (UE^2. $\mathrm{Hz}^{\wedge}-1$ )

uhitenoise

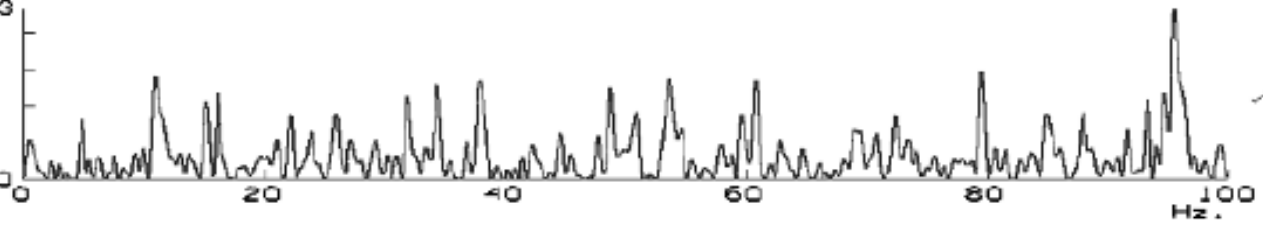

Figure II.47 (A) Narrow-Band, Wide-Band, And White Noise Random Processes,

(B) Power Spectral Densities (Psds) Of Narrow-Band, Wide-Band, And White Noise Random

Processes.

$d b=10 \log _{10} \frac{W_{x}\left(f_{2}\right)}{W_{x}\left(f_{1}\right)}$ 


\section{II.6.5 Level Crossing Rate of Narrow-Band Random Processes}

For a continuous and differentiable stationary process, $X(t)$, the expected number of positively sloped crossing (upcrossing) in an infinitesimal interval is only dependent on $d t$. We have

$$
E\left[N_{a+}(d t)\right]=v_{a+} d t
$$

where $v_{a+}$ is the expected rate of upcrossing per time unit. If $A$ denotes the event that any random sample from $X(t)$ has an upcrossing $x=a$ in an infinitesimal time interval $d t$, the probability of Event $A, P(A)$, is given

$$
P(A)=v_{a+} d t
$$

Equation II.94 allows us to express $v_{a+}$ in terms of $P(A)$. For Event A to exist, we must have

$$
a-X(t)<X(t)<a \quad \text { and } \quad \dot{X}(t)>0
$$

Combining these two conditions, $P(A)$ can be written as

$$
P(A)=P(a-X(t)<X(t)<a \cap \dot{X}(t) \mid 0)
$$

These conditons define a triangle area in the $X(t)-X(t)$ plane, as shown in Figure II.48.

The probability of Event $A$ is calculated by integrating the joint PDF of $X(t)$ and $X \dot{X}(t)$ over this region, i.e.,

$$
P(A)=\int_{0}^{\infty} \int_{a-v d t}^{a} f_{x X}(u, v) d u d v
$$

Substituting Equation II.96 into Equation II.94 leads to the following expression of the level upcrossing rate for a stationary random process:

$$
v_{a^{+}}=\int_{0}^{\infty} v f_{x X}(a, v) d v
$$


If $X(t)$ is Gaussian, the expected upcrossing rate of $x=a$ is

$v_{a^{+}}=\frac{1}{2 \pi} \frac{\sigma_{x}}{\sigma_{x}} \exp \left(\frac{-a^{2}}{2 \sigma^{2}}\right)$

The expected rate of zero upcrossings $E\left[0^{+}\right]$is found by letting $a=0$ in Equation II.98:

$E\left[0^{+}\right]=\frac{1}{2 \pi} \frac{\sigma_{x}}{\sigma_{x}}$

By using Equations II.82 and II.87, the expected rate of zero upcrossing is

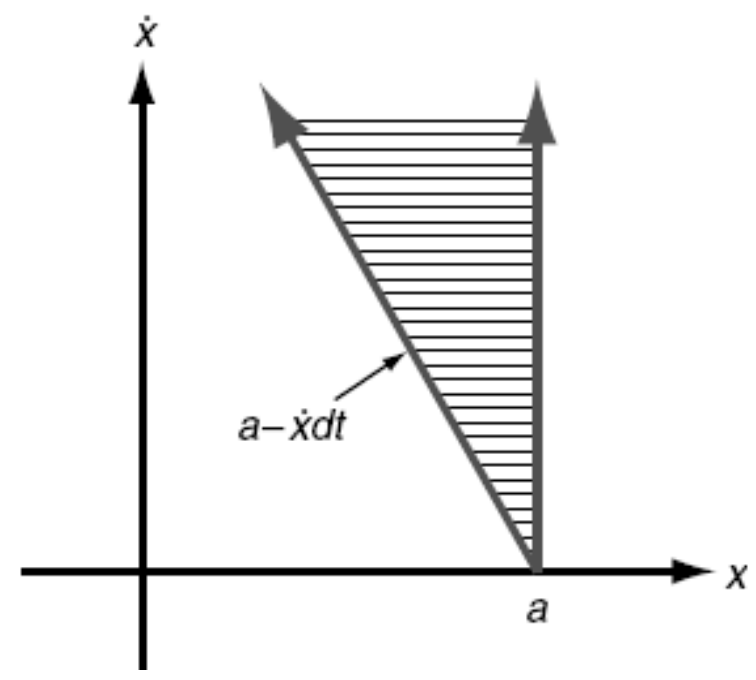

Figure II.48 The Region Where Event A Occurs.

$E\left[0^{+}\right]=\sqrt{\frac{\int_{0}^{\infty} f^{2} W_{x}(f) d f}{\int_{0}^{\infty} W_{x}(f) d f}}$

The expected rate of peak crossing, $E[P]$, is found from a similar analysis of the velocity process $\dot{X}(t)$. The rate of zero downcrossing of the velocity process corresponds to the occurrence of a peak in $\dot{X}(t)$. The result for a Gaussian process is 


$$
E[P]=\frac{1}{2 \pi} \frac{\sigma_{x}^{*}}{\sigma_{x}}
$$

By using Equations II.87 and II.90, we have

$$
E[P]=\sqrt{\frac{\int_{0}^{\infty} f^{4} W_{x}(f) d f}{\int_{0}^{\infty} f^{2} W_{x}(f) d f}}
$$

A narrow-band process is smooth and harmonic. For every peak there is a corresponding zero upcrossing, meaning $E\left[0^{+}\right]$is equal to $E[P]$. However, the wideband process is more irregular. A measure of this irregularity is the ratio of the zero upcrossing rate to the peak crossing rate. The ratio is known as the irregularity factor, $\gamma$, i.e.,

$\gamma=\frac{E\left[0^{+}\right]}{E[P]}$

Figure II.49 shows a simple example of how to calculate the irregularity factor. Note that when $\gamma \rightarrow 0$, there is an infinite number of peaks for every zero upcrossing. This is considered a wide band random process. The vaue of $\gamma=1$ corresponds to one peak per one zero upcrossing and it represents a narrow-band random process.

Alternatively, a narrow- or wide-band process can be judged by the width of its spectrum. For this reason, the spectral width parameter, $\gamma$, is introduced as

$$
\lambda=\sqrt{1-\gamma^{2}}
$$

Note that $\gamma \rightarrow 0$ represents a narrow-band random process.

If $M j$ is the $j$ th moment of a one-sided PSD function (Figure II.50) defined as

$$
M_{j}=\int_{0}^{\infty} f^{j} W_{S a}(f) d f
$$




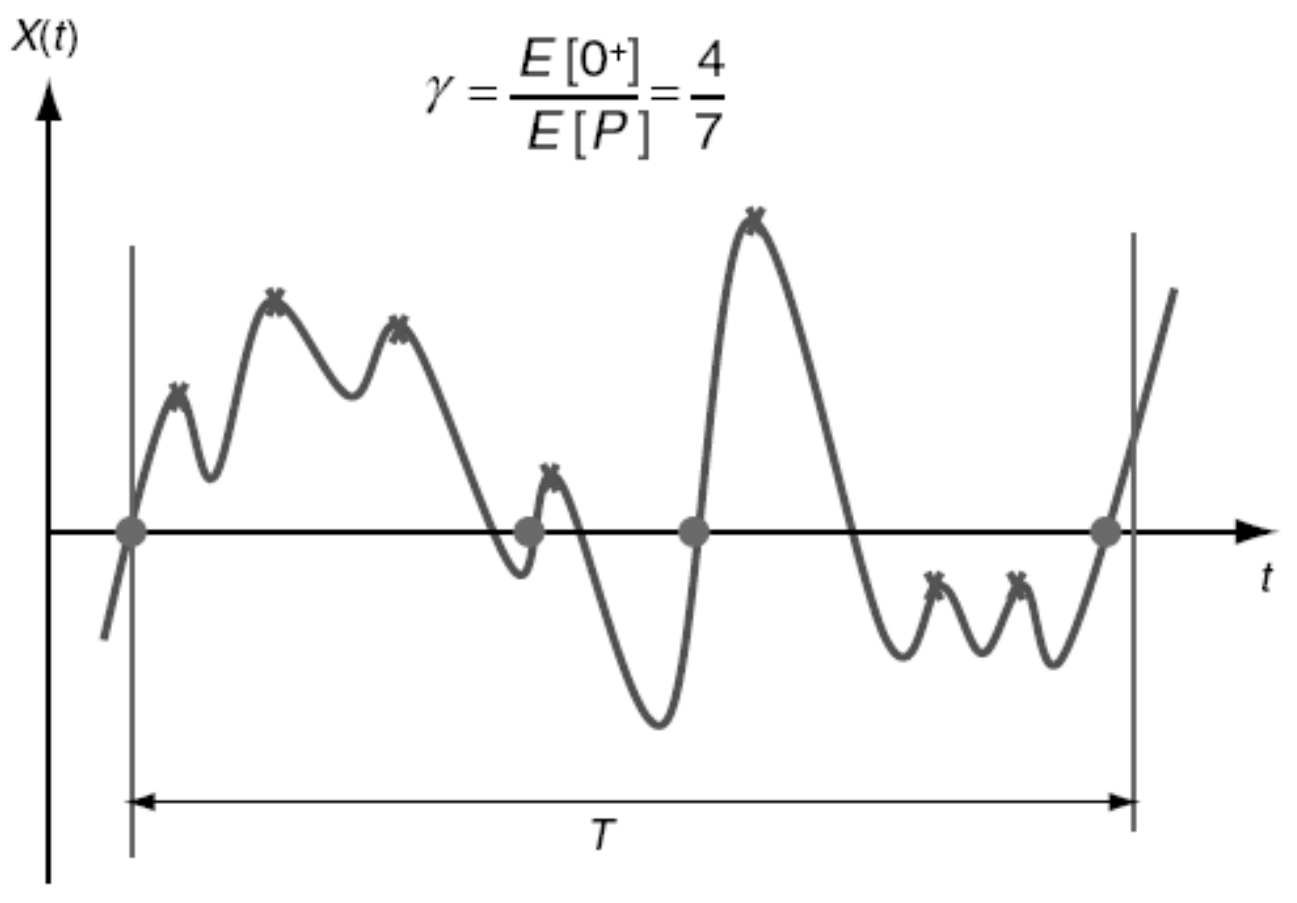

Figure II.49 Calculation Of The Irregularity Factor $\gamma$.

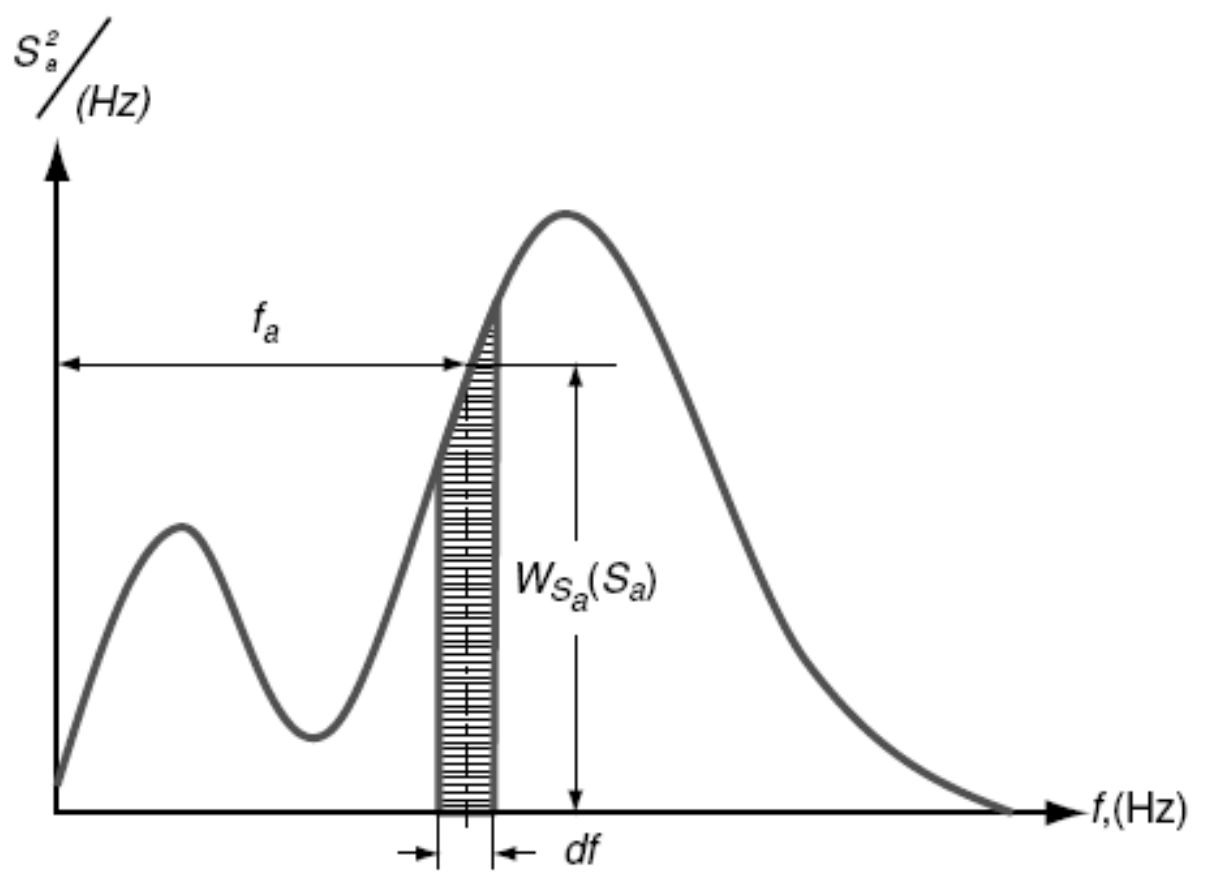

Figure II.50 Moments From A One-Side PSD.

the rate of zero crossings $E\left[0^{+}\right]$and rate of peaks $E[P]$ are given by 


$$
\begin{aligned}
& E\left[0^{+}\right]=\sqrt{\frac{M_{2}}{M_{0}}} \\
& E[P]=\sqrt{\frac{M_{4}}{M_{2}}} \\
& \gamma=\sqrt{\frac{M_{2}^{2}}{M_{0} M_{4}}} \\
& \gamma=\sqrt{1-\frac{M_{2}^{2}}{M_{0} M_{4}}}
\end{aligned}
$$

\section{II.6.6 Models Of Fatigue Damage Under Narrowband Random Processes}

In this section, a linear $\mathrm{S}-\mathrm{N}$ curve in $\log -\log$ coordinates and the linear damage accumulation rule are employed. It is assumed that all stress cycles have the same mean value. If a mean stress exists, it can be accounted for by various mean stress correction models.

Variable amplitude loading is simulated by a sequence of blocks of constant amplitudes. Damage $D$ is defined as

$D=\sum_{i=1}^{k} \frac{n_{i}}{N_{f, i}}$

where $n_{i}$ is the total number of cycles in the ith block of constant-stress amplitude $S_{a, i}, N_{f, i}$ is the number of cycles to failure under $S_{a, i}$, and $k$ is the total number of blocks. Failure occurs when $D \geq 1$. Recall that the relationship between constant stress amplitude $S_{a, i}$ (or constant stress range $S_{r, i}$ ) and the fatigue life $N_{f, i}$ has the following expression:

$S_{a, i}=S_{f}^{\prime}\left(2 N_{f, i}\right)^{b}$

or 
$N_{f, i}=\frac{1}{2}\left(\frac{S_{a, i}}{S_{f}^{\prime}}\right)^{1 / b}$

where $S_{f}^{\prime}$ is the fatigue strength coefficient and $b$ is the fatigue strength exponent. If $m=-1 / b$ and $A=0.5 \times\left(S_{f}^{\prime}\right)^{m}$, an alternative form of the S-N curve is given by

$$
N_{f, i}=A \times S_{a, i}^{-m}
$$

This is a very convenient formula to predict $N_{f, i}$ for a given $S_{a, i}$.

The cycle counting histogram (also called discrete stress spectrum) for a narrowband stress process $S(t)$ can be established by either performing the rainflow cycle counting technique or by the counting the number of peaks $n_{i}$ in the window $\Delta S$ around a stress level. Suppose that the total number of peaks counted in the $S(t)$ process is denoted by $\sum_{i=1}^{k} n_{i}$. The probability $f_{i}$ that a stress amplitude $S_{a}=S_{a, i}$ will occur is

$$
f_{i}=\frac{n_{i}}{\sum_{i=1}^{k} n_{i}}
$$

Thus, $f_{i}$ is the PDF of the random variable $S_{a}$. In this case, the total fatigue damage can be written as

$$
D=\sum_{i=1}^{k} \frac{n_{i}}{N_{f, i}}=\sum_{i=1}^{k} \frac{f_{i} \sum_{i=1}^{k} n_{i}}{N_{f, i}}
$$

By using the linear $\mathrm{S}-\mathrm{N}$ model, the expression for fatigue damage is

$$
D=\frac{\sum_{i=1}^{k} n_{i}}{A} \sum_{i=1}^{k} f_{i} S_{a, i}^{m}
$$


Also, the expected value of $S_{a}^{m}$ is

$E\left(S_{a}^{m}\right)=\sum_{i=1}^{k} f_{i} S_{i}^{m}$

Therefore

$D=\frac{\sum_{i=1}^{k} n_{i}}{A} E\left(S_{a}^{m}\right)$

where the total count of cycles $\sum_{i=1}^{k} n_{i}$ is equal to the rate of upcrossing multiplying the total time period $T\left(=E\left[0^{+}\right] \times T\right)$. Assume that the PDF of stress amplitude $S_{a}$ can be treated as a continuous random variable as shown in Figure II.51. The expected value of $S_{a}^{m}$ is

$E\left(S_{a}^{m}\right)=\int_{0}^{\infty} S_{a}^{m} f s_{a}\left(s_{a}\right) d s_{a}$

Even though any statistical model of $S_{a}$ can be employed, it is common to use the Weibull distribution with the following CDF:

$F s_{a}\left(s_{a}\right)=1-\exp \left[-\left(\frac{s_{a}}{\alpha}\right)^{\beta}\right]$

where $\alpha$ and $\beta$ are the scale parameter (characteristic life) and shape parameter (Weibull slope), respectively. For the Weibull distribution, 


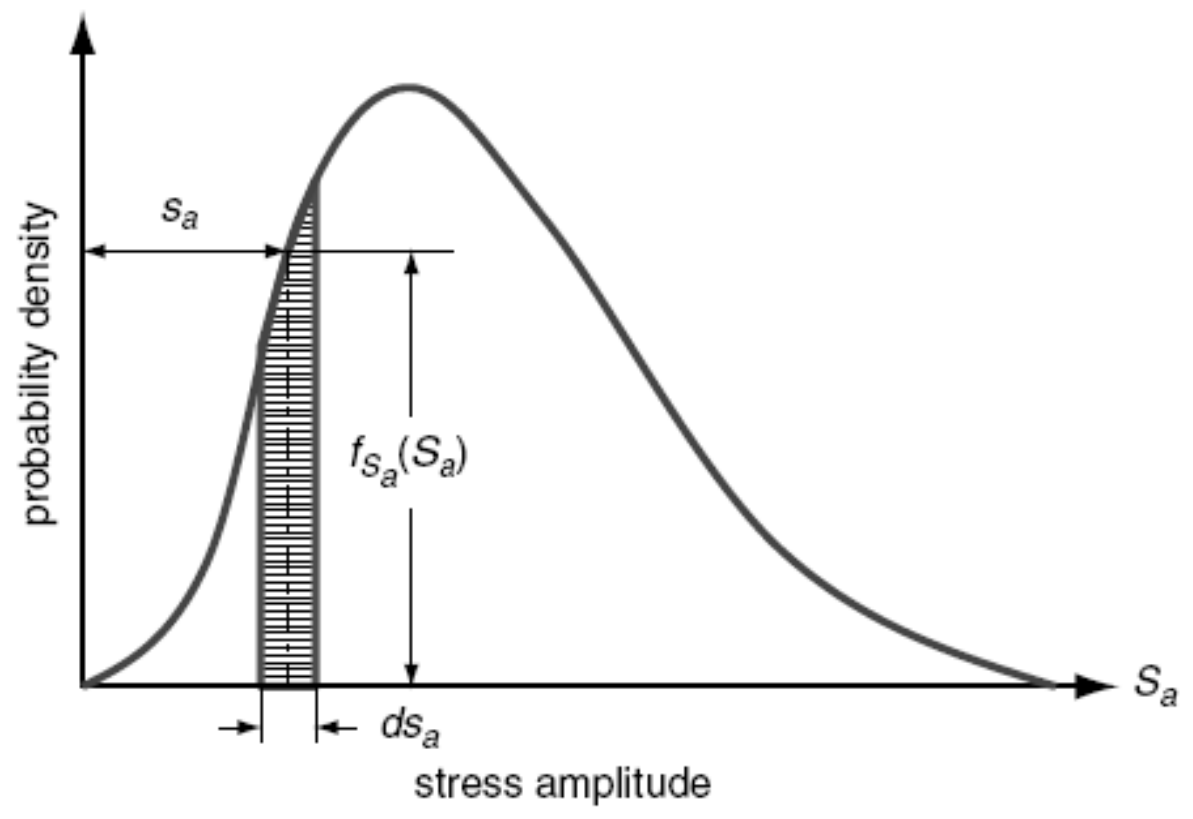

Figure II.51 Continuous PDF Of Stress Amplitude.

$E\left(S_{a}^{m}\right)=\alpha^{m} \Gamma\left(\frac{m}{\beta}+1\right)$

where $\Gamma($.$) is the gamma function.$

In the special case in which $\beta=2$, the Weibull distribution reduces to the Rayleigh distribution. This is an important case, because Rayleigh is the distribution of peaks or ranges or amplitude in a stationary narrow-band Gaussian process that has an RMS value of $\sigma_{s}$. Also, it can be shown that

$\alpha=\sqrt{2 \sigma_{s}}$

Therefore, if $S(t)$ is stationary narrow-band Gaussian and the stressamplitudes follow the Rayleigh distribution,

$E\left(S_{a}^{m}\right)=\left(\sqrt{2} \sigma_{s}\right)^{m} \Gamma\left(\frac{m}{2}+1\right)$

where $\sigma_{s}=\sqrt{M_{0}}$.

In such a case, therefore, the expected total fatigue damage $D_{N B}$ of a zeromean stationary narrow-band Gaussian stress process over a time interval $\tau$ can be written as 
$D_{N B}=\frac{\sum_{i: 1}^{k} n_{i}}{A} E\left(S_{a}^{m}\right)=\frac{E\left[0^{+}\right] \times T}{A}\left(\sqrt{2 M_{0}}\right)^{m} \Gamma\left(\frac{m}{2}+1\right)$

\section{II.6.7 Models Of Fatigue Damage Under Wide-Band Random Processes}

Based on the rainflow counting method, a model for predicting fatigue damage under stationary wide band Gaussian stress process has been proposed by Wirsching and Light (1980). By using the narrow-band approach as a starting point, the general expression for the damage $D_{W B \text {,Wirsching }}$ over a time interval $\tau$ is

$D_{W B, \text { Wirsching }}=\xi_{W} D_{N B}$

where DNB is the fatigue damage under a narrow-band random process and $\xi_{W}$ is the rainflow correction factor. $\xi_{W}$ is an empirical factor derived from extensive Monte Carlo simulations that include a variety of spectral density functions. It is expressed as follows:

$\xi_{S}=a_{S}+\left[1-a_{S}\right](1-\lambda)^{b_{W}}$

where

$a_{S}=0.926-0.033 m \quad b_{S}=1.587 m-2.323$

Note that $\mathrm{m}$ is the slope of the $\mathrm{S}-\mathrm{N}$ curve defined in Equation II.123, and $\lambda$ is the spectral width parameter defined in Equations II.104 or II.109.

Oritz and Chen (1987) also derived another similar expression for fatigue damage, $D_{W B, \text { Ortiz }}$, under wide-band stresses as

$\mathrm{D}_{\mathrm{wB}, \text { Oritz }}=\xi_{\mathrm{O}} \mathrm{D}_{\mathrm{NB}}$

where

$\xi_{O}=\frac{1}{\gamma} \sqrt{\frac{M_{2} M_{k}}{M_{0} M_{k+2}}} \quad$ and $\quad k=\frac{2.0}{m}$

The irregularity factor $\gamma$ is defined in Equation II.103 or II.108. 
Instead of using the damage correction factor from the narrow-band stresses to the wide-band stresses, Dirlik (1985) developed an empirical closed-form expression for the PDF of rainflow amplitude, $f s_{a}\left(s_{a}\right)$, based on extensive Monte Carlo simulations of the stress amplitudes. Dirlik's solutions were sucessfully verified by Bishop (1988) in theory. Dirlik's damage model for a time period of $\tau$ is as follows:

$$
\begin{aligned}
& D_{W B, \text { Dirlik }}=\frac{E[P] \tau}{A} \int_{0}^{\infty} s_{a}^{m} f s_{a}\left(S_{a}\right) d S_{a} \\
& f s_{a}\left(s_{a}\right)=\frac{D_{1}}{2 \sqrt{M_{0}} Q} e^{\frac{-Z}{Q} \times S_{a}}+\frac{D_{2} \times Z}{2 \sqrt{M_{0}} R_{2}} e^{\frac{-Z^{2}}{2 R^{2}} \times S_{a}^{2}}+\frac{D_{3} \times Z}{2 \sqrt{M_{0}}} \times e^{\frac{-Z^{2}}{2} \times S_{a}^{2}}
\end{aligned}
$$

where

$$
\begin{aligned}
& Z=\frac{1}{2 \sqrt{M_{0}}} \quad \gamma=\frac{M_{2}}{\sqrt{M_{0} M_{4}}} \quad X_{m}=\frac{M_{1}}{M_{0}} \sqrt{\frac{M_{2}}{M_{4}}} \\
& D_{1}=\frac{2\left(X_{m}-\gamma^{2}\right)}{1+\gamma^{2}} \quad R=\frac{\gamma-X_{m}-D_{1}^{2}}{1-\gamma-D_{1}+D_{1}^{2}} \quad D_{2}=\frac{1-\gamma-D_{1}-D_{1}^{2}}{1-R} \\
& D_{3}=1-D_{1}-D_{2} \quad Q=\frac{1.25\left(\gamma-D_{3}-D_{2} \times R\right)}{D_{1}}
\end{aligned}
$$

Bishop and Sherratt (1989) and Bishop (1994) concluded that the Dirlik solution gives the better results as compared with the corresponding time domain results. [2] 


\section{CHAPTER III}

\section{FATIGUE LIFE PREDICTION OF A DRAG LINK}

Fatigue life calculation can be made by using different methods. It can be calculated by using different equations in time domain or frequency domain. In time domain , fatigue life can be found by using stress- life (S-N) curve or strain - life $(\mathrm{E}-\mathrm{N})$ curve. And also a lot of different mean stress theories such as Soderberg, Goodman and Gerber Theory can be used. On the other hand, in the frequency domain, different life calculation methods such as Dirlik, Oritz and Chen Method etc. , can be used for calculations. All of these different curves, equations and methods can be appropriately used for different systems and situations. As a result, for making a good converging fatigue analysis an appropriate method must be used.

A drag link is a part which transfers the rotating load from the steering gearbox and pitman arm to wheels by pushing and pulling the steering arm. The drag link converts the sweeping arc of the steering arm to linear motion in the plane of the other steering links. There occurs tensile and compression stress in the drag link body when starting the rotation of the wheels until the steering force overcomes the friction resistance between the ground and the wheels. In respect of the vehicles encounter many different and hard road condition (straight road, rough road, Belgian road etc.) the variable stresses can occur on the drag link body. This variable stress produce the fatigue and micro cracks occurs and the finally drag link can cracks in the advancing times. The forces that are occured due to these different road conditions are called random forces. 


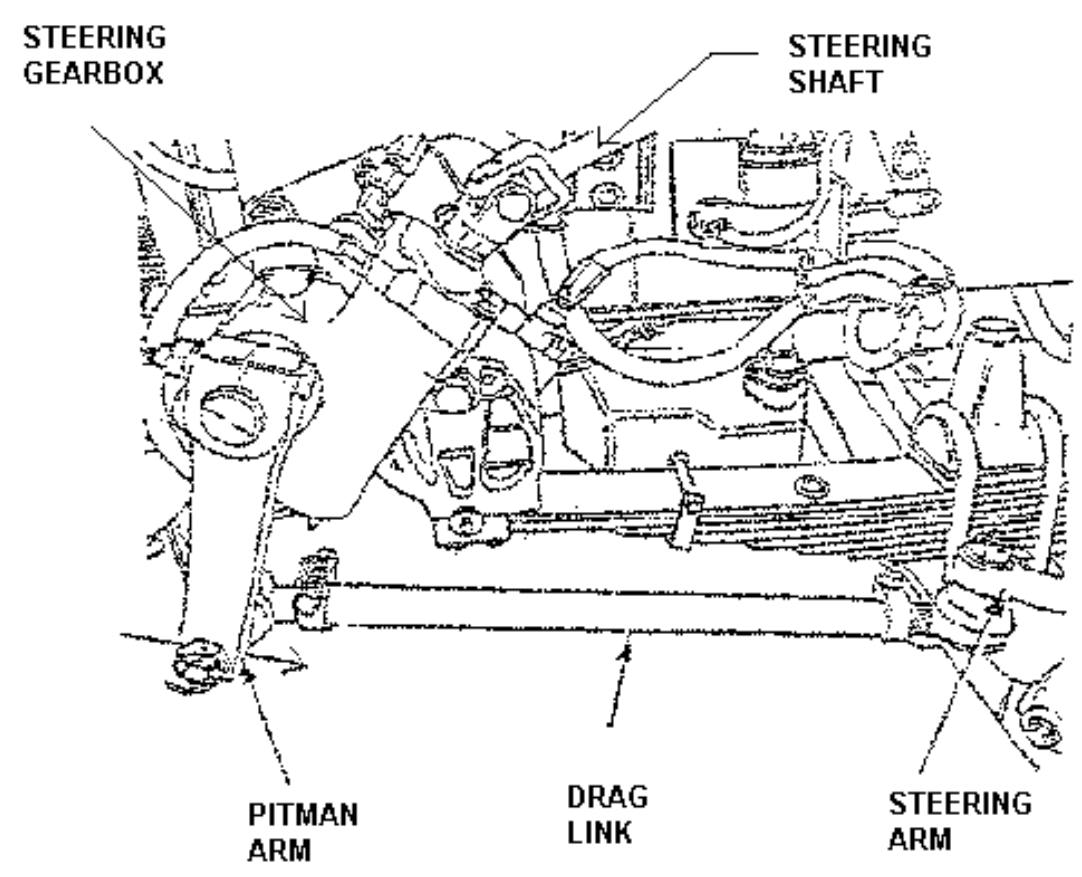

Figure III.1 Steering Mechanism And Drag Link

In the fatigue life prediction of a bus steering drag link, stress - life method which uses the time domain equations was used. The loading charecteristic in this analysis was taken from the fatigue test of the same drag link. And the finally the results from the fatigue analysis and the fatigue test will be compared.

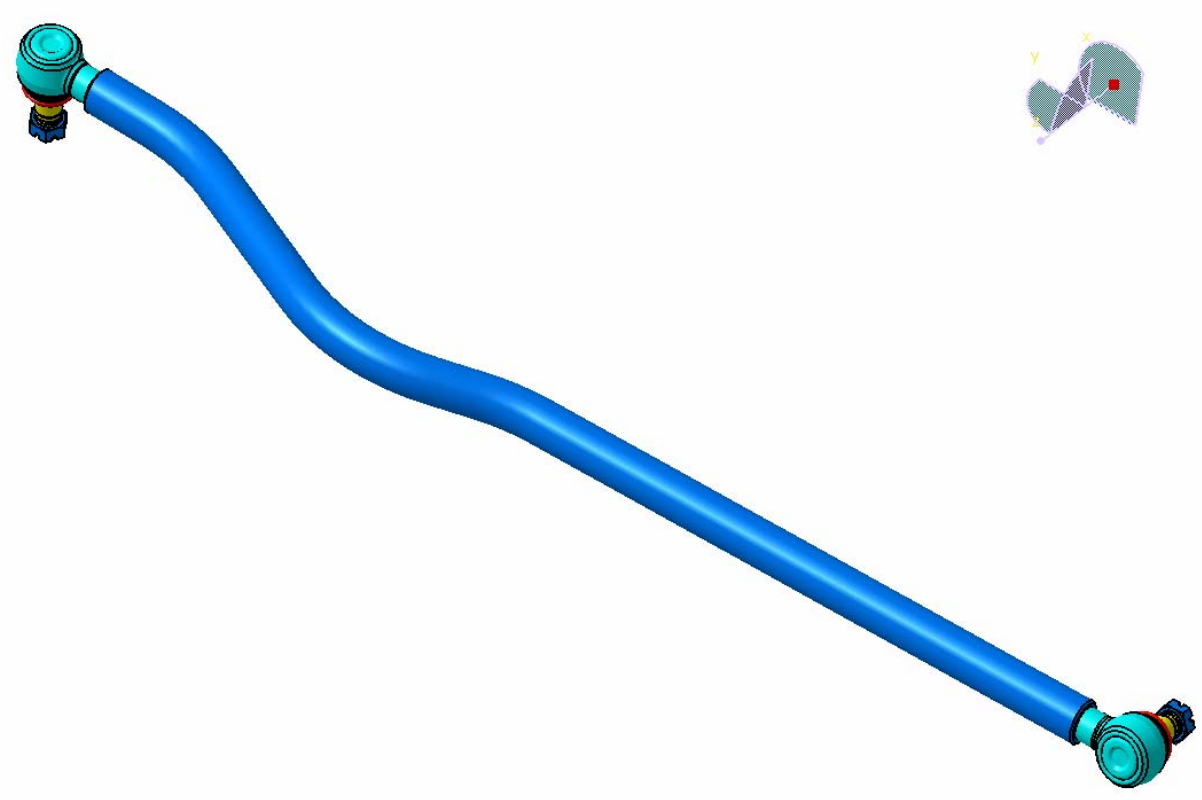

Figure III.2 A Viewing of The Drag Link Which Will Be Used For Analysises 
In the next sub chapter, the road loads was used for predicting the life of the drag link. The road loads had been taken from a data collecting test report which was made before this thesis. The road loads had been calculated by using strain data which had been collected in that test. Using these force inputs, the fatigue life and the damage of the drag link will be computed.

The last step of this thesis is to calculate the fatigue life of the drag link in the frequency domain by using the road loads. By making the analysis in the frequency domain (vibration fatigue) and in the time domain the results can be easily compared. After this comparation, the best method for predicting fatigue life of a draglink will exposed.

\section{III.1. FATIGUE LIFE PREDICTION ANALYSIS BY USING THE EXPERIMENTAL LOADS}

In this section; fatigue analyses of two different drag link have been performed. The second drag link is an alternative of the first one. It is planned to use one of the these drag links which has the best fatigue life. The first one has a $36 \mathrm{~mm}$ diameter and $4.7 \mathrm{~mm}$ wall thickness and the second drag link has a $40 \mathrm{~mm}$ diameter (Figure III.3). In addition to these differencies, the materials of the drag links are also different.

Table III.1 Properties Of The Drag Links

\begin{tabular}{|c|c|c|c|}
\hline Link No & Tube No & Diameter (mm) & Tube Material \\
\hline 1 & A1-1648 & $\varnothing 36 \times 4.7$ & St 52 \\
\hline 2 & A $1-2377$ & $\varnothing 40(\mathrm{Rod})$ & SAE 1045 Norm. \\
\hline
\end{tabular}

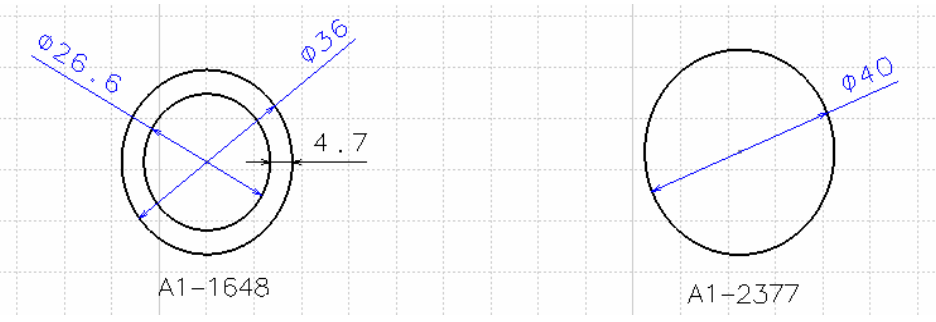

Figure III.3 Cross section areas of the drag links. 
The fatigue analysises of these two drag link were made by using Ansys Workbench 11.0 . Furthermore, fatigue life tests of these drag links were made and the results are compared with the FEA results. The test equipment is shown in the Figure III.4. The fatigue tests were made for both of these two drag links and in laboratory of the drag links vendor in $24.5^{\circ} \mathrm{C}$. Totally six fatigue tests were made for both of the drag links. The experimental load has a sine wave form with frequency of $6 \mathrm{~Hz}$. The peak points of the loading force are $+5.65 \mathrm{kN}$ and $-15.86 \mathrm{kN}$. Fatigue test equipment and the test laboratory are shown below.

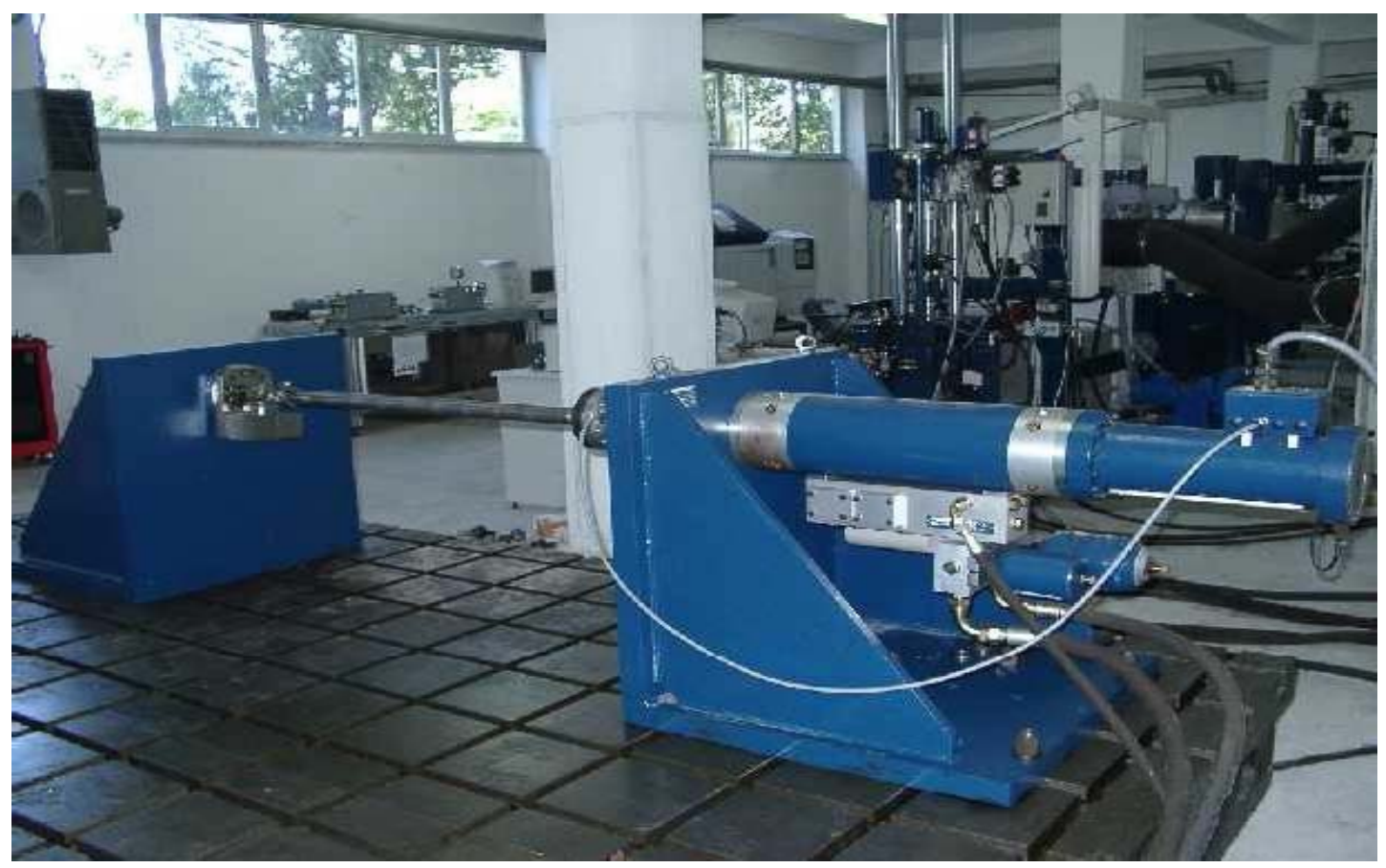

Figure III.4 Used Fatigue Test System (Ditaş Company’s Fatigue Testing Lab.)

Table III. 2 . The Loading Properties.

\begin{tabular}{|c|c|c|c|}
\hline \multirow{2}{*}{ Cycles } & \multicolumn{3}{|c|}{ LOADING } \\
\cline { 2 - 4 } & Amp. (kN) & Frequency & Wave Form \\
\hline Until Break & +5.65 & & Sine \\
$\begin{array}{c}\text { (Stop at 1e6 } \\
\text { cycles.) }\end{array}$ & -15.86 & $6 \mathrm{~Hz}$. & \\
\hline
\end{tabular}

As mentioned before, for fatigue analysises of both of these drag links experimental sine wave load was used. This load values and wave form was used to simulate the static steering condition. In the analyses, the surface beside the steering 
arm was fixed and the loading force was applied on the surface beside the pitman arm ( Figure III.7 ) .

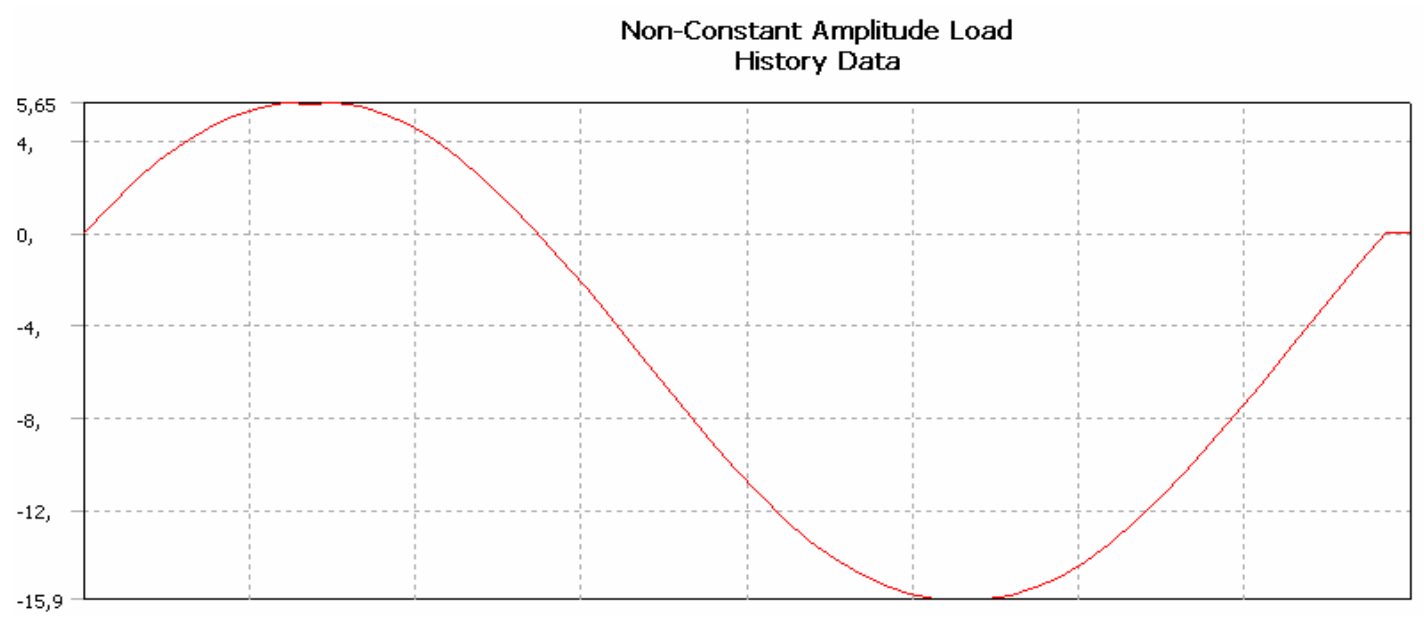

Figure III.5 The Loading Curve

The S-N curve of the first drag link (St 52) and meshed drag link are shown below. Linear isotropic material model was used for analysises. Ansys Workbench considers only the elastic material model for fatigue analysis. Because of the good converging advantage, hexahedron elements were used for meshing. After meshing operation 11244 elements and 46572 nodes were created.

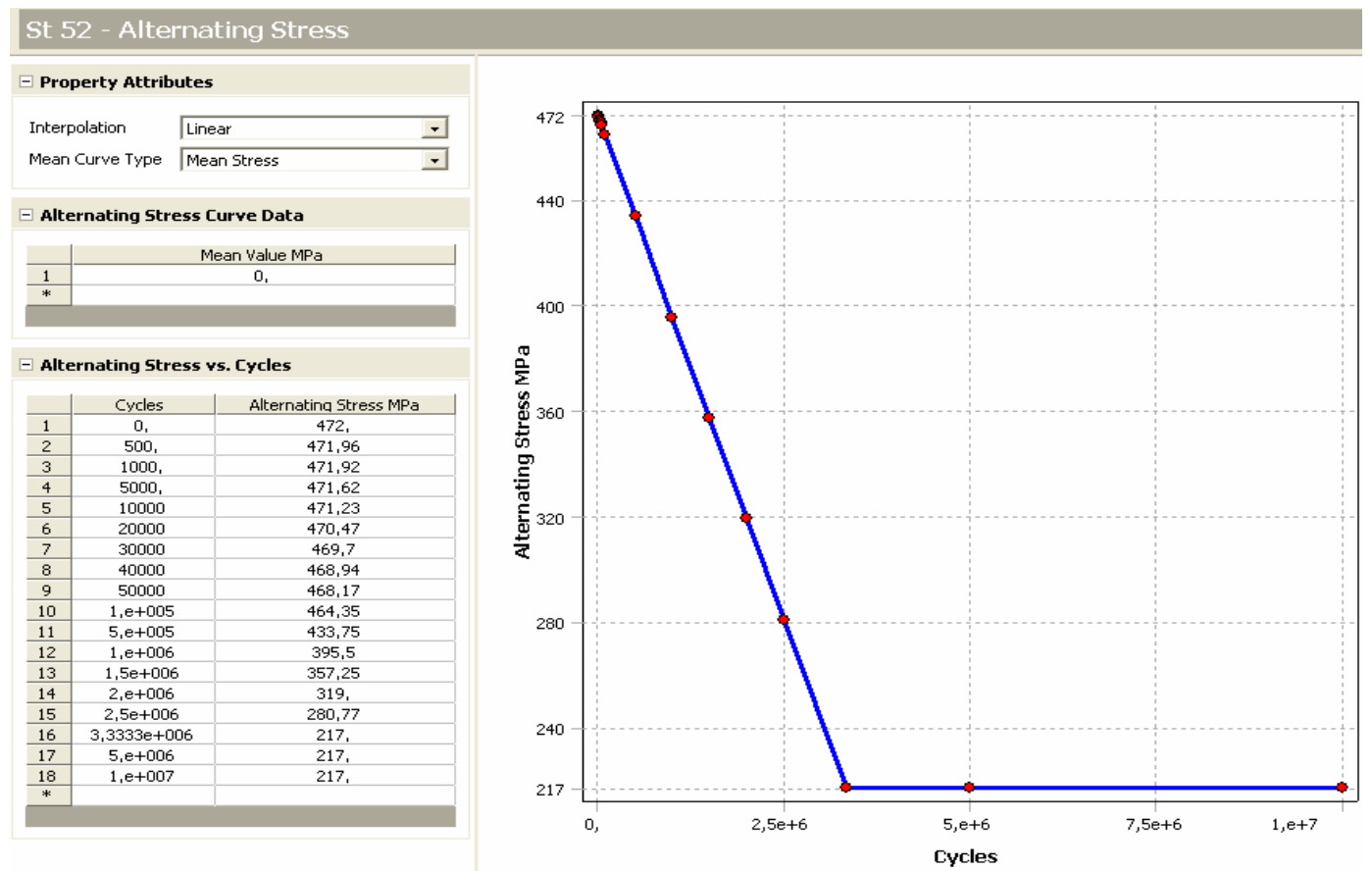

Figure III.6 The S-N Curve Of A1-1648 (St 52) 


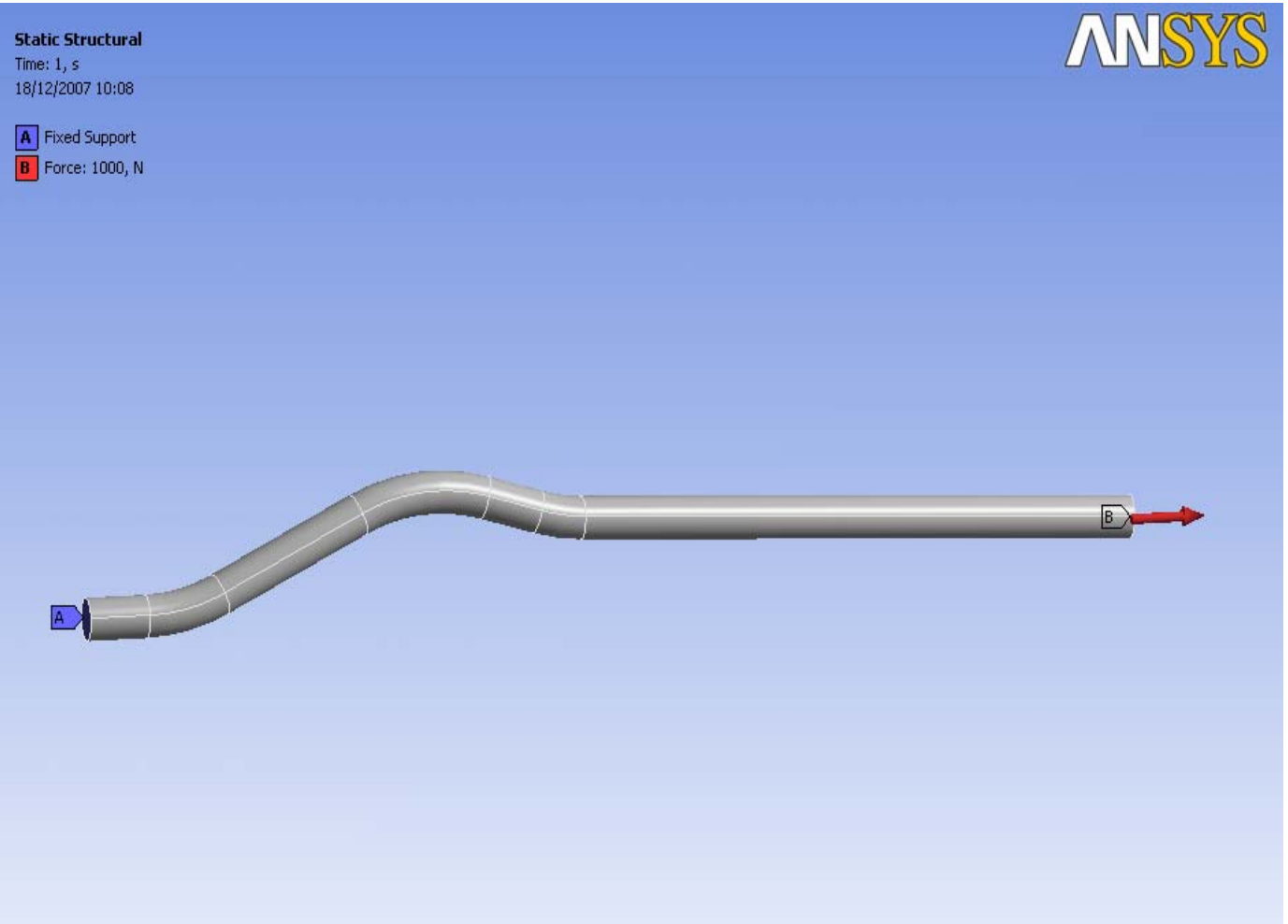

Figure III.7 Boundary Conditions

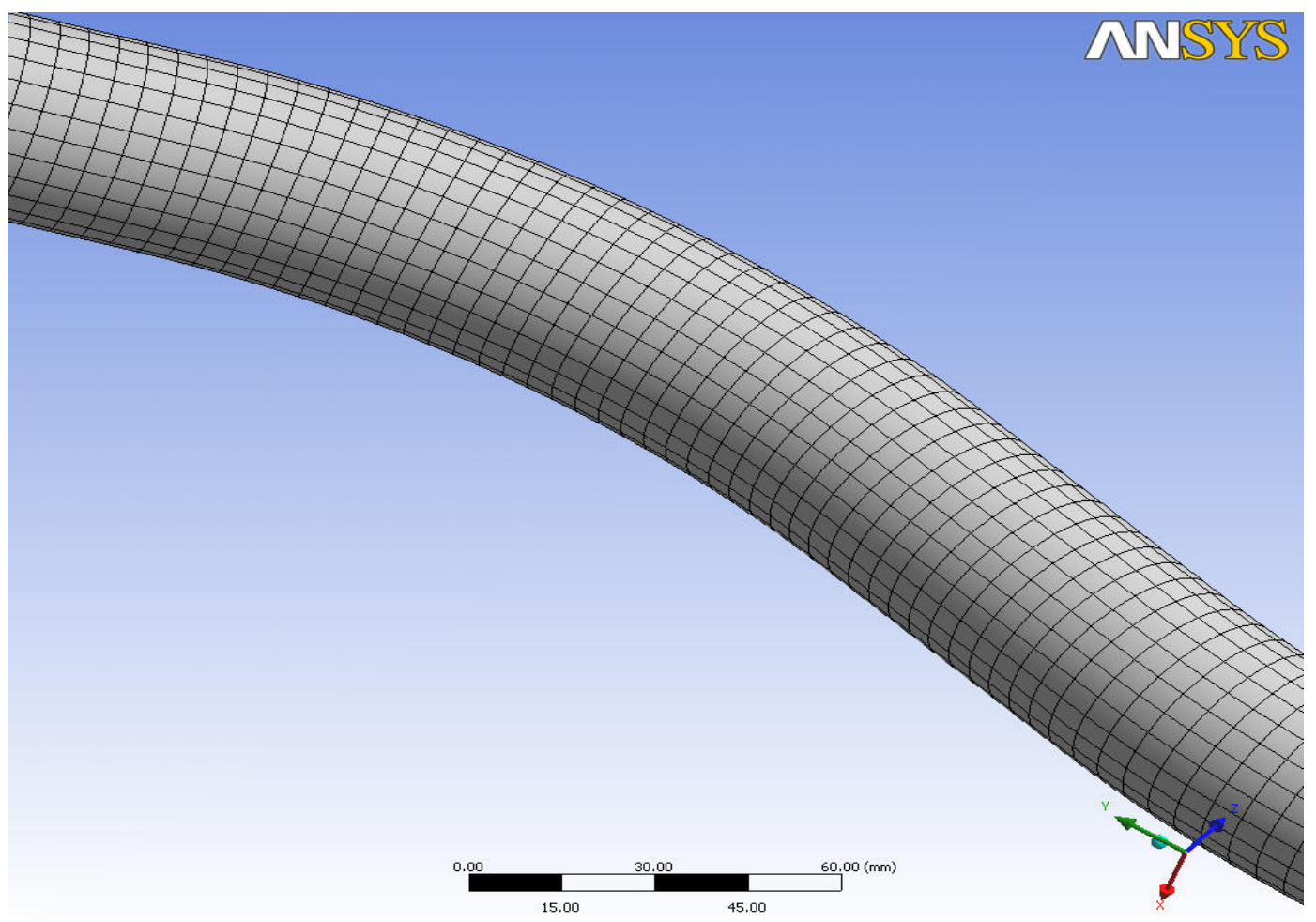

Figure III.8 Meshed Drag Link (Extended Critical Area) 
The manufacturing operations of the drag links are hot rolling and cold forming. The residual stress in the drag links is terminated by making a normalization operation. On the other hand they were subjected to tension and compression loads. The fatigue strength factor calculated as 0.6 by using Equation II.26 and Table II.1 for surface factor, Equation II.28 and II.29 for size factor, Table II. 2 for load factor. As a result, 0.6 was used for fatigue strength factor. On the other hand, the Soderberg Mean Stress Method was used for mean stress effect. The reason that using the Soderberg is that, this theory is appropriate for the ductile materials and the it considers the mean tensile stress as a decreasing effect for the fatigue life and mean compression stress with no effect for the fatigue life. The life contour result for drag link A1-1648 is shown below.

For these two drag links desired design life is 100000 cycles. Safety factor and damage which compares the design life and the available life, are shown in Figure III.11 and 12.

$$
\text { Damage }=\frac{\text { Life }_{\text {Design }}}{\text { Life }_{\text {Available }}}
$$

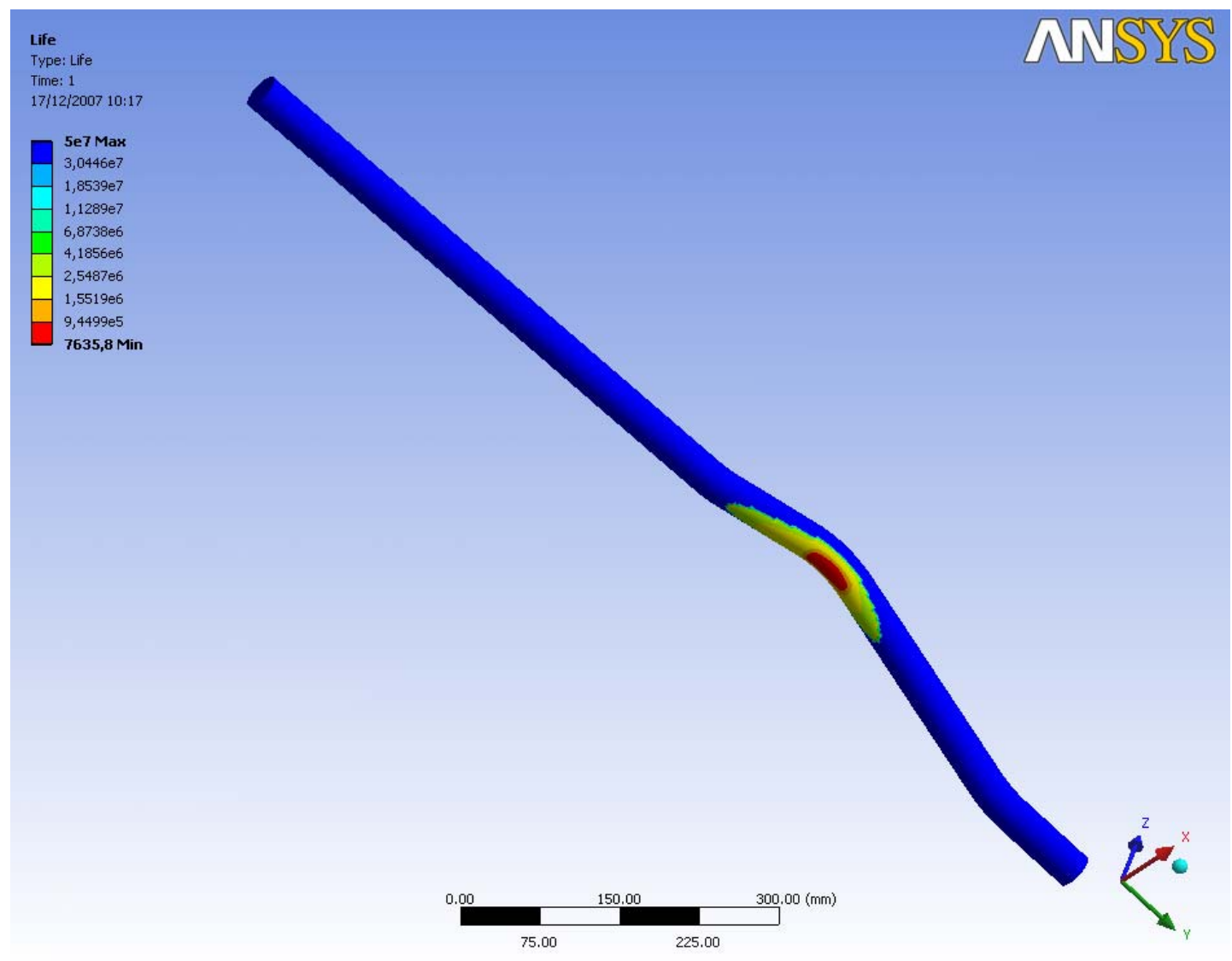

Figure III.9 The Fatigue Life Of A1-1648 In Cycles. 


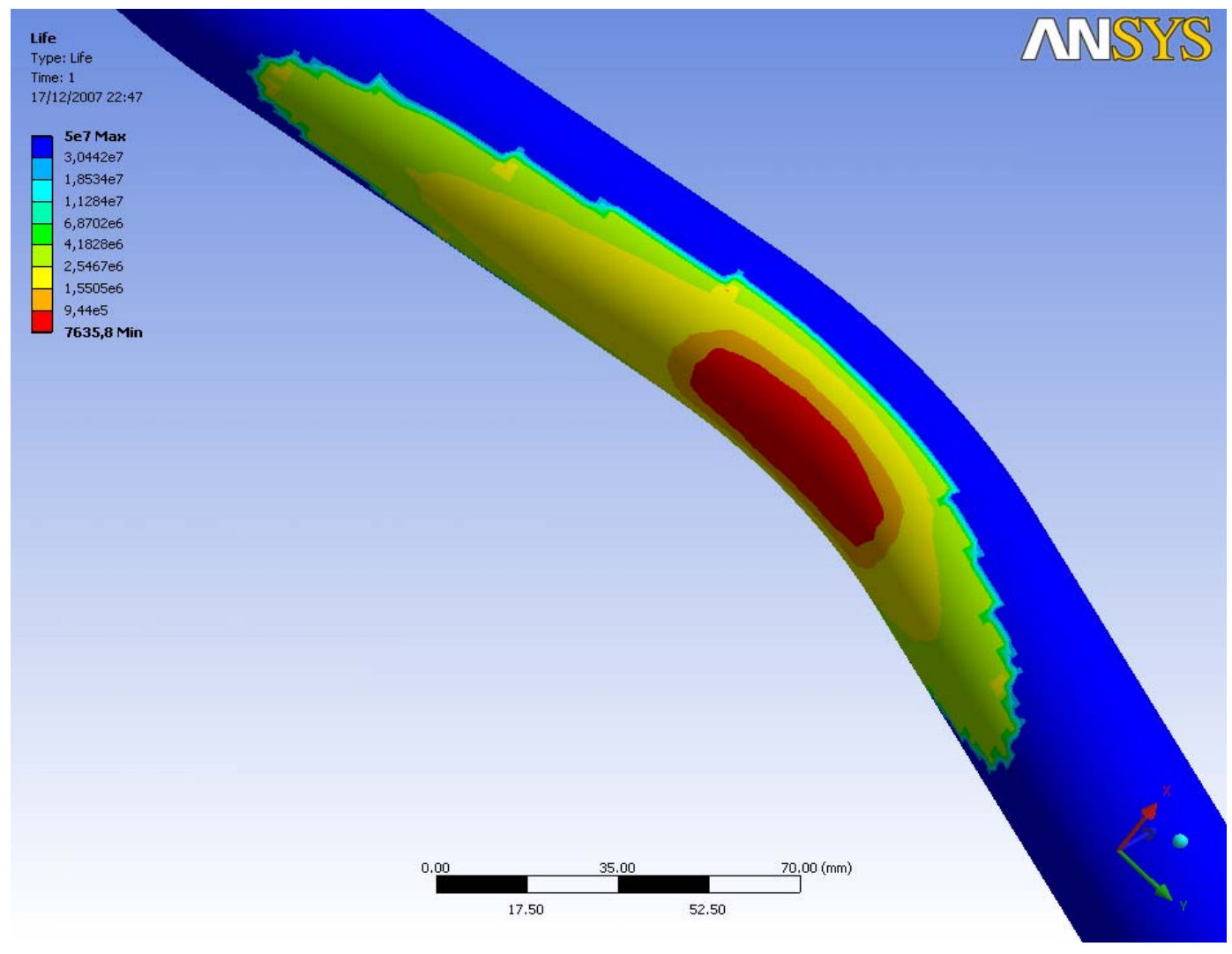

Figure III.10 The Fatigue Life Contours (Extended Critical Area)

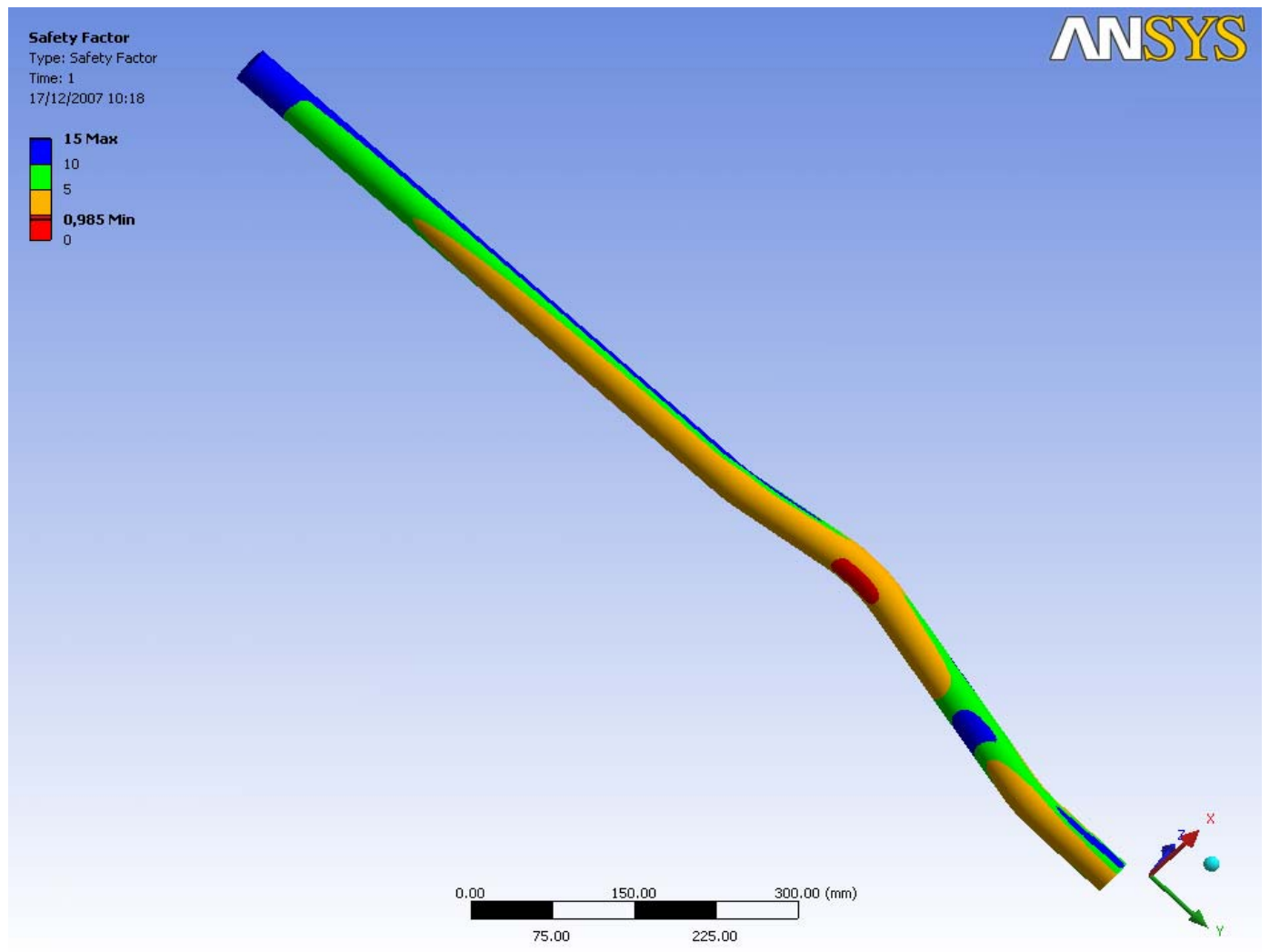

Figure III.11 The Safety Factor Contours Of A1-1648. 


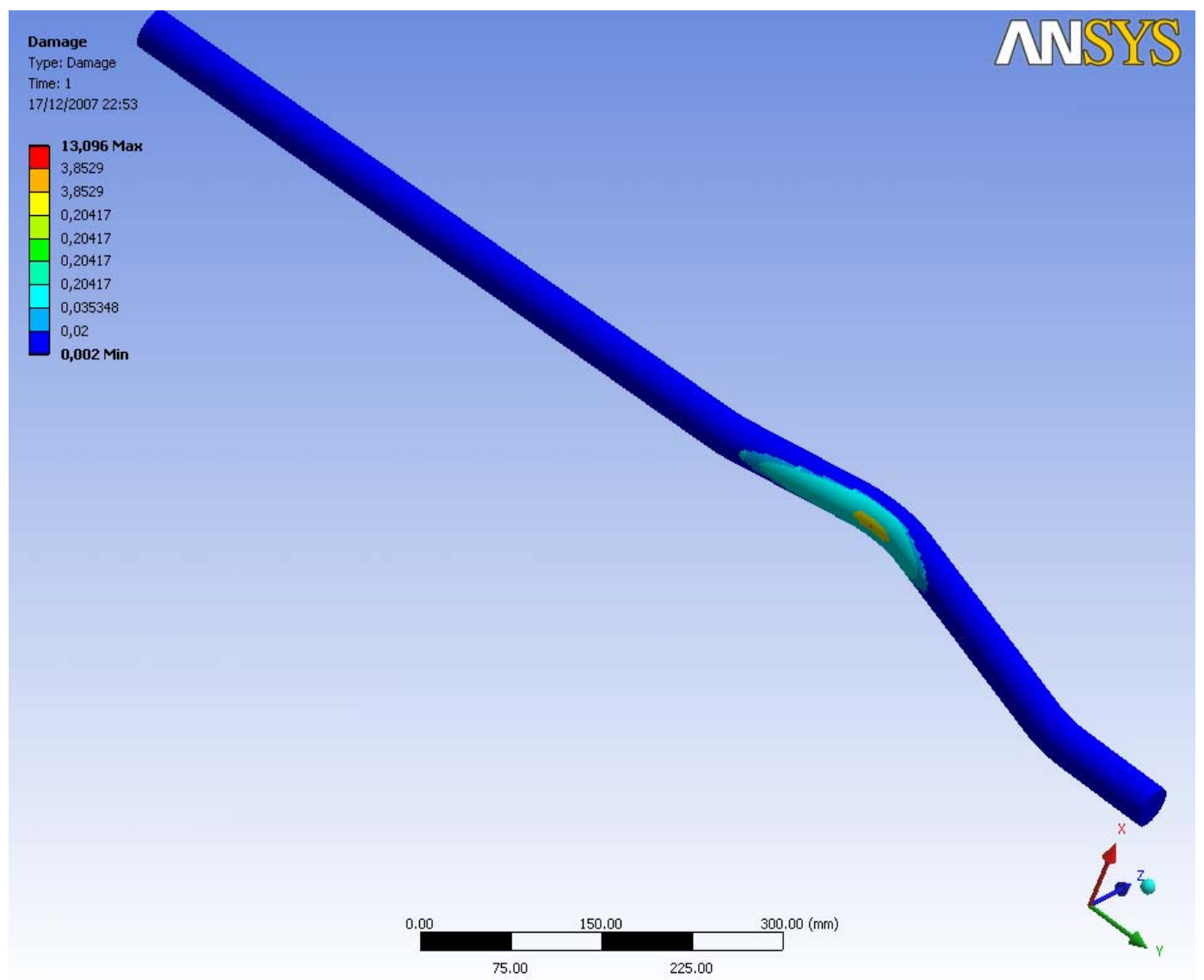

Figure III.12 The Damage Contours Of A1-1648.

For the other drag link (A1-2377) the same meshing and loading conditions were used to create the same analysis conditions. The S-N curve of the first drag link (SAE 1045) and meshed drag link are shown below. Hexahedron elements were used for meshing. After meshing operation 15180 elements and 70375 nodes were created. The fatigue strength factor calculated as 0.44 by using Equation II.26 and Table II.1 for surface factor, Equation II.28 and II.29 for size factor, Table II. 2 for load factor . As a result, 0.44 was used for fatigue strength factor. As mentioned before Soderberg Mean Stress Correction Method was used to correct the mean stress effect. The fatigue life, safety factor and damage factor for the design life (100.000 cycles) are shown in the Figure III.14, 15 and 16 respectively. It can be said that, the fatigue life of A1-2377 is greater than the A1-1648. And it also meets the design life reguirements. So, from now on, the drag link A1-2377 will be used for the following analysis and tests. 


\section{SAE 1045_153 HB - Alternating Stress}
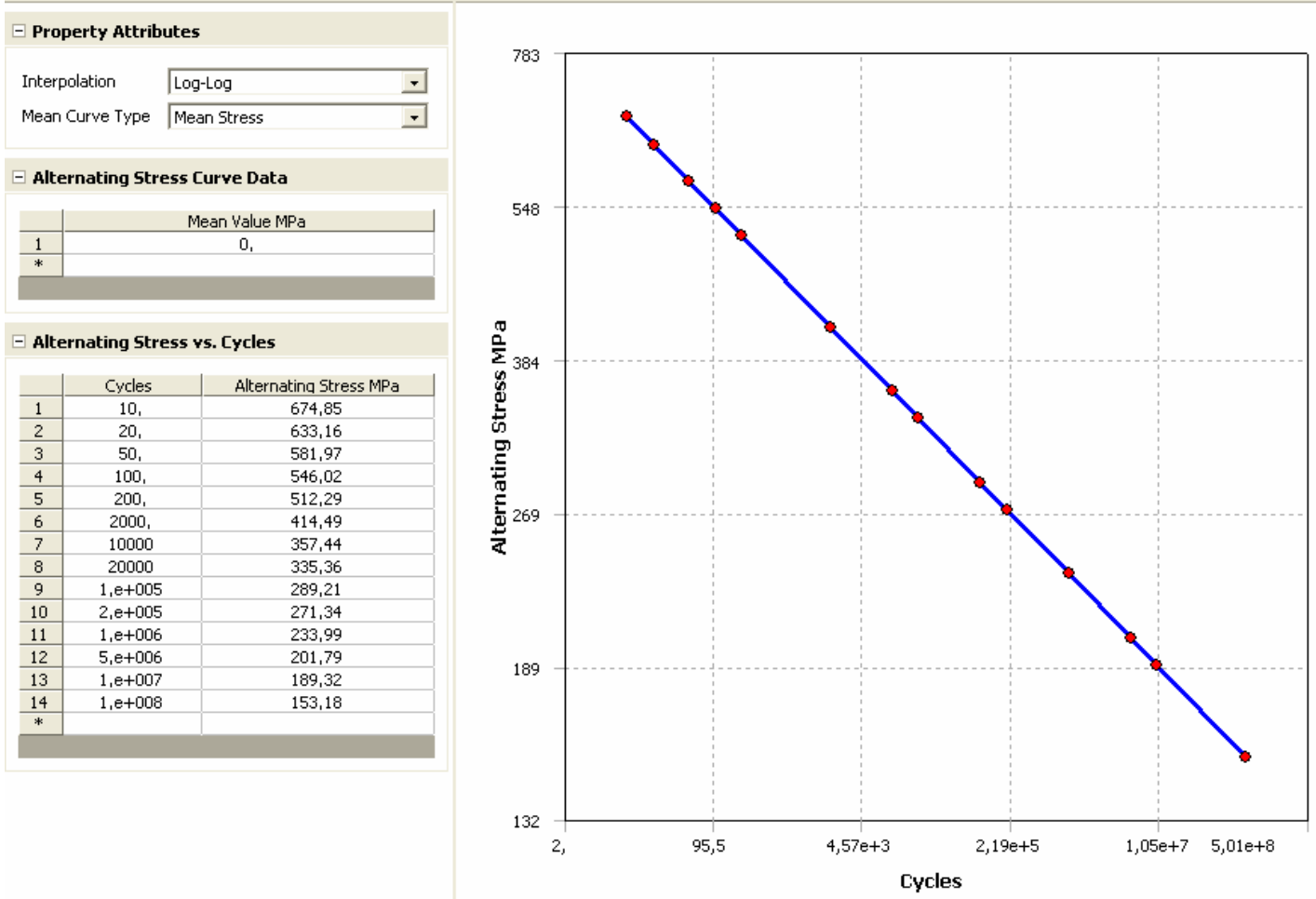

Figure III.13 The S-N Curve Of A1-2377 In Log -Log Scale (SAE 1045 Normalized)

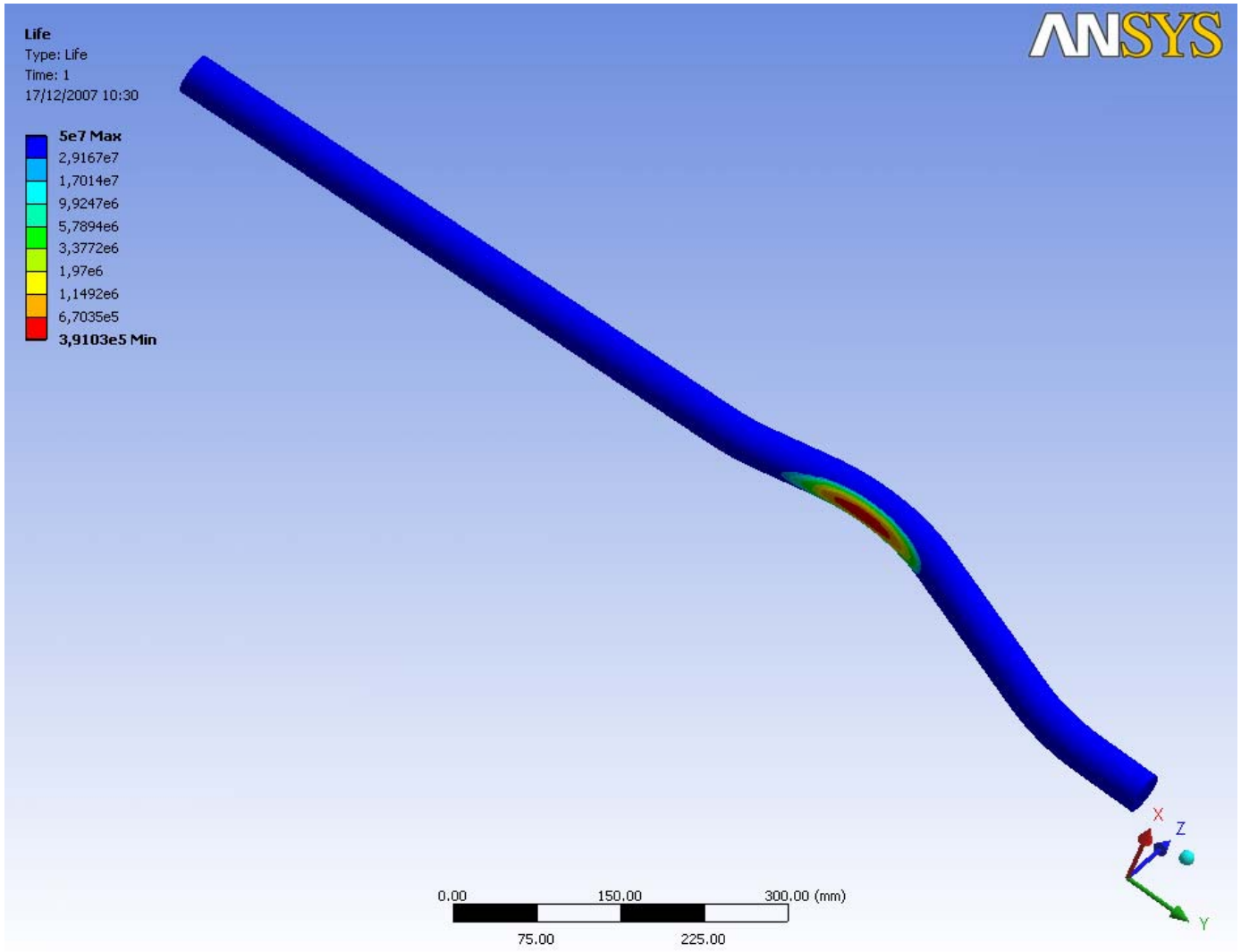

Figure III.14 The Fatigue Life Of A1-2377 In Cycles. 


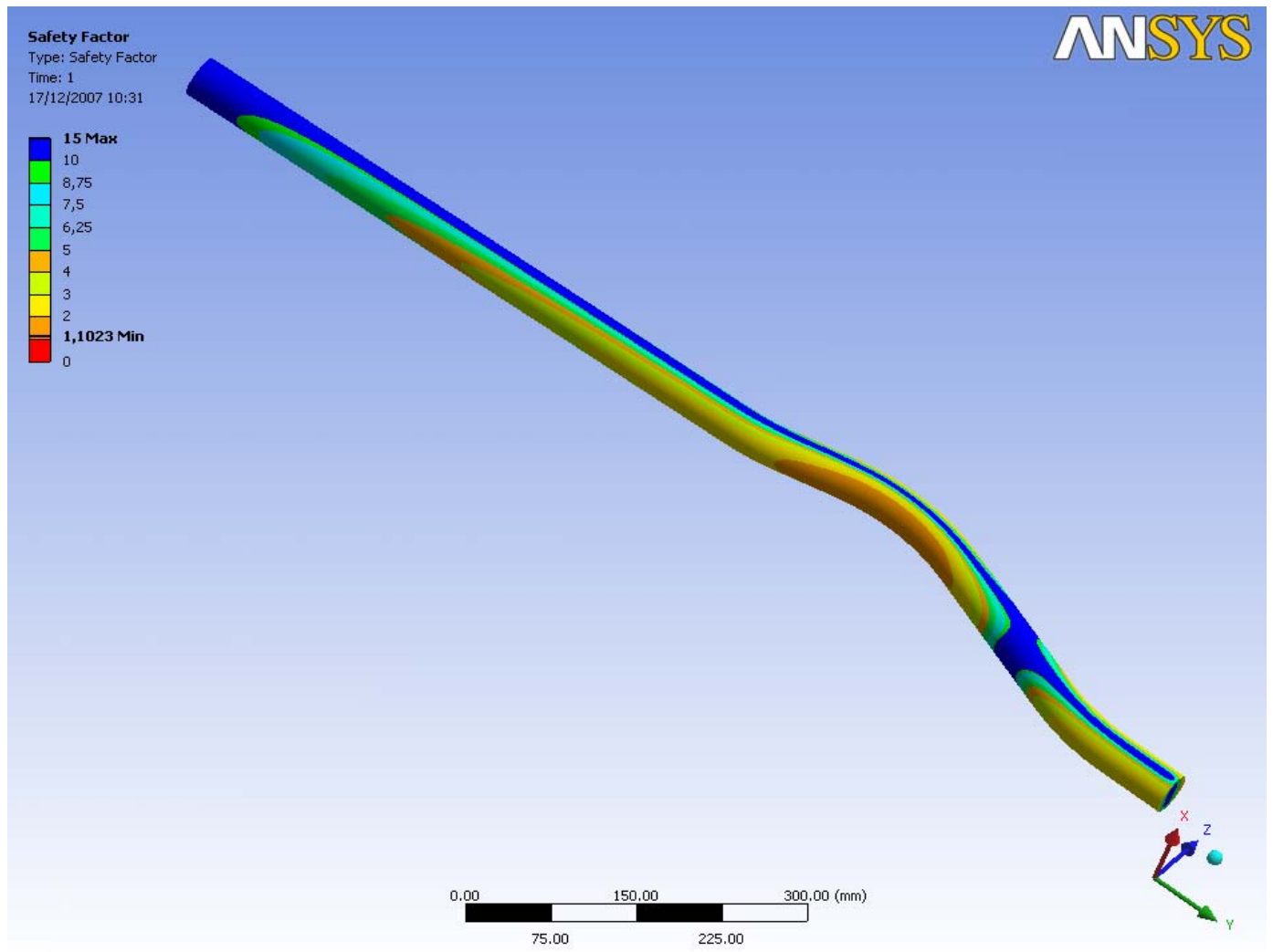

Figure III.15 The Safety Factor Of A1-2377.

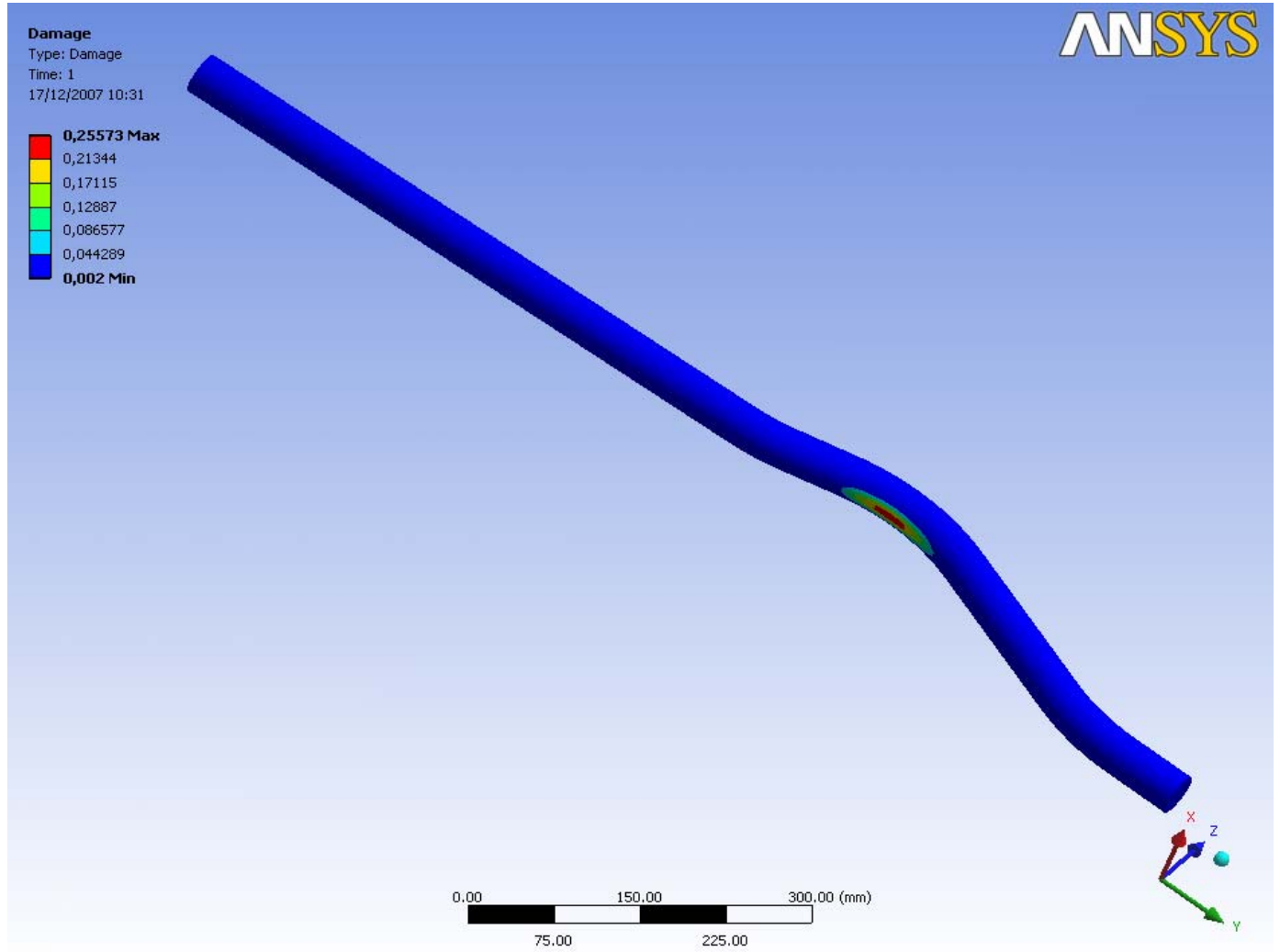

Figure III.16 The Damage Factor Of A1-2377 . 
The test and analysis resuts are shown in the Table III. 3 . The numerical life results correlations for both of these two drag link are not perfect. But for the fatigue litaratures it can be said that the results are good. [2- 8]

Table III. 3 . Correlation Between The Test Results And FEA Results.

\begin{tabular}{|c|c|c|c|c|c|}
\hline $\begin{array}{l}\text { Drag } \\
\text { Link }\end{array}$ & $\begin{array}{l}\text { Results } \\
\text { From }\end{array}$ & $\begin{array}{l}\text { Breaking } \\
\text { Cycles }\end{array}$ & Breaking Area & $\begin{array}{c}\text { Target } \\
\text { Durability }\end{array}$ & Convergence \\
\hline \multirow{5}{*}{ A1- 1648} & \multirow{4}{*}{ Fatigue test } & 30.497 & \multirow{4}{*}{$\begin{array}{c}\text { Tube bending } \\
\text { area }\end{array}$} & \multirow{8}{*}{$\begin{array}{c}100000 \\
\text { cycles }\end{array}$} & \multirow{5}{*}{ Poor } \\
\hline & & 30.679 & & & \\
\hline & & 31.597 & & & \\
\hline & & 38.888 & & & \\
\hline & FEA & 7.635 & & & \\
\hline \multirow{3}{*}{ A1- 2377} & & 953.297 & Rod bending area & & \multirow{3}{*}{ Poor } \\
\hline & Fatigue & & No break & & \\
\hline & FEA & 391.030 & & & \\
\hline
\end{tabular}

It can be said that, the A1-2377 drag link meets the design reguirements . It's fatigue life for static steering conditions from the tests and FEA results is greater than the design life. So these results prove that , the drag link A1 - 2377 which has a material specifications as SAE 1045 can be used safely. The most important result is that , the minimum fatigue life area from the analysis is same as the cracking area from the fatigue tests. The cracking zone from the tests is shown in the Figure III.17 , 18 and 19 for the drag link A1-1648 .

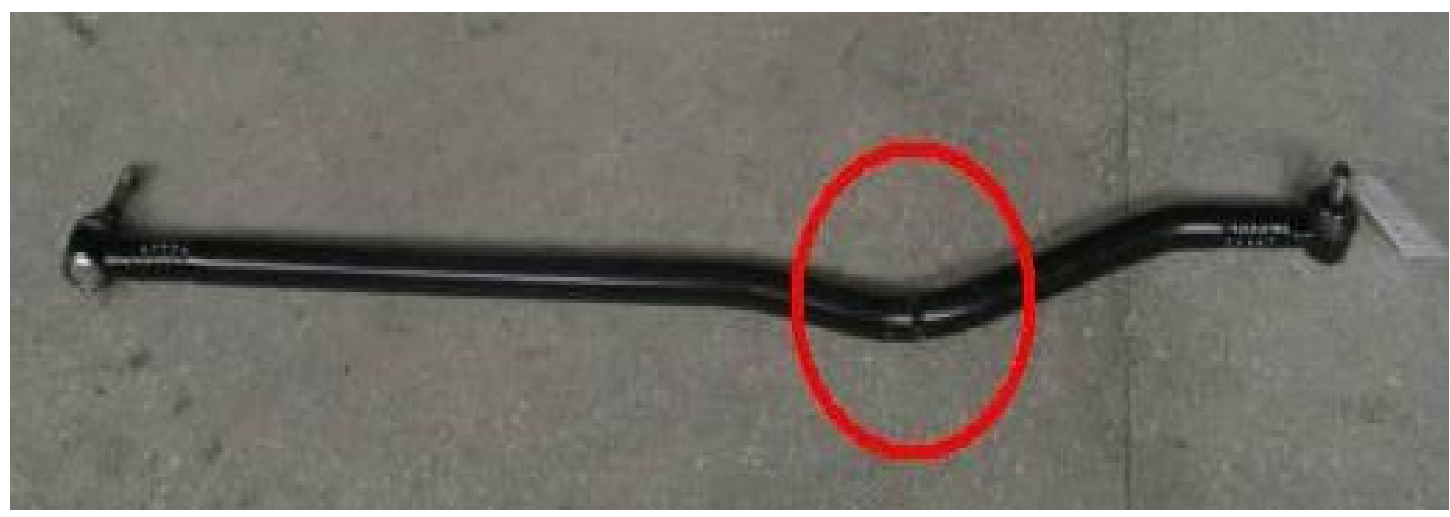

Figure III.17 The Cracking Zone From The Fatigue Tests. 


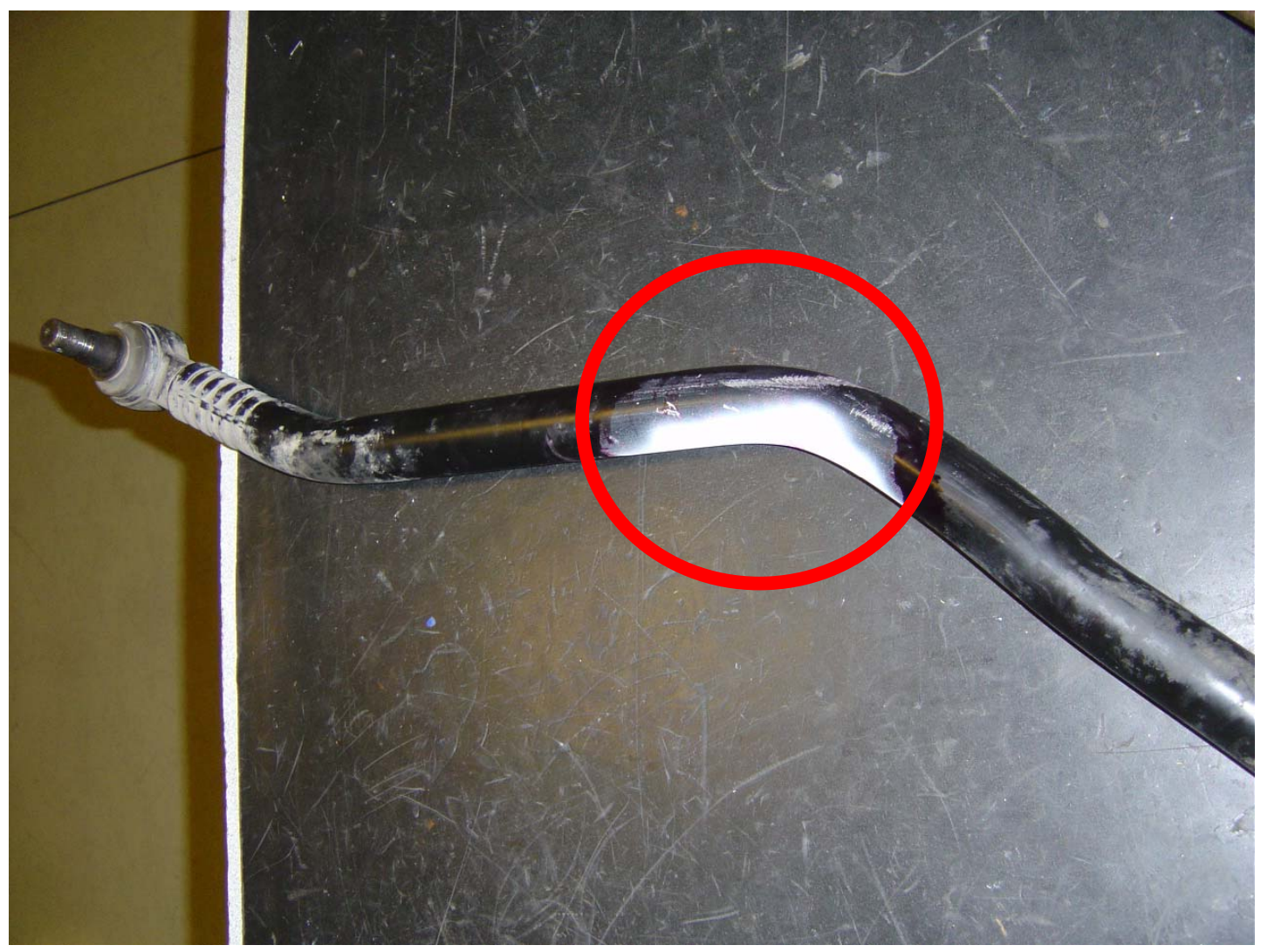

Figure III.18 A Photograph Of The A1-1648 After The Fatigue Test ( Crack Sprey Squirted On The Drag Link After The Fatigue Test To See The Cracks ).

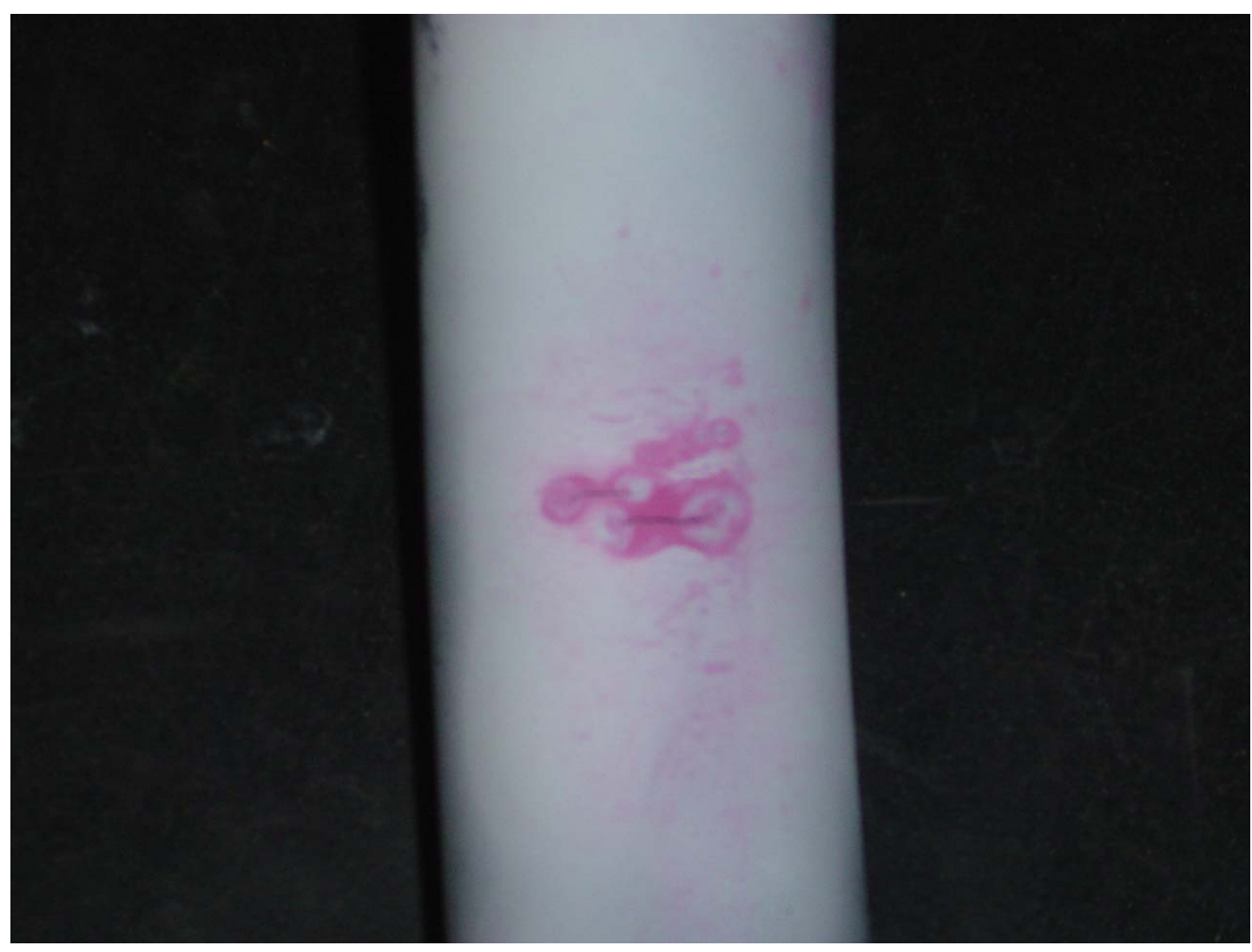

Figure III.19 Cracks Occurs At The Inferior Zone Of The Bending Area. 


\section{III.2. FATIGUE LIFE PREDICTION BY USING THE ROAD LOADS IN THE TIME DOMAIN (RANDOM VIBRATIONS)}

In this section, fatigue life prediction analysis of the drag link A1-2377 will be done by using collected road loads in the time domain. Firstly, used data collection tecnique will be explained. Finally, the fatigue life prediction analysis will be done by using the road loads. The analysis will be done in the time domain. In the section III.3. fatigue life prediction analysis of the same drag link will be done by using the same road loads and frequency domain method. The collected data is not specific to this thesis. It has been collected and used for another project about the drag links.

\section{III.2.1. Collecting Strain From The Critical Points}

As mentioned before, the collected road loads are not specific to this thesis. They have been used in the another project which examined the static stress in the drag link A1-2377 [11]. In the engineering problems, for analysing the stress conditions of a random point in the bodies, measuring or collecting the stress data is not possible. In spite of this, strain components can be measured and stress can be calculated using of them. So, strain gauges had been used to collect strain data from the bending area of the drag link at the different road and driving conditions. After collecting strain data, stress at the bending zone and the loads at the extremity area near the pitman arm have been calculated by using the Hookes's equations. [11]

Strain gauge rosettes had been settled at the critical areas at different angles for colllecting the three dimensional strain data (Figure III.20) . $500 \mathrm{~Hz}$ had been used as sample rate in the data collection operation. On the other hand, ESAM Traveller Plus 32 channel computer -controlled signal conditioning amplifier had been used as data collection system (Figure III.21) . The test bus which had contained the test drag link had been drived at different road conditions on the test track. Firstly, the bus had been drived at a $20 \mathrm{~km} / \mathrm{h}$ velocity at the straight road . After that, the bus had been drived to a bended and sloping road at the same velocity. Thirdly, the bus had been drived on the road which has Albenian pavements at a $20 \mathrm{~km} / \mathrm{h}$ velocity. And the finally the bus had been drived at a left sloping road at $50 \mathrm{~km} / \mathrm{h}$ velocity and it 
had been stopped. As a result, a 210 seconds duration strain data had been collected. The data have included the strain data at $\mathrm{X}, \mathrm{Y}$ and $\mathrm{Z}$ axises.

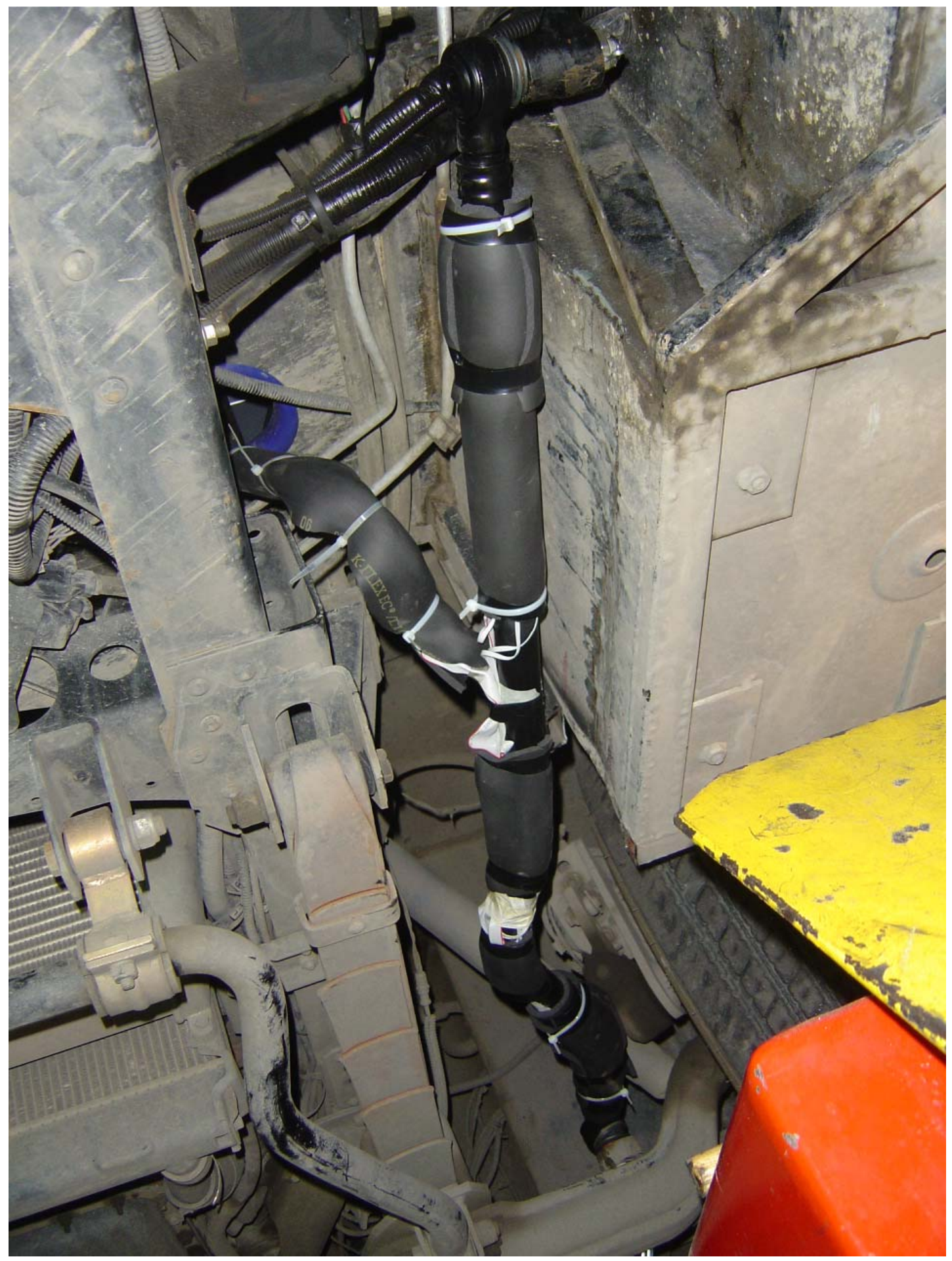

Figure III.20 Strain Gauges On The Drag Link. 


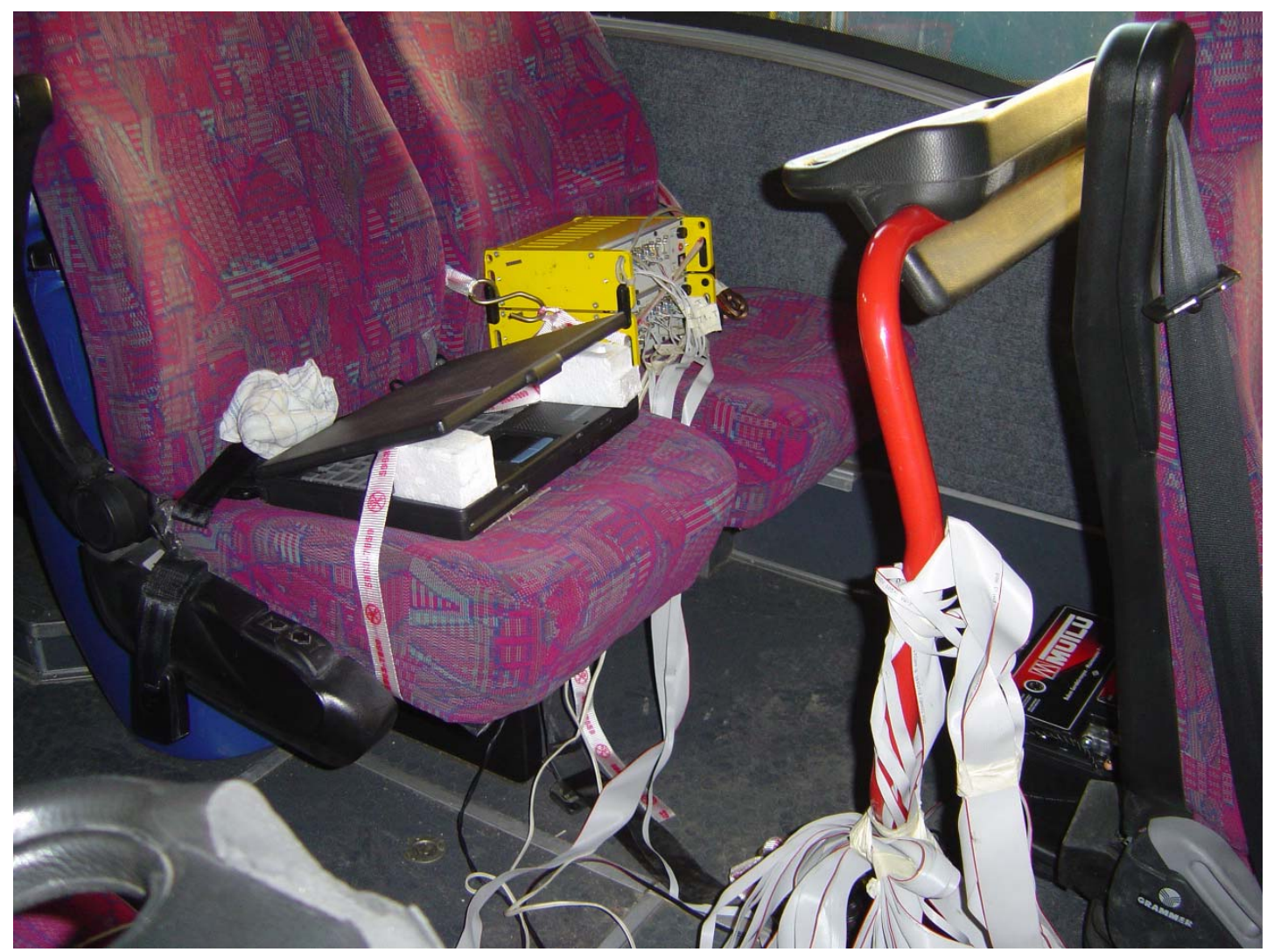

Figure III.21 ESAM Traveller Plus 32 Channel Signal Conditioning Amplifier In The Bus.

Stress values on the drag link at the strain gauges points had been calculated by using the measured strain values and Hooke's equations. And the finally load values at the extremity point near the pitman arm had been calculated by using the calculated stress values for the $\mathrm{X}, \mathrm{Y}$ and $\mathrm{Z}$ axises. But in this thesis, it is decided to use only the load values at the $\mathrm{Y}$ axis direction . Because, the $\mathrm{X}$ and $\mathrm{Z}$ axises values are so small as negligable. So, the assumtion is that, there is only the $\mathrm{Y}$ axis loads on the drag link. As a result, to simplify the fatigue life calculation, only the Y axis values will be used in the fatigue analysis. 


\section{III.2.2. Fatigue Life Prediction Analysis By Using The Road Loads}

As the proceeding fatigue analysises, the fatigue analysis was made by using Ansys Workbench which is a FEA program. But before making the analysis, data filtering operations were made for the Y direction road loads. For filtering NCode Glyphworks program was used. The PSD (power spectral density) graph of the road loads has been drawed by using the GlyphWorks for examining load spectrum in the frequency domain (Fig. 21) .

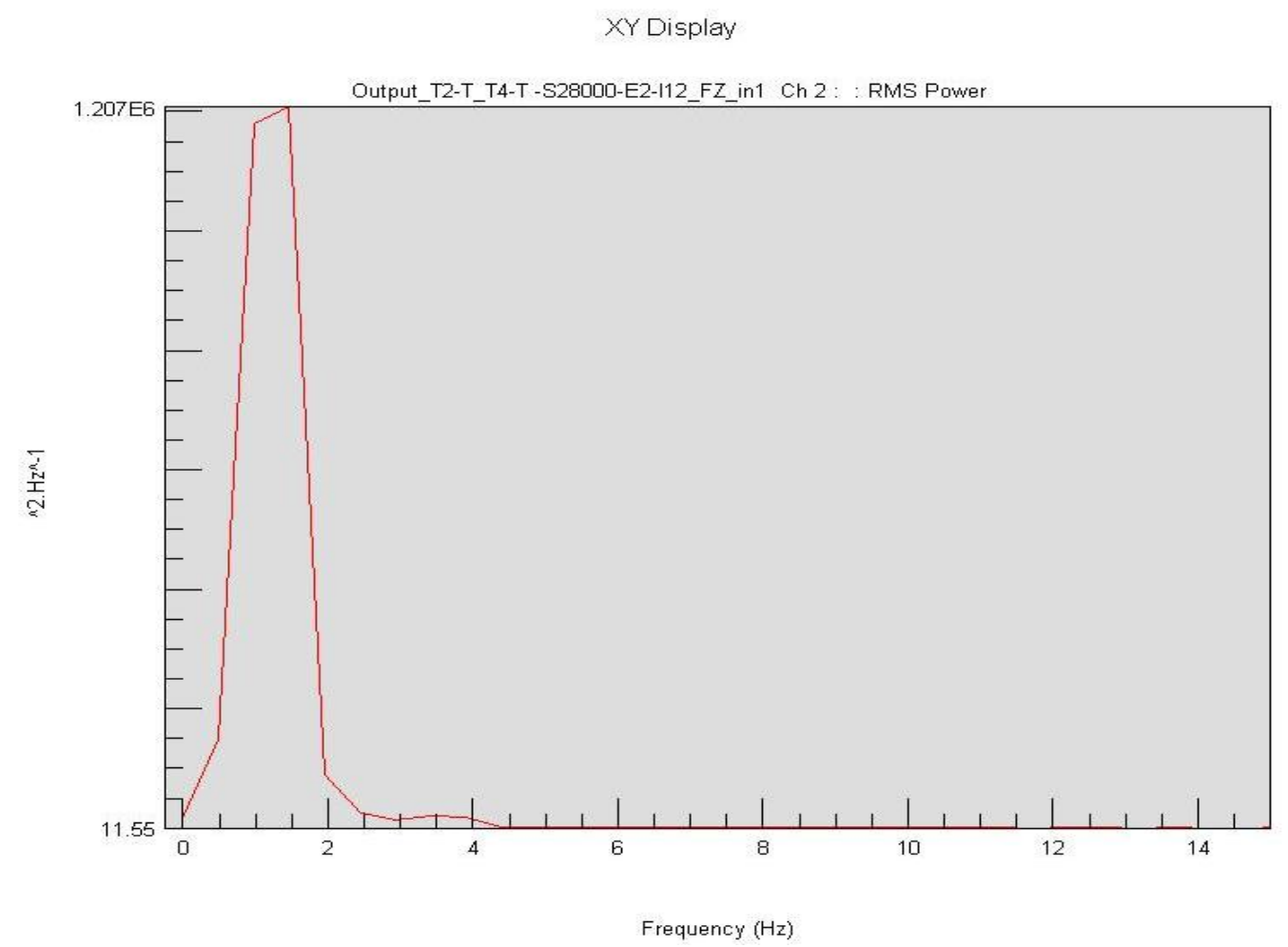

Figure III.22 PSD Graph Of The Loads Before The Filtering.

Figure III.22 shows the PSD values versus the frequency in Hz. In the graph, it can be easily considered that , there are some loads which have larger frequencies than $5 \mathrm{~Hz}$ and also are relatively smaller than the others. These type of loads have no effect on the fatigue life [13] . So they can be neglected. In the following analysises, the road loads that have the frequency larger than $6 \mathrm{~Hz}$ were filtered. 


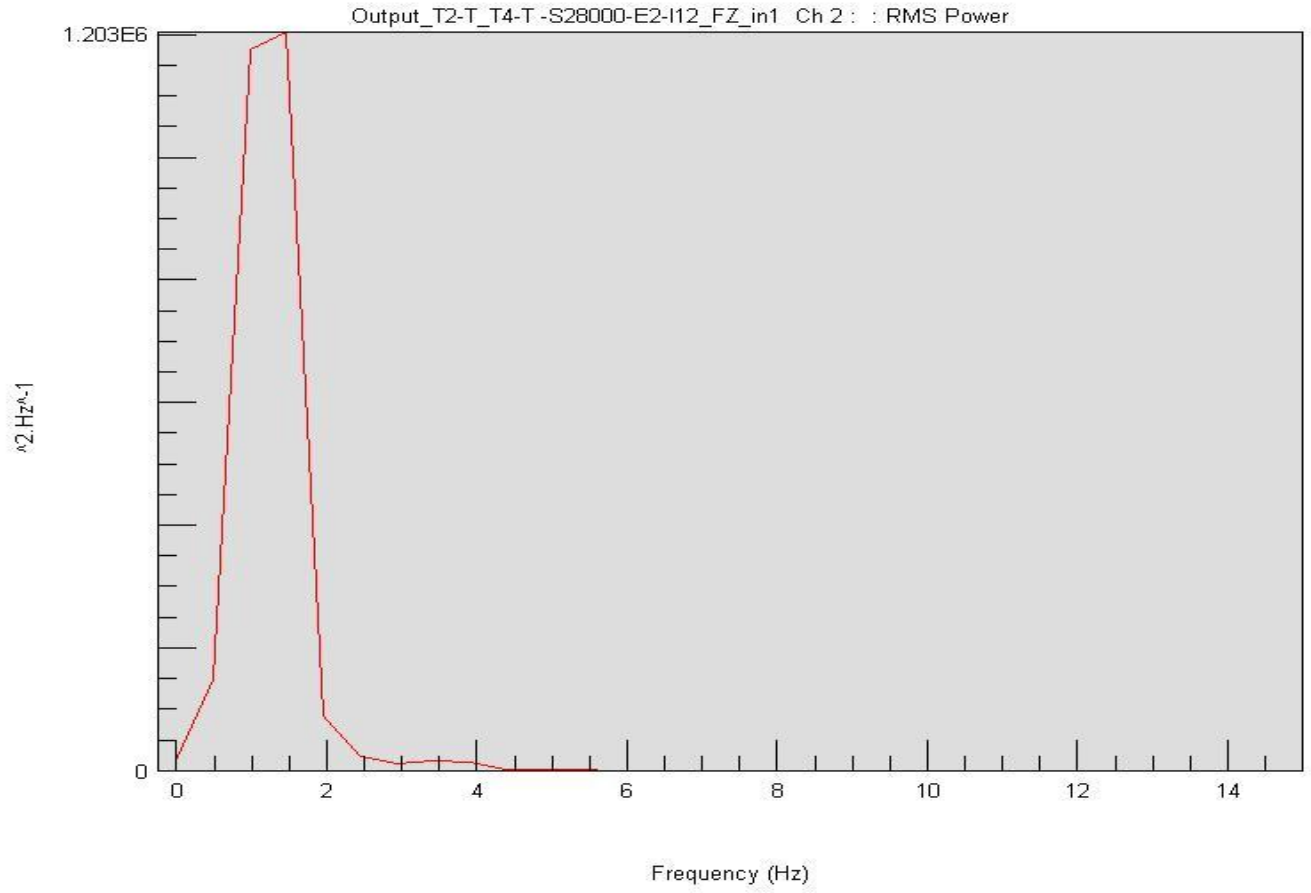

Figure III.23 PSD Graph Of The Loads After The Filtering

A figure from the filtering operation by using the GlyphWorks is shown in the Figure III.24.

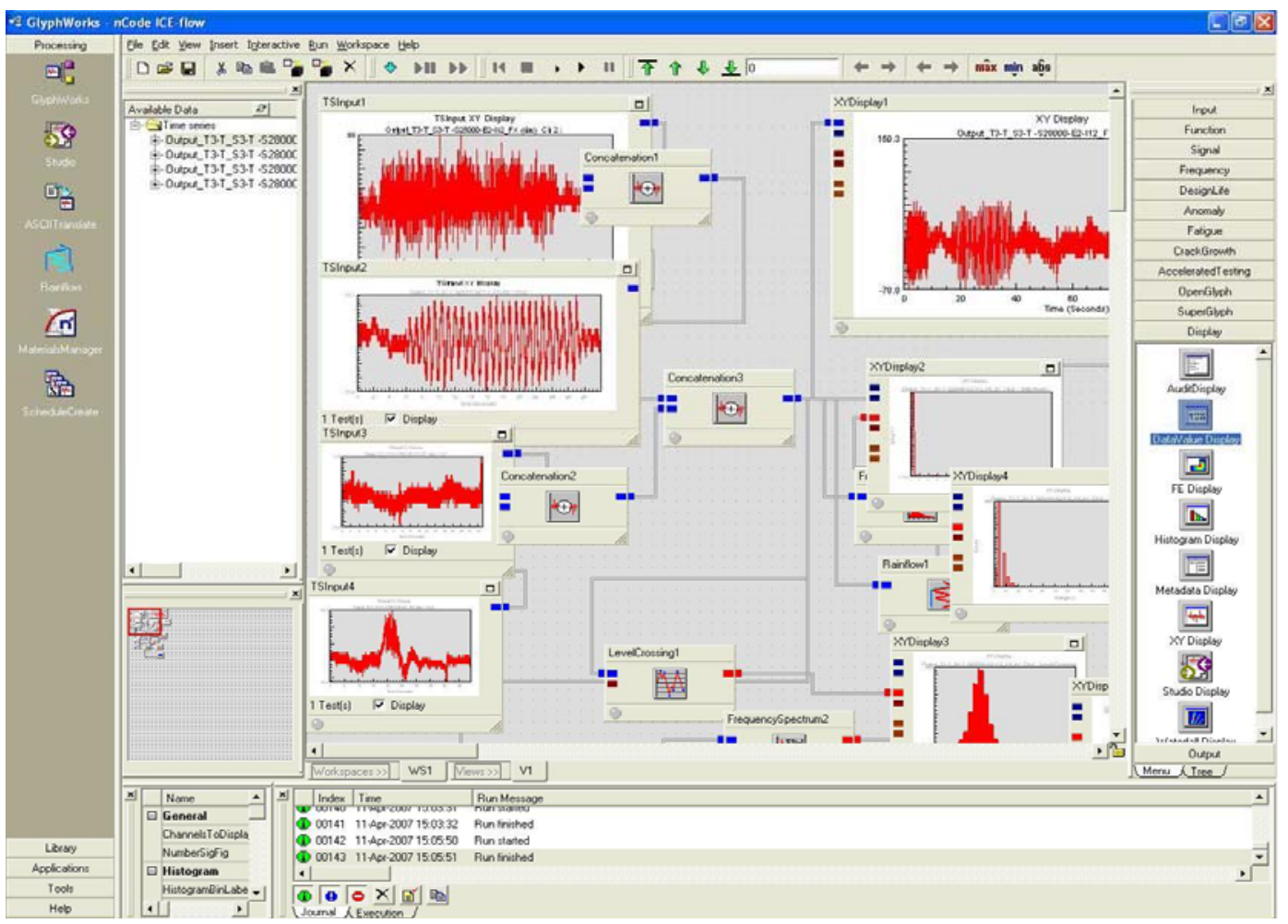

Figure III.24 A View Of Glyphworks And The Filtering Operation. 
Rainflow histogram and load - time graphs are shown in the Figures III .25 and 26 respectively.
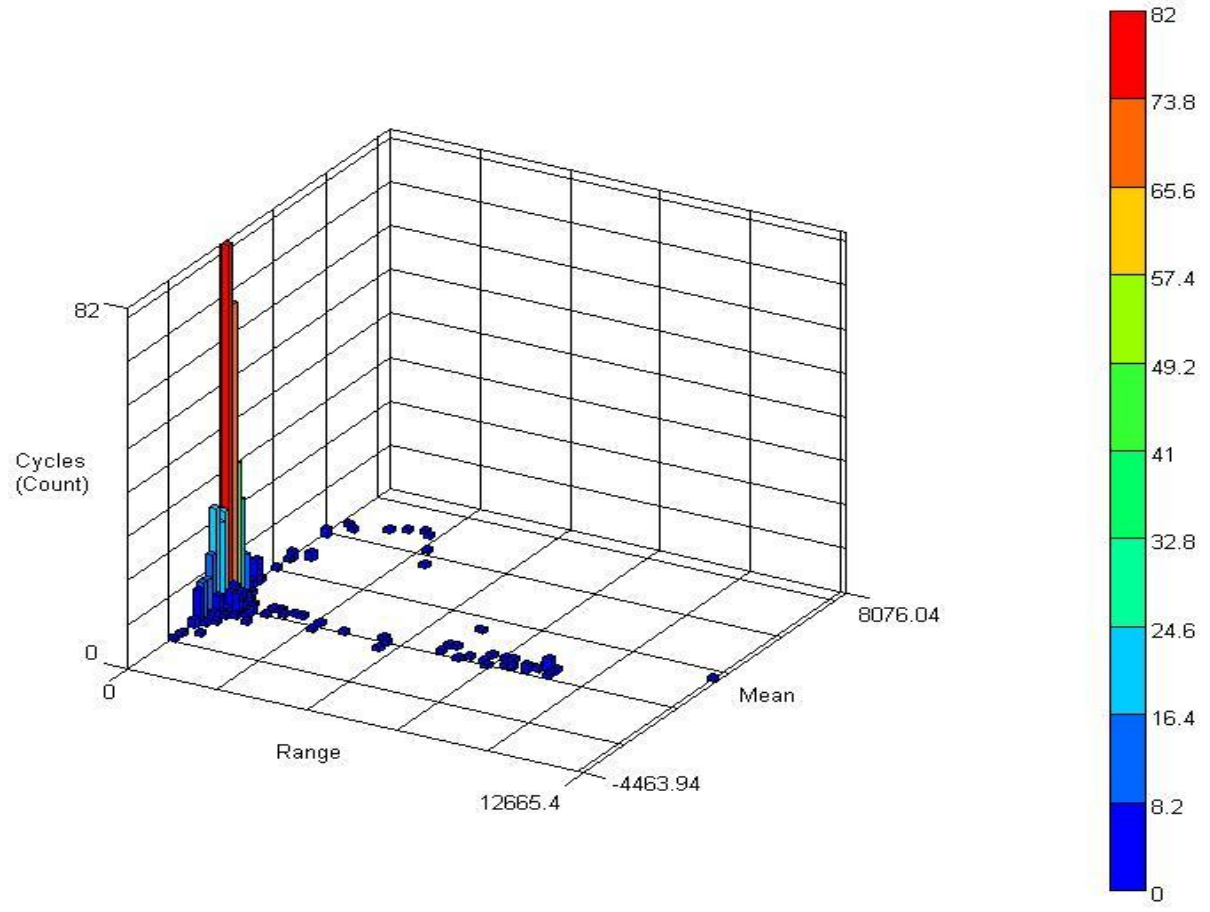

Figure III.25 Rainflow Histogram Of The Loads.

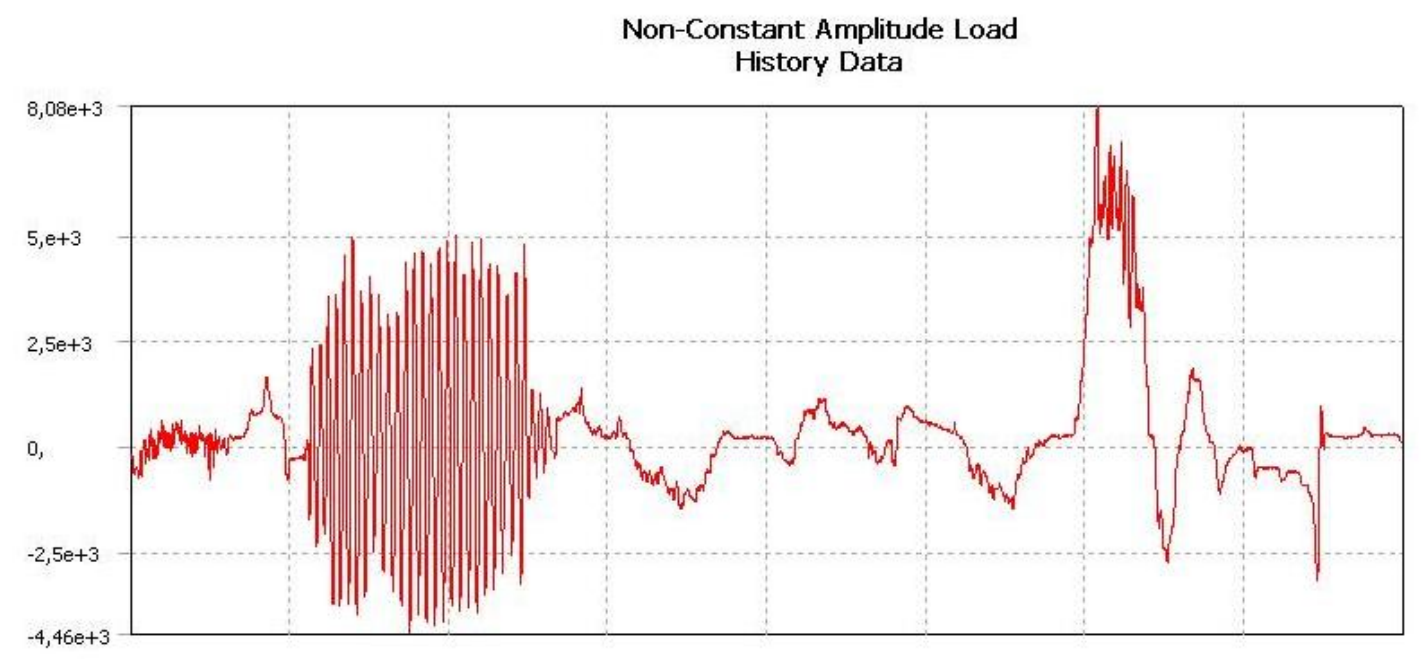

Figure III.26 Load (N) Vs Time (Seconds) Graph . 
As the proceeding analysises, stress- life analysis type has been choosed for this analysis, because of it is a high cycle fatigue . And also Soderberg Mean Stress Theory has been used to correct the predicted fatigue life by using the mean stress effect. On the other hand, fatigue life prediction has been made by using the absolute maximum principal stress component because of the obligation in the vibration fatigue analysis . It means that, there is only chance to use the absolute maximum principal stress as the stress component in the vibration fatigue. So , absolute maximum principal stress is used in the time domain as the stress component for predicting fatigue life to make a real comparation between the results from time and frequency domains. The fatigue life contour disturbition is shown in the Figure III. 27.

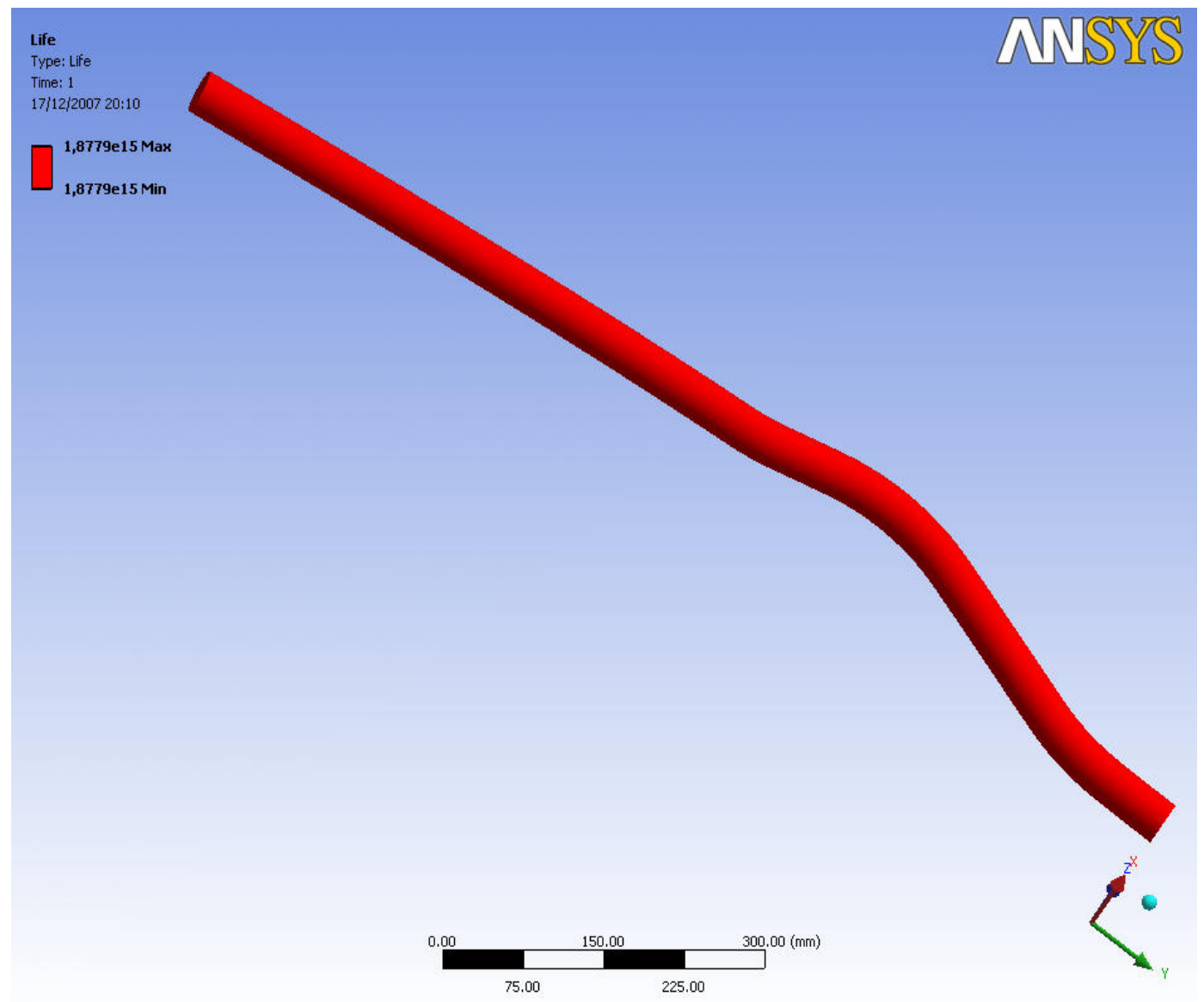

Figure III.27 Fatigue Life Distribution

The minimum fatigue life is calculated as $1,8779 \times 10^{15}$ cycles. Because of the miniumum life value is larger than the maximum cycles in the material S-N curve 
(Figure III.13), the all of the life contour color is red. Ansys uses the red colour for all of the fatigue life contours if the calculated minimum life in the body is smaller than the infinite life in the S-N curve.

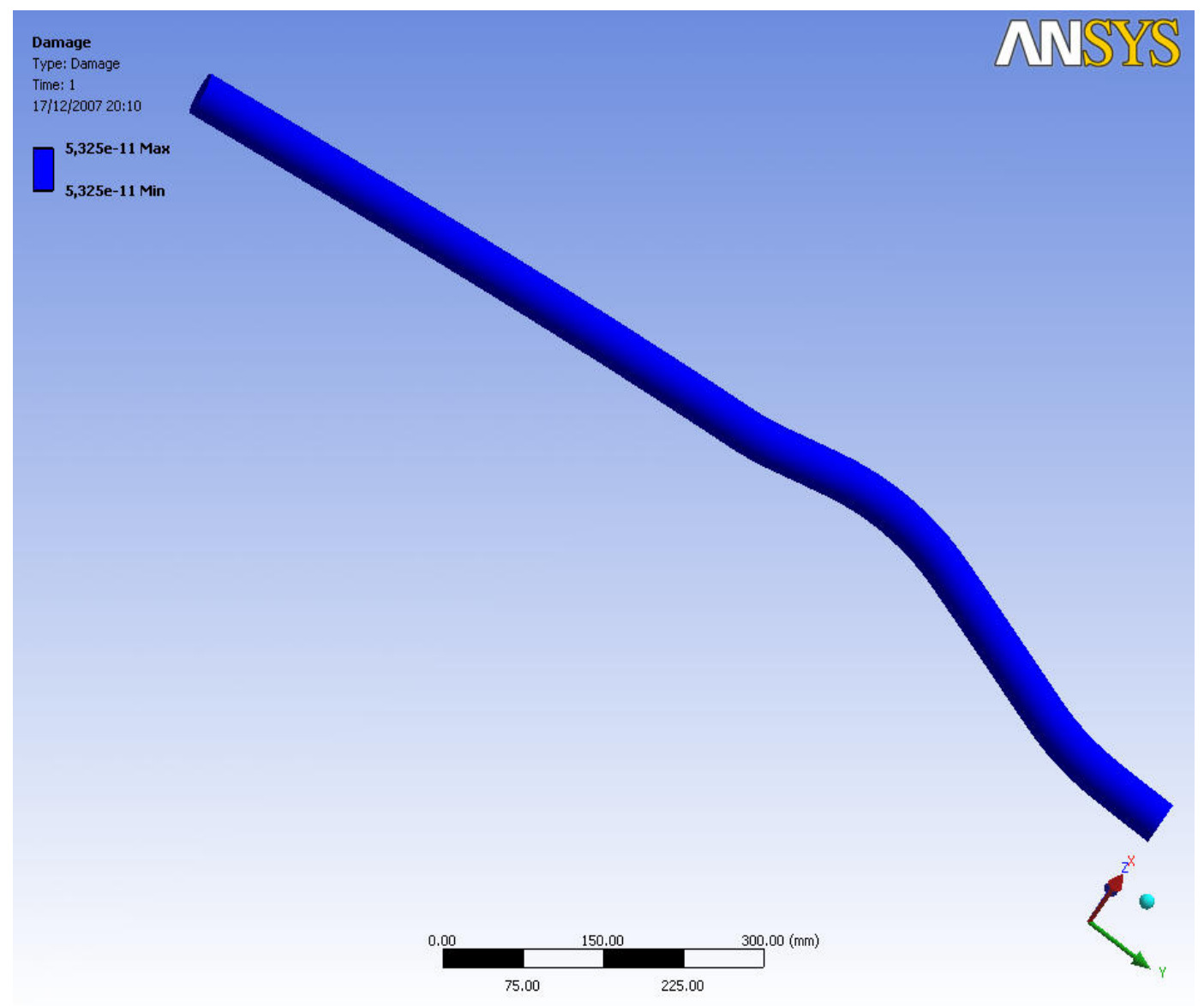

Figure III.28 Damage Distribution .

Damage distribution on the drag link is shown in the Figure III. 28. The value all over the body is $5,325 \times 10^{-11}$. As mentioned before, the design life for the all of the analysises is 100.000 cycles. The damage factor equation (Eq. 3.1) can be easily used for the checking the minimum life result .

$$
\begin{aligned}
& \text { Damage }=\frac{\text { Life }_{\text {Design }}}{\text { Life }_{\text {Available }}} \\
& 5,325 \times 10^{-11}=\frac{100000}{\text { Life }_{\text {Available }}} \\
& \text { Life }_{\text {Available }}=1,8779 \times 10^{15} \text { cycles }
\end{aligned}
$$




\section{III.3. FATIGUE LIFE PREDICTION BY USING THE ROAD LOADS IN THE FREQUENCY DOMAIN (VIBRATIN FATIGUE)}

Fatigue life calculation have been made in the section III.2 in the time domain. In this section fatigue life calculation of the drag link in the frequency domain will be done. The results from the time domain and frequency domain will be compared. And the finally, investigation of that if there is a vibration fatigue on the drag link or not will be done. For making fatigue analysis in the frequency domain ( vibration fatigue ), Msc. Nastran and also Glyphworks will be used. The vibration fatigue analysis procedure is shown below. [2]

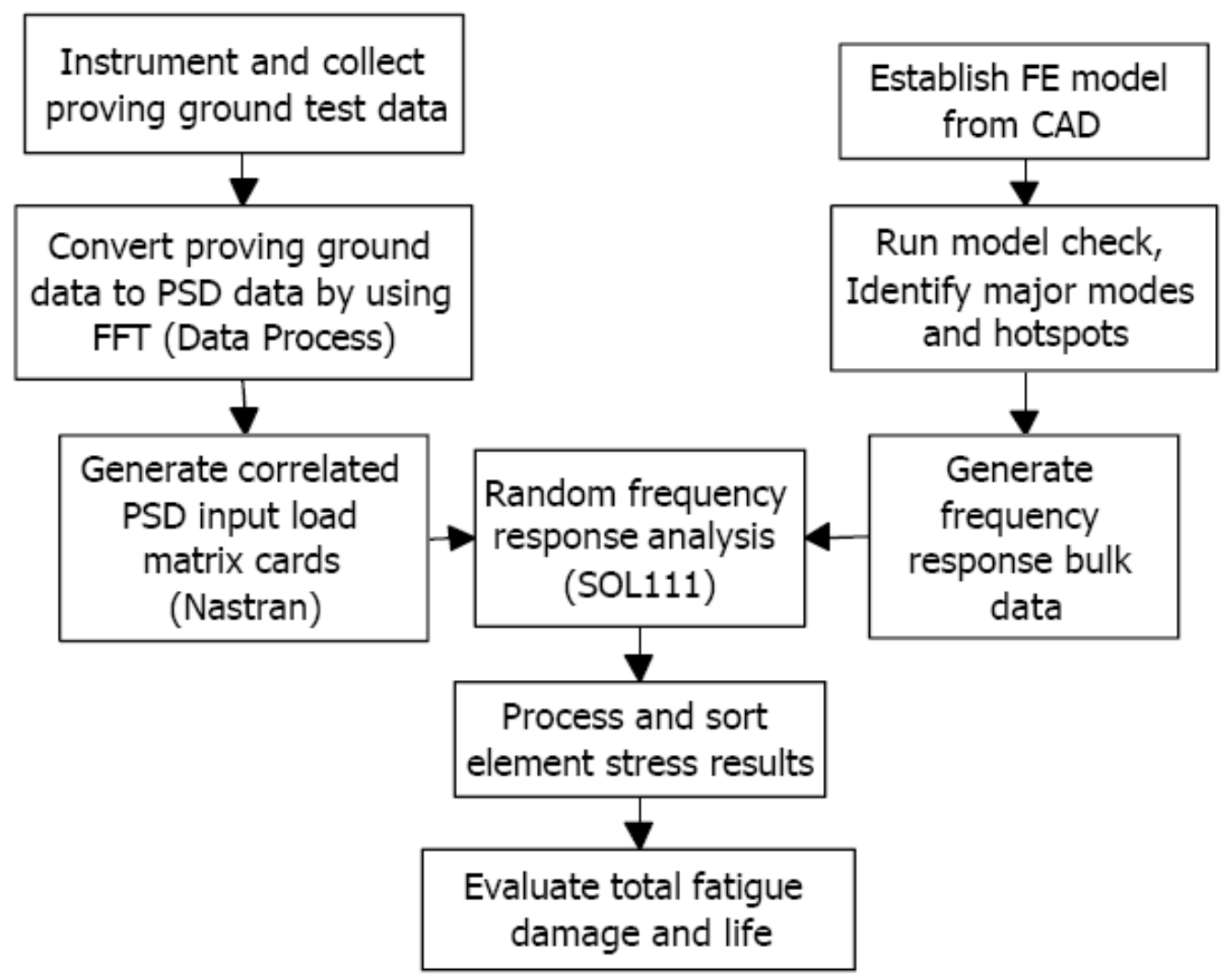

Figure III.29 Vibration Fatigue Procedure. 
Data collection tecnique was explained before. Collected load data (as declared before only $\mathrm{Y}$ direction loads will be used for fatigue analysis in frequency domain as in the time domain) were used to calculate PSD by using the GlyphWorks. The GlyphWorks has a glyph which calculates the PSD by using the Fast Fourier Transformation (FFT). After that, a frequency response analysis were done in Msc. Nastran with a unit force to find the dynamic behaviour of the drag link. By using the frequency response analysis results it is interpreted that if there is a vibration fatigue on the drag link or not. And the finally, vibration fatigue analysis were done by using calculated transfer function which is calculated from frequency response analysis and calculated PSD. The Dirlik fatigue damage theory was used to evaluate the fatigue life of the drag link. It is the most used and popular fatigue damage theory for the vibration fatigue. On the other hand, Soderberg Mean Stress Theory and absolute maximum principal stress component are used as the proceeding analysis .

The first step of the vibration fatigue analysis is to make a frequency response analysis. To make a frequency response analysis as the first step of the vibration fatigue analysis is used to obtain the transfer function. The transfer function is used to find the response signals to the input signals. So , to find the correct transfer function is the most important part of the vibration fatigue analysis. Because, if the wrong or less correct transfer function is found, the response of the body to the input signals will not be correct. To obtain a correct transfer funtion; selecting the correct frequency interval is the first requirement. The frequency interval must be minimum 1.5 times of the PSD frequency interval [16]. On the other hand, selecting the correct frequency resolution of the transfer function has also influence to capture all of the input PSD [17]. If the frequency pitch for the interval is small enough, all of the input PSD points is used to find the fatigue life. If it has no enough points in the resolution, there will be some missed point from the input PSD. This situation produces less damage relative to the real. Because the interpolation is occured within the input PSD at frequency points in the transfer function. The opposite of this situation is also true. That is to say, if the defined frequency pitch in the transfer fuction is smaller than the frequency pitch in the input PSD, there will be more damaging effect relatively to the real and it consumes more time. This is illustrated in Figure III. 30 for different two cases. The " $x$ " axis represents the frequency and the "y" axis represents the PSD values in the Figure III.30. 


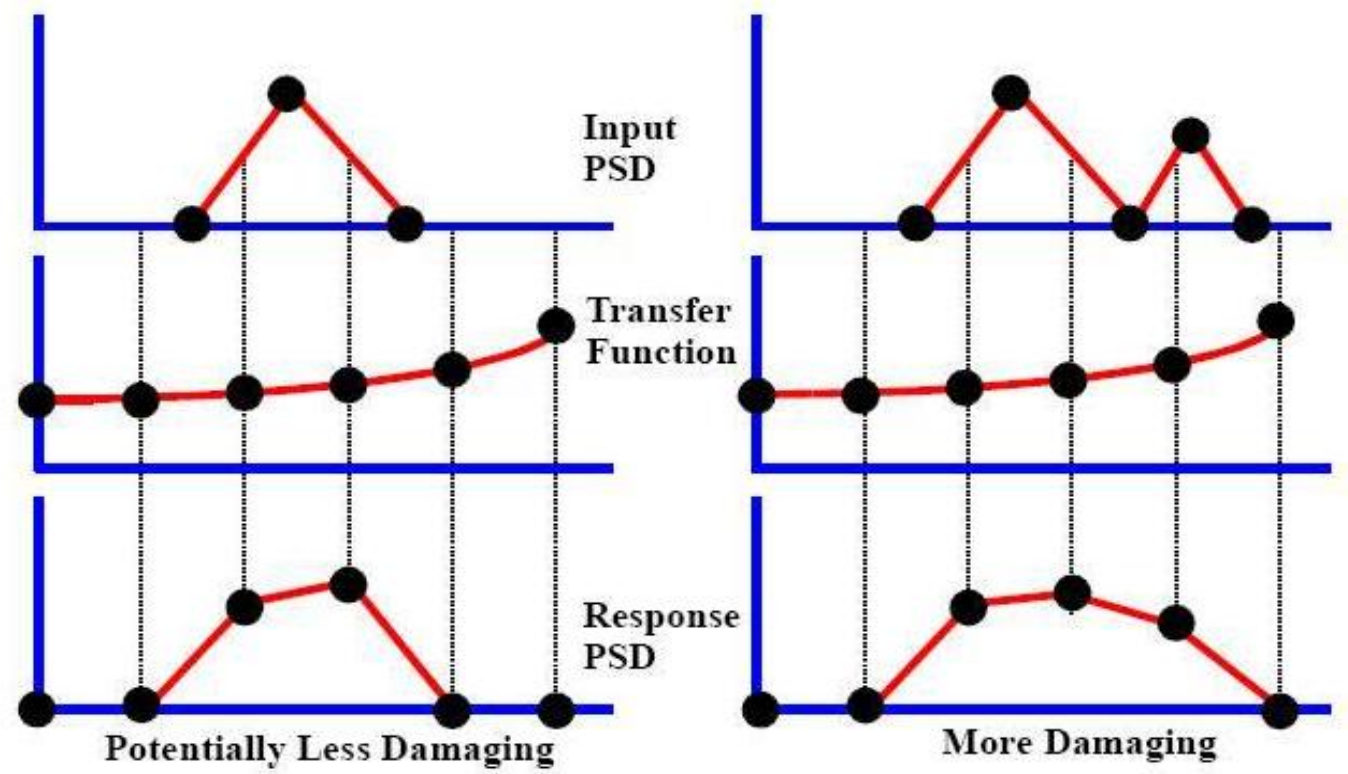

Figure III.30 Effect Of Frequency Resolution.

Because of the this situation explained above the frequency interval was choosen as $0-30 \mathrm{~Hz}$ (the interval is $0-14 \mathrm{~Hz}$ approx. in the input PSD) and the frequency pitch was selected as 0.5 . The frequency pitch in the input PSD is approximately same as the selected pitch. The frequency response analysis was made and the maximum principal stress contours at $0 \mathrm{~Hz}$ ( static conditions) are shown below.

Figure III.31 Maximum Pricipal Stress Contours At $0 \mathrm{~Hz}$. 
As shown in the Figure III.31, maximum principal stress at zero Hertz occurs at node 6019 . It is calculated as $7.82 \times 10^{-3}$ for a unit force. Unit force is used to calculate the transfer function of the drag link. The real force have been defined after the frequency response analysis as PSD. Maximum principal stress - frequency graph at $0 \mathrm{~Hz}$. and node 6019 is shown in the Figure III. 32.
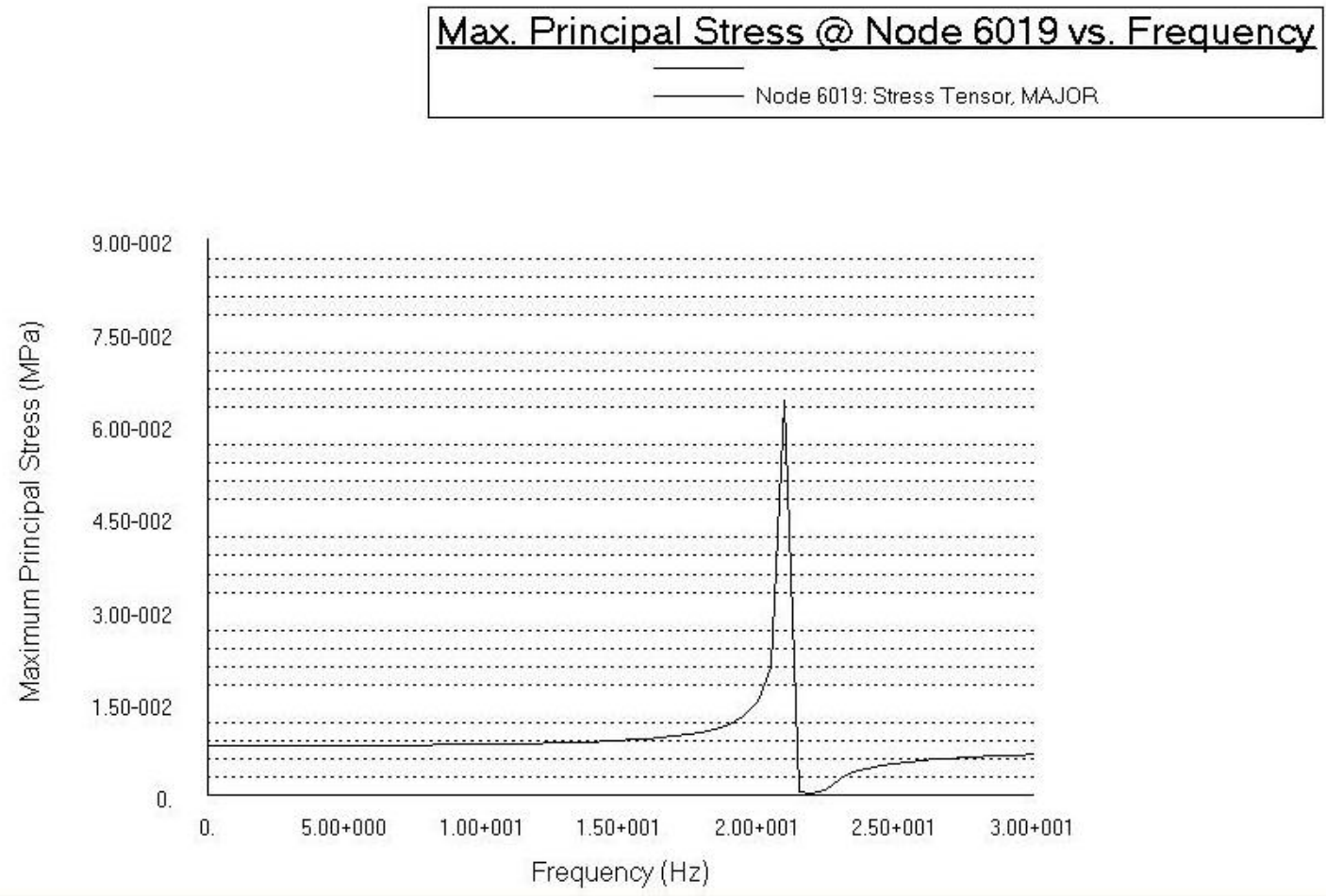

Figure III.32 Maximum Pricipal Stress Vs. Frequency.

The drag link responses the force as a static force up to $21 \mathrm{~Hz} .21 \mathrm{~Hz}$ is the first natural frequency of the drag link. The drag link's response for input force at 21 $\mathrm{Hz}$. has a peak value. So, the system acts approximately staticly up to $21 \mathrm{~Hz}$. After making the frequency response analysis, vibration fatigue analysis has been done. The input force PSD graph is declared in the Figure III. 23. Msc. Nastran calculated the output stress PSD and other output results by using the input PSD and the transfer functions calculated from the frequency response analysis. And the finally, the vibration fatigue life by using the output results and Dirlik Method was predicted. The predicted life contour is shown in the Figure III. 33 . 


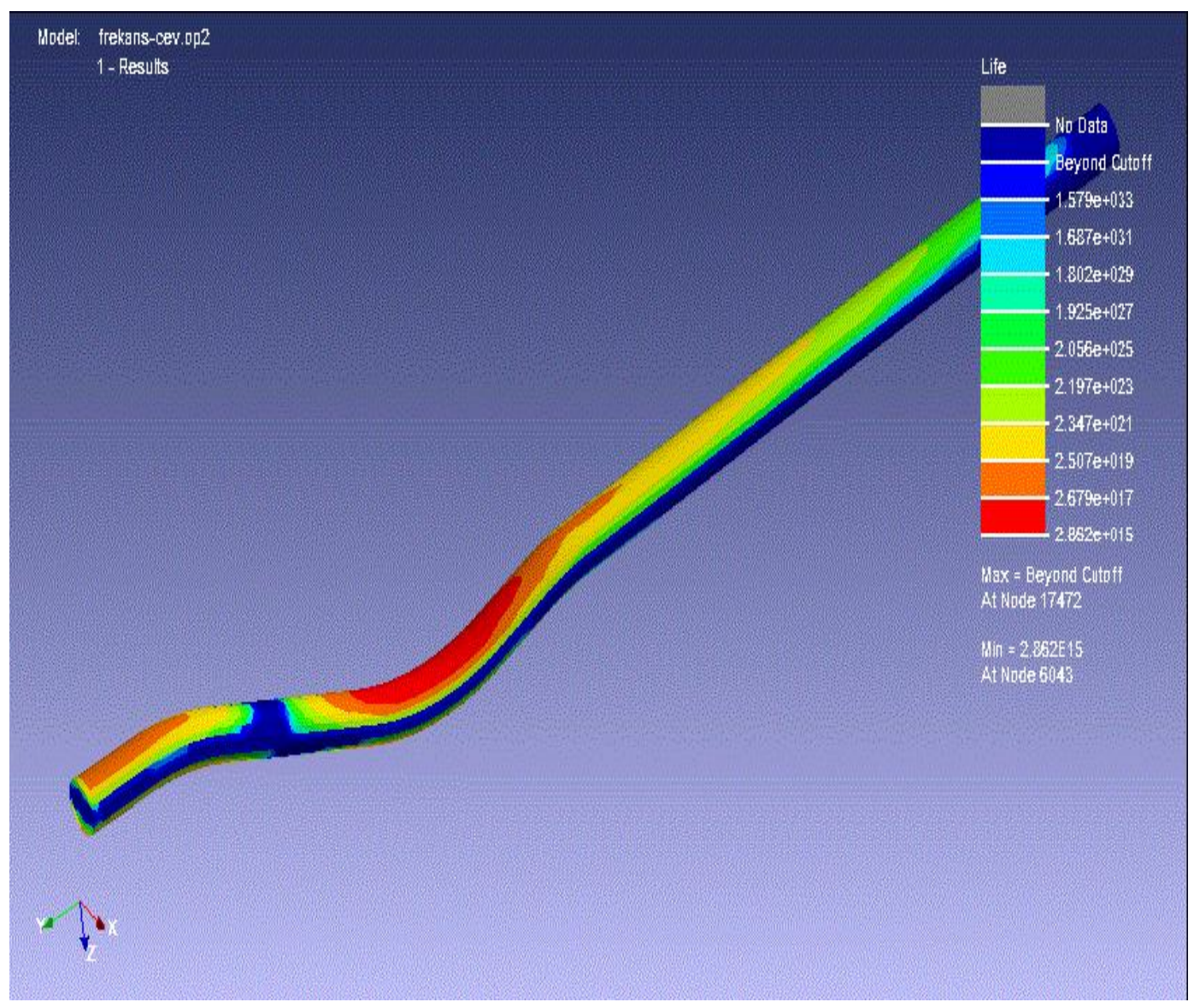

Figure III.33 Vibration Fatigue Life Contours.

The minimum predicted life occurs at the inferior bending zone ( like the proceeding analysises). Predicted minimum life occurs at node 6043 and the value is $2.862 \times 10^{15}$. The life result from the frequency domain converges the life predicted from time domain.This is because, the first natural frequency of the drag link is greater than the maxiumum frequency of the input PSD. So there is no vibration fatigue for this input PSD. The predicted life values from time domain and frequency domain are shown in the Table III. 4.

Table III.4 Predicted Life Values From The Time Domain And Frequency Domain.

\begin{tabular}{|c|c|c|c|}
\hline Domain & $\begin{array}{c}\text { Predicted Life } \\
\text { (cycles) }\end{array}$ & Domain & $\begin{array}{c}\text { Predicted Life } \\
\text { (cycles) }\end{array}$ \\
\hline Time & $1,8779 \times 10^{15}$ & Frequency & $2.862 \times 10^{15}$ \\
\hline
\end{tabular}




\section{CHAPTER IV}

\section{RESULTS}

Fatigue life analysises of two different drag link have been done as a first phase of this thesis by using Ansys Workbench. On the other hand the fatigue tests of these two drag links have been made to compare the result from analysises and tests. A sinusoidial force had been applied to the surface beside the pitman arm and the surface beside pitman arm had been fixed. The fatigue life contours of the drag link A1-1648 and A1-2377 had been given in the Figure III. 9 and Figure III. 14.

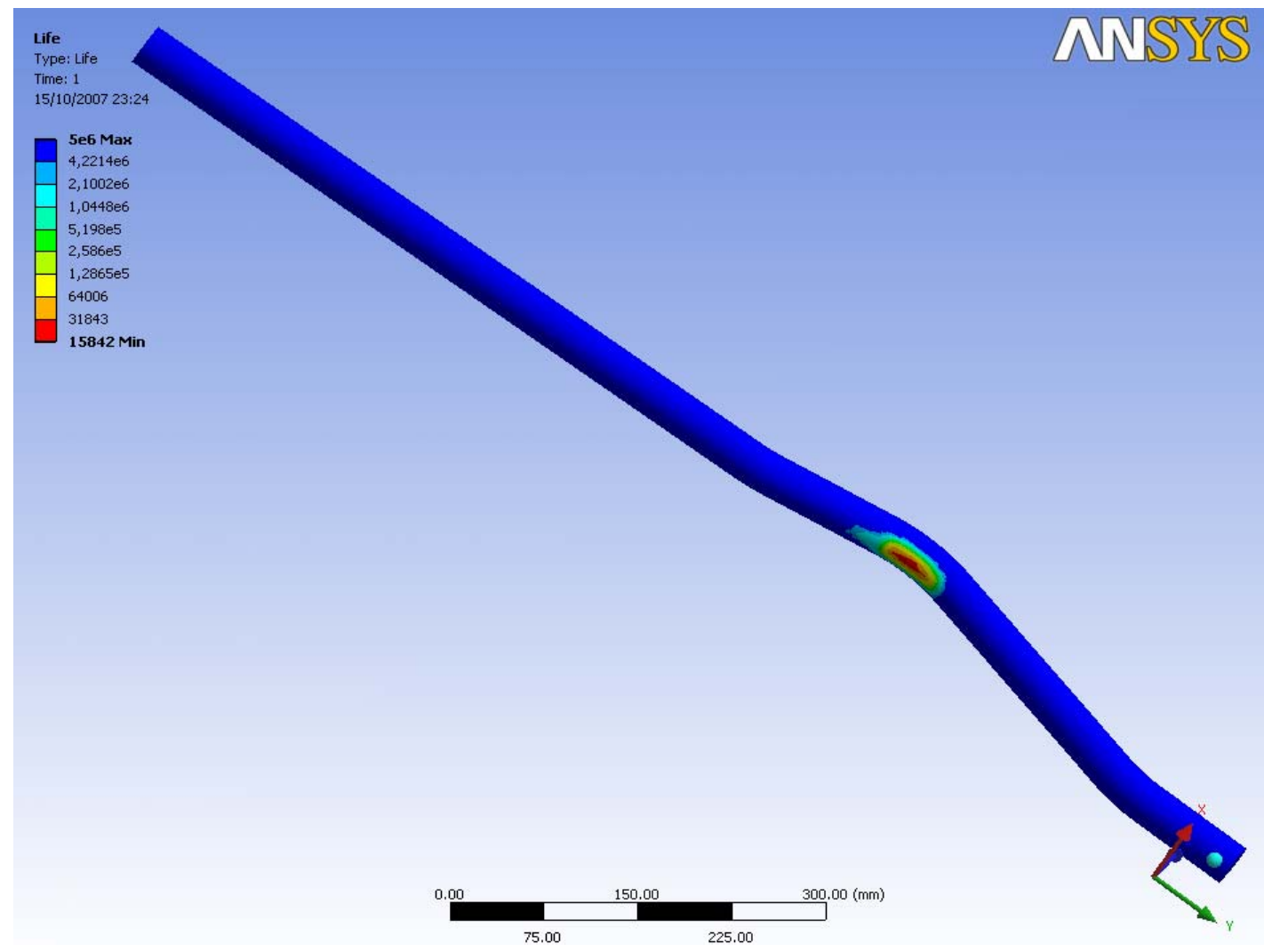

Figure III.9 The Fatigue Life Of A1-1648 In Cycles. 


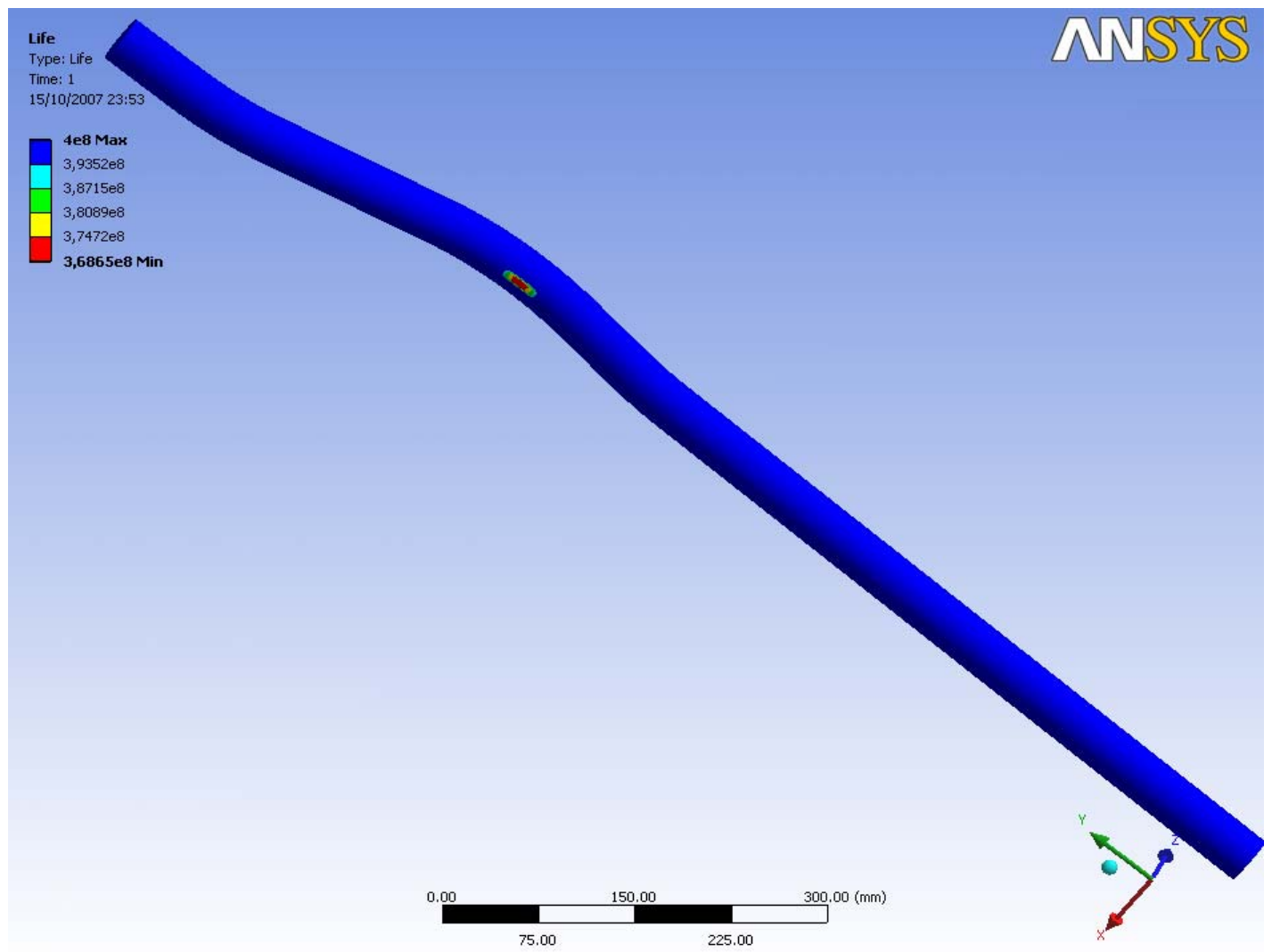

Figure III.14 The Fatigue Life Of A1-2377 In Cycles.

The results from the fatigue tests and fatigue analysises for A1-1648 and A12377 had been compared in Table III.3.

Table III. 3 Correlation Between The Test Results And FEA Results.

\begin{tabular}{|c|c|c|c|c|c|}
\hline $\begin{array}{l}\text { Drag } \\
\text { Link }\end{array}$ & $\begin{array}{l}\text { Results } \\
\text { From }\end{array}$ & $\begin{array}{l}\text { Breaking } \\
\text { Cycles }\end{array}$ & Breaking Area & $\begin{array}{c}\text { Target } \\
\text { Durability }\end{array}$ & Convergence \\
\hline \multirow{5}{*}{ A1- 1648} & \multirow{4}{*}{ Fatigue test } & 30.497 & \multirow{4}{*}{$\begin{array}{c}\text { Tube bending } \\
\text { area }\end{array}$} & \multirow{8}{*}{$\begin{array}{c}100000 \\
\text { cycles }\end{array}$} & \multirow{5}{*}{ Poor } \\
\hline & & 30.679 & & & \\
\hline & & 31.597 & & & \\
\hline & & 38.888 & & & \\
\hline & FEA & 7.635 & & & \\
\hline \multirow{3}{*}{ A1- 2377} & Fatique test & 953.297 & Rod bending area & & \multirow{3}{*}{ Poor } \\
\hline & Falugue test & & No break & & \\
\hline & FEA & 391.030 & & & \\
\hline
\end{tabular}

If the Figure III. 9,14 and 19 are examined, it is easily considered that the minimum fatigue life zone from the analsysises and tests are the same. But that can't be said, the predicted life from the analysises and breaking cycles from the tests are 
not the same. The reasons of this situation will be explained in Chapter V. As shown in the Table III.3, only the drag link A1-2377 meets the design requirement. The fatigue life results for drag link A1-2377 by using the different mean stress theories are given in the Table IV.1

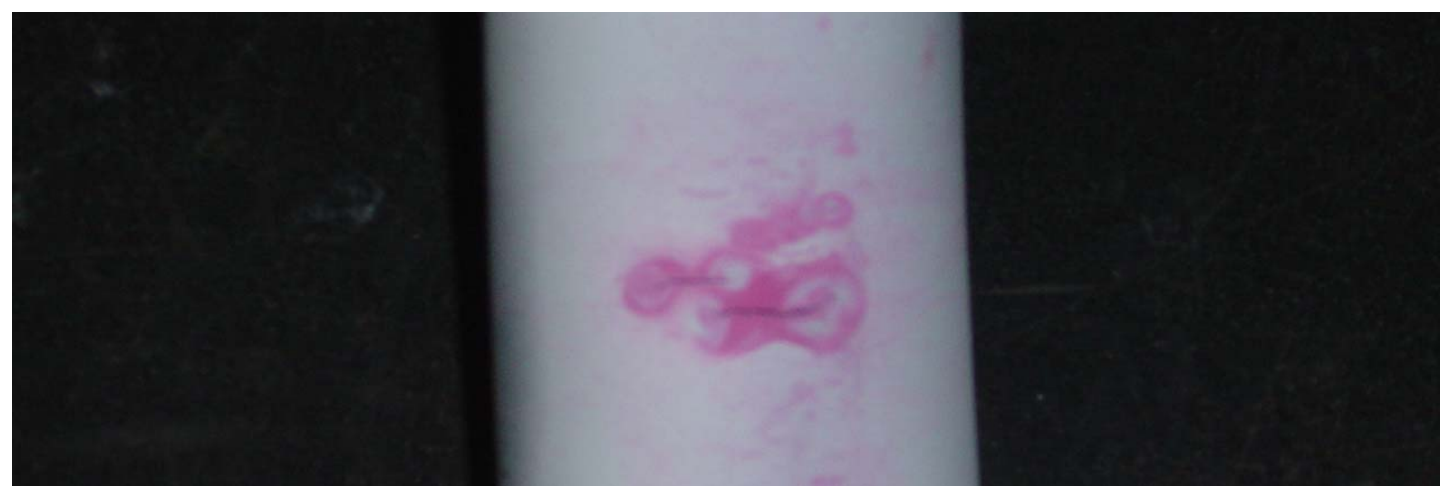

Figure III.19 Cracks Occurs At The Inferior Zone of The Bending Area.

The fatigue life prediction analysis of the drag link A1-2377 had been done by using the collected road loads as a second phase. The FEA program had been used for this analysis was also Ansys Workbench. The collected road loads had been used after a filtering operation. And it had been considered that, the drag link A1-2377 has a infinite life if there are such road loads as collected loads on it. The A1-2377 drag link have been used in the buses for a long time. It is a proof for the result that , there is no cracking claim for the drag link A1-2377 from the bus users. As a final phase of this thesis, a fatigue life prediction analysis in the frequency domain by using the same loads and boundary conditions for A1-2377 had been done. The Msc. Nastran and GlyphWorks had been used for the vibration fatigue analysis. The results from the vibration fatigue analysis had told the same thing .It is that , A12377 has a infinite life for collected road loads. The fatigue life contours from the analysis in the time domain and vibration fatigue had been given in the Figure III. 27 and 33 respectively.

Table IV. 1 Mean Stress Theories For A1-2377 (Exp. Loads) .

\begin{tabular}{|l|c|c|c|c|}
\hline & \multicolumn{4}{|c|}{ Mean Stress Theory } \\
\cline { 2 - 5 } Fatigue Life $\left(\mathbf{x} 1 \mathbf{0}^{\mathbf{5}}\right.$ cycles) & Soderberg & Goodman & Gerber & None \\
\cline { 2 - 5 } & 3,9103 & 3,9103 & 3,4783 & 3,9103 \\
\hline
\end{tabular}




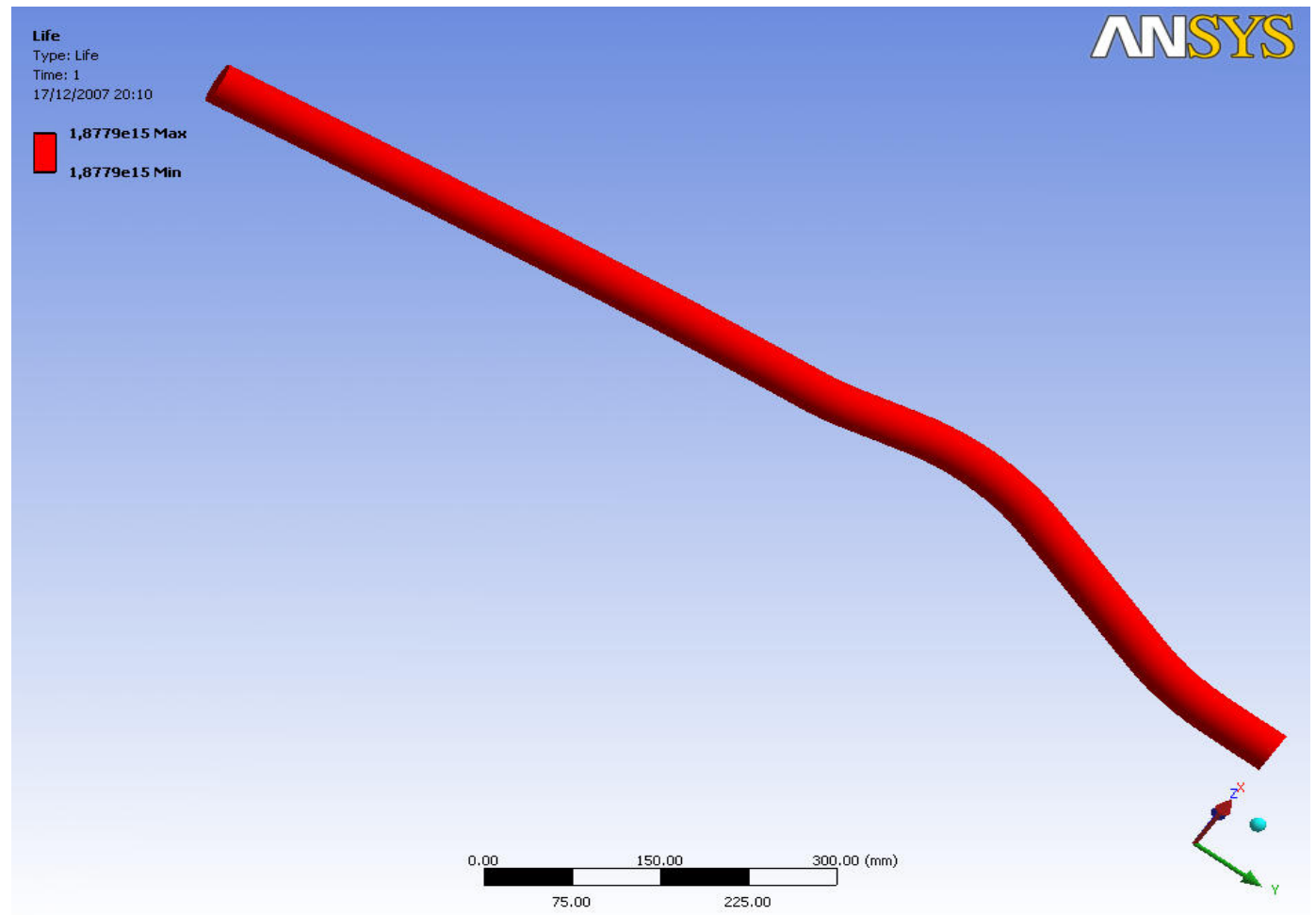

Figure III.27 Fatigue Life Distribution From The Analysis In The Time Domain

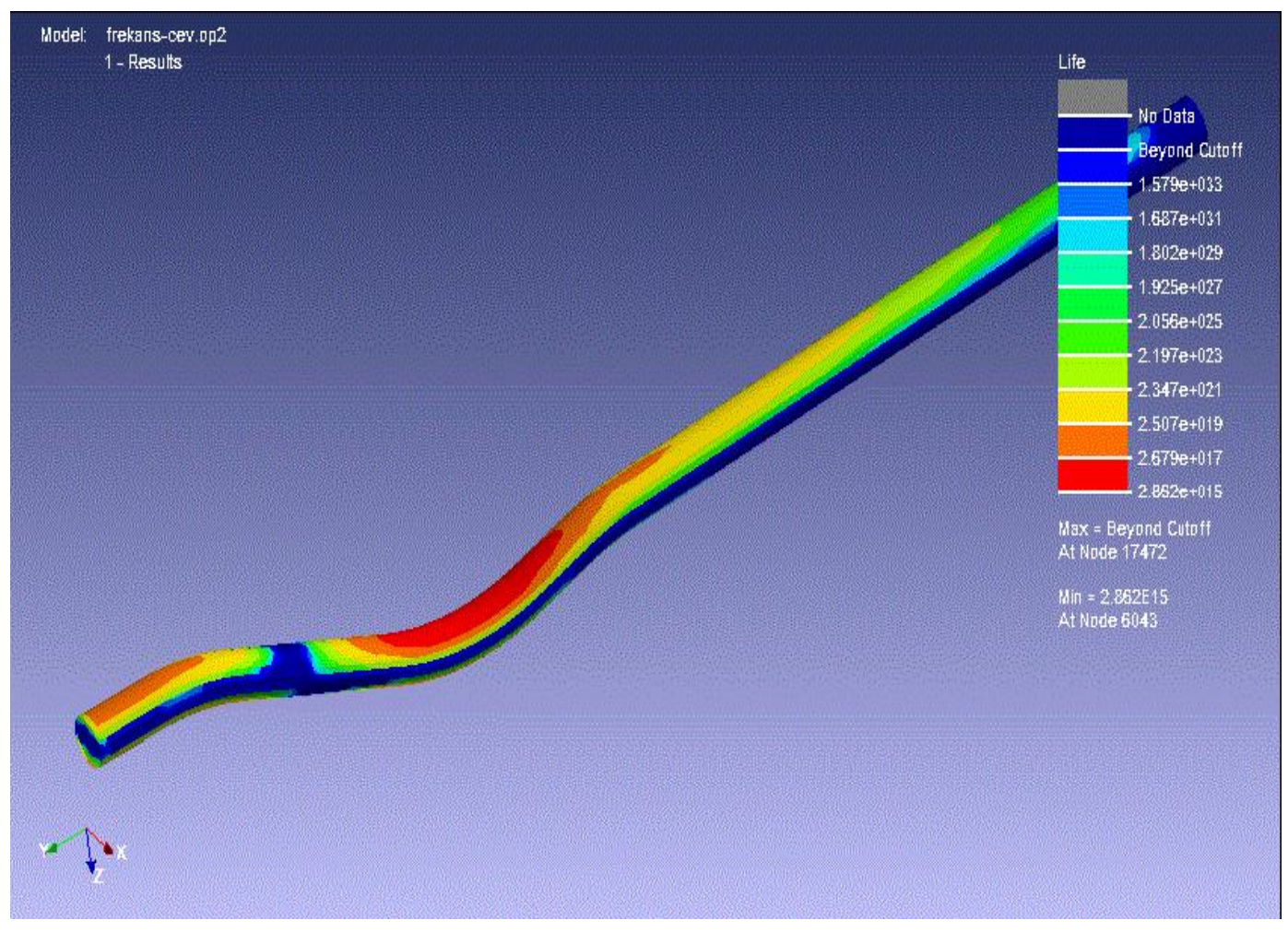

Figure III.33 Vibration Fatigue Life Contours. 


\section{CHAPTER V}

\section{CONCLUSIONS AND RECOMMENDATIONS}

There are two important conclusions obtained from this thesis. The first one is about the correlation between the results from analysises and tests. It can be considered that, for the minimum fatigue life area, the FEA program has a good agreement with the fatigue test and real life results. But if the section III.1. is examined, it is easily considered that, there is not good convergence between the test result and FEA results. It can be said that, the bad convergence between the tests' and analysis' results is normal if the litaratures about the fatigue life analysis are examined [2]. The reasons of this bad convergence are :

- It is so difficult to obtain the real S-N curves of materials.

- The sample which is used to obtain S-N curve has a $10 \mathrm{~mm}$ diameter. But in the real, the diameter and the correction factor of diameter has a empirical value . So, the factor does not always reflect the real value.

- The surface finishing factor also does not always reflect the real situations.

- And there are always a mean stress effect .

- And the finally, there are sometimes some micro cracks and internal structure problems . They are not considered by the FEA programs.

In addition to all of the these reasons there is a special mean stress effect of the analysises. The mean stress (mean load) in the section III.1 has a direction as compression stress. The Soderberg Method does not change the fatigue strength limit if the mean stress is a compressive stress (Table IV.1). But in the real conditions it is known that, the compressive mean stress has a positive increasing effect on the fatigue life. So, it is also a reason that, the life results of the analysises are smaller than the real test results. As a result, there are so much assumptions not only in the 
solving phase but also in the pre processing phase. So this non cenvergence results are normal. But the designers should make the fatigue analysis of the parts or machines affected by dynamic loads. The optimization tecniques can be used when the designer makes a fatigue analysis. So, the convergence between the analysis results and real is not important for the pre- design phase.

And the second important conclusion of this thesis is the importance of the vibration fatigue. The results declared in the section III.3. showed that, there is no requirement to make a vibration fatigue analysis to the drag link affected by such road loads. Because there is a natural frequency of the drag link at $21 \mathrm{~Hz}$ and the force spectrum's maximum frequency is approximately $6 \mathrm{~Hz}$. So, the drag link responses the forces as static conditions. If the maxiumum frequency in the PSD values had been larger than the first natural frequency of the drag link, making a vibration fatigue had been a requirement. Such a condition, the results from the fatigue analysis in the time domain can be so mistakefull. In the real, there are sometimes advantages to make a vibration fatigue instead of fatigue analysis in the time domain. Because, the parts and machines affected by random loads sometimes are broken by the vibrational forces. The other advantages of the vibration fatigue are it's computational efficiency and capability to give a synthetic representation of a random process.

Recommendations for fatigue analysis of a product are :

- For performing good converging fatigue analysis, the surface finishing factor, size factor and other modifying factors should be obtained by making some fatigue tests before the fatigue analysis.

- If there is no chance to make some fatigue test to obtain the appropriate modifying factors, fatigue analysis can be performed for optimization .

- In the design phase of a product the force spectrum should be examined before considering the type of the fatigue analysis. 


\section{REFERENCES}

[1] Roylance, D. : "Fatigue ", Department of Materials Science and Engineering, Massachusetts Institute of Technology, Cambridge ,USA (2001) 1-9

[2] Lee,Y.,L.; Pan, J.; Hathaway, R., B. ; Barkey, M. E. : “ Fatigue Testing and Analysis ", Elsevier Butterworth - Heinemann , USA (2005) 369 -394

[3] Karaağaç ,C. : " Fracture and Fatigue Analysis Of An Agitator Shaft With An Circumferential Notch", Msc. Thesis , İzmir (2002) 35-50

[4] Schütz,W. : “A History Of Fatigue ", Pergamon Press , Ottobrunn, Germany (1996) 263-287

[5] Fatigue Calculator Web Site, www.fatiguecalculator.com (2007)

[6] Rice, C, R. : “Fatigue Design Handbook”, SAE, Warrendale , USA (1997) $125-230$

[7] Schijve , J. : " Fatigue of Structures and Materials " , Kluwer Academic Publishers, Dordrecht (2001)

[8] $\mathrm{Su}, \mathrm{H}$. . : "Automotive CAE Durability Analysis Using Random Vibration Analysis ", Visteon Corporotion , USA (2003) 1-16

[9] Raman, M. ; Ariffin , A. , K. : "Effects of surface finish and treatment on the fatigue behaviour of vibrating cylinder block using frequency response approach", Journal of Zhejiang University SCIENCE A , Malaysia (2005) 1-9

[10] Bishop , N., V., M. ; Frimley , M. ; Caserio , A. ;Mesa , C. : "Vibration Fatigue Analysis in the Finite Element Environment "Americas User Conference, California (2005) 1-15

[11] Tüfekçi , E. ; Bozdağ , E. ; Sünbüloğlu , E. ; Özdemirci , Ö. : “ Direksiyon Rot Kolunun Deneysel ve Sayısal Gerilme Analizi " ITÜ Makina Fakültesi ISUZU Test Raporu (2004) 1-77

[12] Irvine , T. : “An Introduction to Random Vibration " Course Notes (2004) 
[13] Halfpenny, A. : “ A Practical Discussion on Fatigue " N Code Notes (2007) $1-5$

[14] Suresh, S. : "Fatigue Crack Growth " Course Notes (2007) 1-10

[15] Rowell, D. : “ Introduction to Frequency Domain Processing " Course Notes, Massachusetts Institute of Technology (2004) 1-55

[16] Fatigue Module Introduction, Ansys Workbench Manual (2007)

[17] MSC. Fatigue Quick Start Guide, MSC. Nastran Manual (2007)

[18] Frequency Theory and Software, GlyphWorks Manual (2007)

[19] Socie , F , D. : "Fatigue Made Easy" , Course Notes, University of Illinois at Urbana-Champaign (2002)

[20] Socie , F , D. : "Multiaxial Fatigue", Course Notes, University of Illinois at Urbana-Champaign (2003)

[21] Newman, J. , A. ; Piascik ,R., S. ; Lindenberg, R., A. : "Failure Analysis of a Helicopter External Fuel-Tank Pylon” NASA STI Program Office (2002)

[22] Carpinteri , A. ; Spagnoli , A. : "Biaxial / Multiaxial Fatigue and Fracture" Elsevier Publication, Italy (2003)

[23] Bathias , C. ; Paris , C., P. : "Biaxial / Multiaxial Fatigue and Fracture" Markel Deker Publication, New York USA (2005)

[24] Ambrosini, R., D. ; Riera , J., D.; Danesi , R. , F. : “Analysis of Structures Subjected to Random Wind Loading by Simulation in the Frequency Domain" Probabilistic Engineering Mechanics - Elsevier Publication, USA (2002)

[25] Sweitzer, A. , K. ; Ferguson , N., S.: "Mean Stress Effects On Random Fatigue of Nonlinear Structures" ICSV 12 , Lisbon (2005)

[26] Schwab, H. , L. ; Jaffrey , F. ; Lin , J: "Fatigue Analysis Using Random Vibrations" Ford Motor Company, Lisbon (2007)

[27] Sheratt , F.; Bishop , N., V., M. ; Dirlik , T.: "Predicting Fatigue Life From Frequency Domain Method : Current Methods "Elsevier Science B.V. (1994) $1-10$

[28] Vibration Fatigue, NCode International Manual (2007)

[29] As, S., K. : "Fatigue Life Prediction of an Alluminium Alloy Automotive Component Using Finite Element Analysis of Surface Topography" Norwegian University of Science and Technology - Doctoral Thesis , Norway (2006)

[30] Forrest , P., G. : "Fatigue of Metals" Pergamon Presss, USA (2005) 210- 240 
[31] Klesnil , M. ; Lukas , T. : "Fatigue of Metallic Materials" Elsevier Scientific Publishing Company , USA (2006) 133- 183 


\section{CIRRICULUM VITAE}

Barış KOCA was born in Kartal, Istanbul in 1981. After he had completed his elemantary and middle school education, he had completed his high school education at Neşet Yalcin Super Lisesi, Gebze . After the high scool he had completed his B.Sc university education in Kocaeli University Mechanical Engineering Department at 2004 . At the same year, he has started to M.Sc. education at Marmara University, Institute for Graduate Studies in Pure and Applied Sciences, Mechanical Engineering Department in Istanbul . He is still a student at Marmara University. He started his first professional experience in Arge Engineering Company in 2004. He had worked at there for 1.5 years as an application engineer. After Arge Engineering Company, he had completed his militiary service in Ardahan, Turkey. Now, he works for Anadolu ISUZU as a design engineer. He uses CAD/ CAE and also PLM programs. Especially he uses CATIA V5 for design application and Ansys, Msc Nastran for FEA application. Also he is an expert of CATIA V5. He is engaged and he is planning to get married in the next year. 
T.C.

MARMARA UNIVERSITY

THE INSTITUTE FOR

GRADUATE STUDIES IN PURE AND APPLIED SCIENCES

\title{
ACCEPTANCE AND APPROVAL DOCUMENT
}

\author{
FATIGUE LIFE PREDICTION OF A DRAG LINK BY \\ USING FINITE ELEMENT METHOD
}

Established committee listed below, on $24 \cdot 12,2007$ and $2007 / 28-11$

by the INSTITUTE FOR GRADUATE STUDIES IN PURE AND APPLIED SCIENCES" Executive Committee, have accepted Mr. Barış KOCA 's Master of Science thesis, titled as "FATIGUE LIFE PREDICTION OF A DRAG LINK BY USING FINITE ELEMENT METHOD" in Mechanical Engineering .

\section{COMMITTEE}

Advisor

: Assist. Prof. Dr. Bülent EKICI

Member

: Prof. Dr. A. Kerim KAR

Member

: Assoc. Prof. Dr. Nihat AKKUŞ

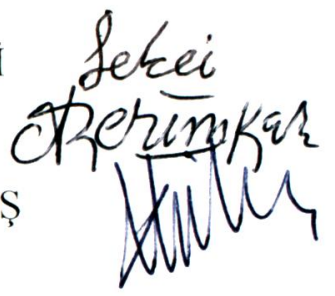

Date of thesis// dissertation's defense before the committee : 17:01.2008.

\section{APPROVAL}

Mr. Barış KOCA has satisfactorily completed the requirements for the degree of Master of Science in Mechanical Engineering at Marmara University. Mr. Barıs KOCA is eligible to have the degree awarded at our convocation on 04.02.20088.3.2003./.03....... Diploma and transcripts so noted will be available after that date.

Istanbul

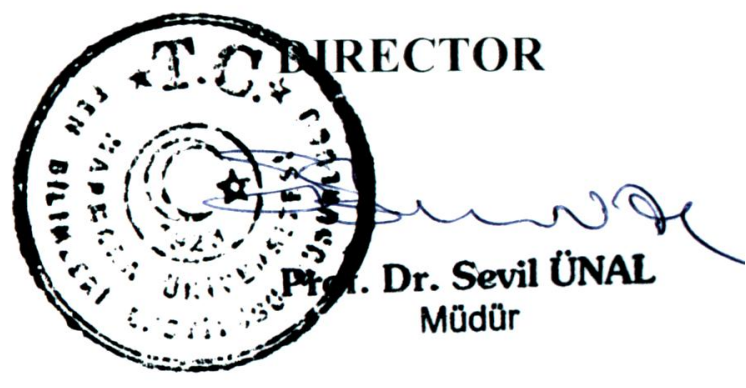

